\title{
WestVirginiaUniversity
}

THE RESEARCH REPOSITORY @ WVU

Graduate Theses, Dissertations, and Problem Reports

2009

\section{Preparing medical students to counsel for smoking cessation}

Aubree M. Guiffre

West Virginia University

Follow this and additional works at: https://researchrepository.wvu.edu/etd

\section{Recommended Citation}

Guiffre, Aubree M., "Preparing medical students to counsel for smoking cessation" (2009). Graduate Theses, Dissertations, and Problem Reports. 2882.

https://researchrepository.wvu.edu/etd/2882

This Dissertation is protected by copyright and/or related rights. It has been brought to you by the The Research Repository @ WVU with permission from the rights-holder(s). You are free to use this Dissertation in any way that is permitted by the copyright and related rights legislation that applies to your use. For other uses you must obtain permission from the rights-holder(s) directly, unless additional rights are indicated by a Creative Commons license in the record and/ or on the work itself. This Dissertation has been accepted for inclusion in WVU Graduate Theses, Dissertations, and Problem Reports collection by an authorized administrator of The Research Repository @ WVU.

For more information, please contact researchrepository@mail.wvu.edu. 
Preparing Medical Students to Counsel for Smoking Cessation

\author{
Aubree M. Guiffre \\ Dissertation submitted to the \\ College of Human Resources and Education \\ at West Virginia University \\ in partial fulfillment of the requirements \\ for the degree of \\ Doctor of Philosophy \\ in \\ Counseling Psychology
}

\author{
Margaret K. Glenn, Ed.D., Chair \\ James W. Bartee, Ph.D. \\ Reagan Curtis, Ph.D. \\ Jeannie A. Sperry, Ph.D. \\ Roy Tunick, Ed.D. \\ Morgantown, West Virginia \\ 2009
}

Keywords: Self-efficacy, medical students, attitudes, motivational interviewing 


\section{ABSTRACT \\ Preparing Medical Students to Counsel for Smoking Cessation}

Aubree M. Guiffre

Smoking is a national epidemic. Medical providers are the first line of defense to help patients reduce or stop smoking. However, smoking cessation counseling does not occur consistently or regularly. Medical providers must be trained to counsel for smoking cessation, with certain areas requiring attention in order for the training to be successful. There is a relationship between medical students who have high rates of self-efficacy related to smoking cessation counseling and high rates of actual counseling. Understanding the relationships between knowledge, skills, attitudes, and the medical school year in training on self-efficacy is important to better prepare medical students to counsel for smoking cessation. Medical students of all training years at a regional university were asked to participate in this study. They were divided into two groups; pre-clerkship year (Cohorts 1 and 2) and clerkship year (Cohorts 3 and 4). Thirty-five participants completed a 96 item questionnaire. This exploratory study examined the relationship between knowledge about smoking use, attitudes toward patients who smoke, attitude toward communication skills training, attitude toward smoking cessation counseling, use of motivational interviewing (MI) skills, as well as the year in medical school and the effects of medical student self-efficacy on smoking cessation counseling. Pearson correlations and a Spearman rank-order correlation examined the strength of the relationships between the variables. Significant results were found for knowledge and attitudes on self-efficacy, but skills did not show a significant relationship with selfefficacy. Additionally, differences between medical student knowledge and attitudes were explored using a Mann-Whitney test. There were no significant differences between groups in these variables. Limitations, clinical implications, and recommendations for future research relate to the study design, recruitment process, curriculum changes, and interventions for medical students are also discussed. 
This work is dedicated to my husband and sons who always provided me with the motivation, reason, and love to pursue this dream. 


\section{ACKNOWLEDGEMNTS}

The completion of this project would not have been possible if not for the support, encouragement, time and emotional investment, and guidance of many people. I would like to thank Margaret Glenn, Ed.D. for her support as chair of this project. Dr. Glenn offered long distance feedback and support and quickly mobilized efforts in order for me to reach my goals, which I will always appreciate. I would like to acknowledge and thank my other committee members for providing regular consultation, recommendations, and support on this project. I am aware that their commitment and flexibility allowed me to fulfill my goals and I am truly grateful for their efforts. I want to thank Dr. Bartee for his unwavering commitment to my education and clinical experiences and appreciate his advocacy during my four years at WVU. I would like to thank Dr. Curtis for his help with statistical procedures and flexibility to meet with me (and my son). I would like to thank Dr. Tunick for his flexibility and thought provoking questions to help me better understand this project. I want to thank Dr. Sperry for modeling the realities of life as a clinical psychologist and providing me with guidance and often a soft place to land. She often took on more than was reasonable in order to provide me with excellent clinical training and I am a better therapist for that sacrifice. I have learned a tremendous amount from Dr. Sperry, both in and out of the therapy room, for which I will always be grateful.

The faculty at the Psychiatry/Psychology department at my Internship site, Allegheny General Hospital, particularly Michael Franzen, Ph.D., Glen Getz, Ph.D., Joseph Greenberg, Ph.D., Nancy Kennedy, Psy.D., and Terri Meyers, Ph.D., provided incredible practical and emotional support for managing the dissertation writing process and defense. My Internship cohort provided immeasurable support and advice and I want to thank everyone for all they have done to help me accomplish my goal.

I want to thank Ann Cather, M.D. at the West Virginia University School of Medicine for her assistance in recruiting participants for this project.

I would like to thank Vicki Railing for her support and guidance while I was a student both on and off campus. Her constant and reliable assistance made the dissertation submission process better than I might imagine.

I would like to thank Margalit Persing for her editorial support and eagerness to understand this project.

I want to thank all my family and friends for their unconditional support and encouragement, particularly while a student at WVU. I would like to thank Kelly Garner for providing editorial advice whenever asked, in addition to always being an incredible friend. Accomplishing this goal would not have been possible without all of you and I will always be grateful for having you in my life. Most importantly, my husband Chris, made sacrifices and commitments that allowed me to fulfill my dream of completing this degree and there are no words that can adequately express my gratitude to him. The love, commitment, and comfort provided will always be honored. 
Table of Contents

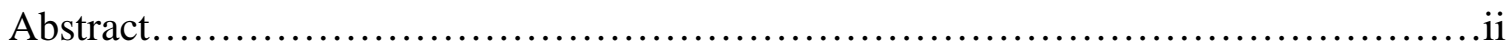

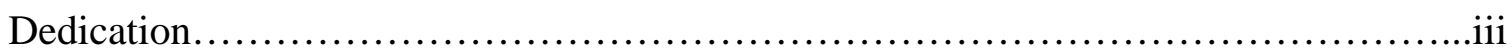

Acknowledgments..............................................................

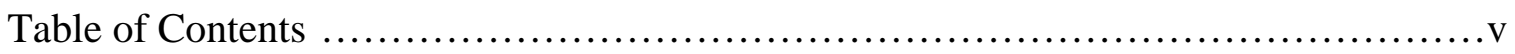

Chapter $1:$...................................................................

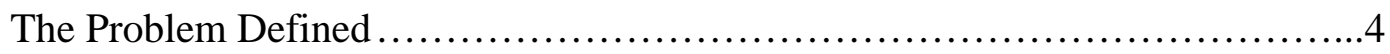

Status of Medical Provider Smoking Cessation Counseling .....................5

The Role of Psychology ................................................5

Preparing Medical Students to Facilitate Smoking Cessation Counseling..........7

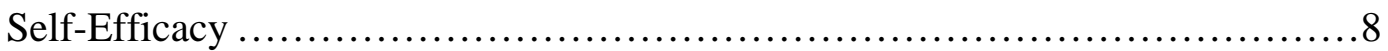

Development of self-efficacy ...................................9

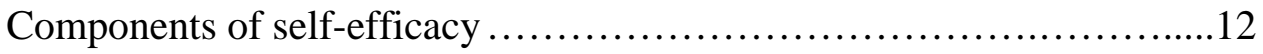

Medical students and self-efficacy ..................................14

Contributing Factors that Influence Development of Self-Efficacy ...............17

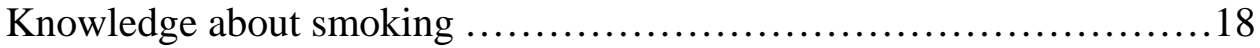

Physician attitudes about patients with addictive disorder..............21

Medical provider attitudes about screening for smoking................23

Medical provider attitudes toward smoking cessation counseling .......27

Medical provider attitudes toward general communication...............30

Motivational interviewing as an intervention skill ....................37

Role of self-efficacy in motivational interviewing ....................43

Motivational interviewing and smoking cessation ...................43 
Motivational interviewing and medical students .46

Instrumentation and study methodology...........................49

Statement of the Problem..............................................50

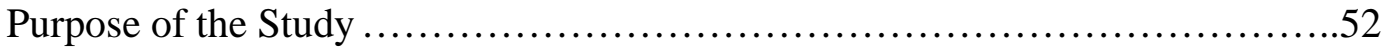

Definitions of Important Concepts.......................................52

Chapter II.................................................................... 54

Methodology .........................................................54

Participants........................................................54

Table 1. Demographic Characteristics of the Sample n.....................................55

Table 2. Medical Student Demographics....................................................58

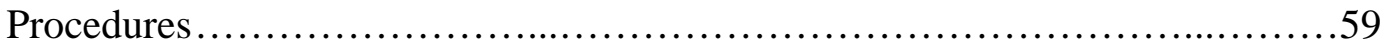

Instruments.....................................................60

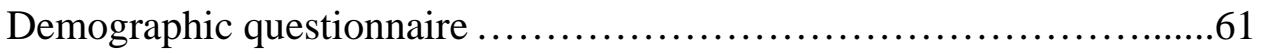

Provider Self-Efficacy Questionnaire ..............................61

Tobacco Use in American Medical Schools ..........................62

Attitude toward Smoking Cessation Counseling .......................63

Communication Skills Attitude Scale ..............................64

The Video Assessment of Simulated Encounter- Revised ...............64

Research Design .................................................67

Data Analysis .....................................................67

Research question one..........................................68

Research question two........................................69

Obtaining Reliability and Validity Scores for the Tobacco Use in American 
Chapter III. .72

Results.

Participant Characteristics ...........................................73

Table 3. Chi Square Goodness of Fit Test....................................74

Instrumentation........................................................ 76

Reliability and validity of the Tobacco Use in American Medical Schools

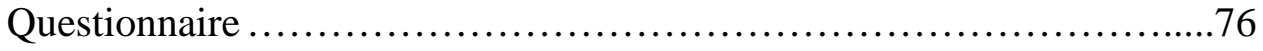

Results of Data Analysis ..............................................77

Research question one........................................77

Table 4. Mean and Standard Deviations of Correlations ........................78

Research question two ........................................83

Table 5. Correlations for Self-efficacy, Knowledge, Attitudes, and Skills ........80

Table 6. Non-parametric Correlations .....................................82

Research question two $\ldots \ldots \ldots \ldots \ldots \ldots \ldots \ldots \ldots \ldots \ldots \ldots \ldots \ldots \ldots \ldots \ldots . \ldots \ldots$

Table 7. Mann-Whitney Test Statistic ......................................84

Table 8. Mann-Whitney Descriptive Test................................85

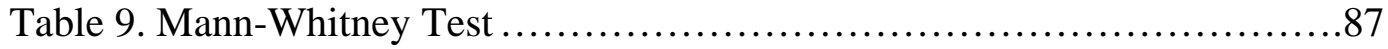

Summary of Results ................................................88

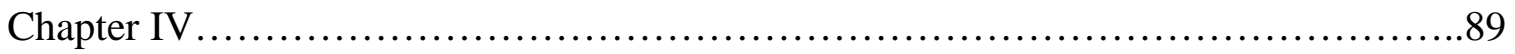

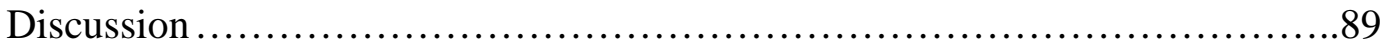

Limitations .....................................................99

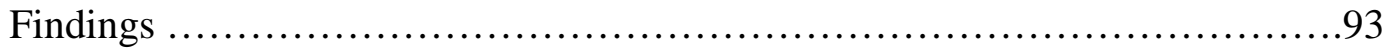




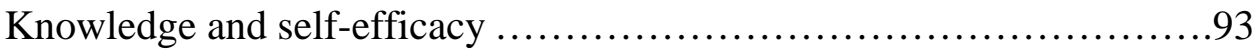

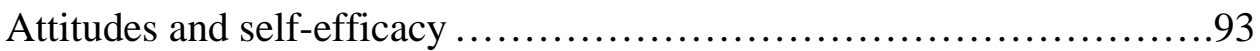

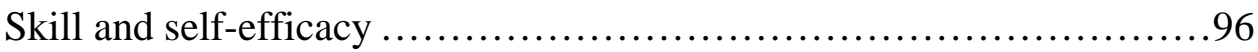

Development of clinical training ........................................

Recommendations and Implications for Clinical Applications and Future

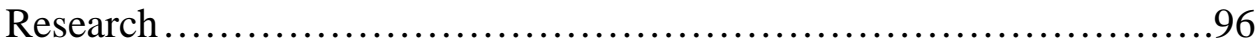

Knowledge about smoking and smoking cessation counseling...........96

Attitudes about patients who smoke ..................................101

Attitudes about learning communication skills........................103

Attitudes about smoking cessation counseling ........................105

Motivational interviewing skills .....................................107

Medical School Year in Training.....................................109

Study Design....................................................... 110

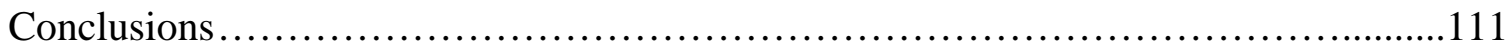

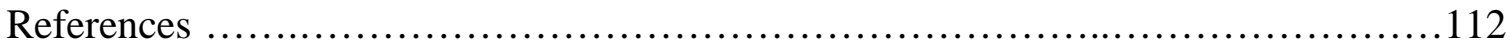

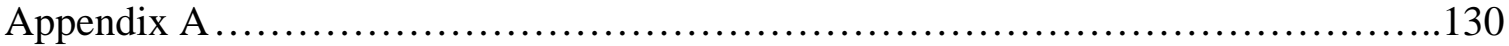

Demographics Questionnaire...........................................131

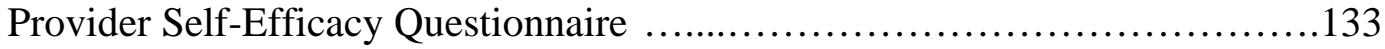

Tobacco Use in American Medical Schools ....................................135

Communication Skills Attitude Scale ....................................140

Quality Improvement Trial for Smoking Cessation Questionnaire ..............144

The Video Assessment of Simulated Encounter- Revised .......................148

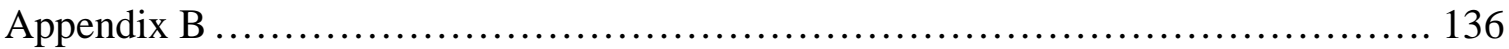


Informed Consent Letter ...............................................153 


\section{CHAPTER I}

Tobacco use is associated with major health problems in the United States. Tobacco use can result in behavioral and psychiatric dependencies, (American Psychiatric Association, 2002), high morbidity, and high monetary costs (Centers for Disease Control, 2000). Medical providers are on the front lines for battling the tobacco epidemic in this country. Thus, screening for smoking use and smoking cessation counseling are essential to the efforts of health professionals to impact this major health issue.

While a majority of physicians indicate smoking cessation is an important issue to address with patients (Smith, Lancaster, Delhenem, \& Fleming, 2002), it does not appear many physicians actually provide smoking cessation counseling (Swan et al., 2003). Many physicians believe it is too time-consuming and ineffective. This lack of confidence is coupled with a lack of knowledge (Vogt, Hall, \& Marteau, 2005) with both impacting the sense of self-efficacy in facilitating this type of behavior change (Bandura, 1977). A meaningful intervention to facilitate behavior change is difficult to create without knowledge, skills, or high self-efficacy. As knowledge and confidence increase, so may self-efficacy.

The required knowledge to counsel for smoking cessation encompasses both the psychological and biomedical components of nicotine dependence because these factors influence each other and lack of knowledge of them can complicate interventions directed at stopping smoking. Addressing only one of these components will likely not support smoking cessation. Medical providers must have a full understanding of patient smoking because this shapes the intervention. 
Physicians report their formal medical training did not prepare them to effectively assist patients to quit smoking (Cantor, Baker, \& Hughes, 1993). This knowledge deficit is one area to be addressed in order to support the ability to effectively facilitate patient behavior change. Training medical students in this specific area may be an efficient and proactive way to address this issue. The literature, however, exhibits inconsistencies related to medical year in training and attitudes about general communications training, patients who smoke, and smoking cessation counseling. Researchers have found that medical student year in training, attitudes, and self-efficacy can have either a positive or negative effect on smoking cessation counseling (Pololi \& Price, 2000; Schkrohowsky, Kalesman, \& Alberg, 2007). An examination of how self-efficacy emerges during medical training will add greatly to an understanding of how best to facilitate its development.

Understanding the possible connections among these aforementioned variables on the timing of medical school training in smoking cessation counseling is important information because it can provide details of student learning that, in turn, affect patient care. A careful examination of the relationships among knowledge, attitudes, skills, and year in training of medical students on self-efficacy is necessary because these variables affect the facilitation of change in patients who present with a difficult treatment problem — cigarette smoking. Given the conflicting data about attitudes, skills, knowledge, and year in training, further exploration is needed to understand the impact of these variables on medical student self-efficacy.

Acquiring the appropriate skill set required to make an appropriate intervention is imperative. There are numerous approaches to implementing an intervention to help 
patients quit smoking, such as self-help approaches, counseling, pharmacology, or a combination of any of the above (Ranney, Melvin, Lux, McClain, \& Lohr, 2006). One empirically supported approach is Motivational Interviewing (MI), an intervention that aims to increase intrinsic patient motivation to alter a behavior (Hettema, Steele, \& Miller, 2005; Miller \& Rollnick, 2002; Miller, Rollnick, \& Butler, 2007; Resnicow, Dilorio, Soet, Borrelli, Hecht, \& Ernst, 2002; Rollnick, Miller, \& Butler, 2008). In this intervention, the focus is on current patient behavior, future goals, and the building of a discrepancy between the two, which highlights the need for change (Britt, Hudson, \& Blampied, 2003). Motivational interviewing is an appropriate intervention for use in medical settings by medical providers because it can be brief (Miller \& Rollnick, 1991), taught in a structured fashion (Miller, Zweben, DiClemente, \& Rychartik, 1992), and integrated into a standard medical examination in an efficient manner (Rollnick, Miller, \& Butler, 2008).

Since smoking is a national epidemic and medical providers must frequently deal with this problem, they should be prepared to manage this increasing health crisis, with certain areas requiring attention in order for training to be successful. It appears that numerous variables may impact the development of specific skills, attitudes, and knowledge about smoking cessation in medical training. This research study aims to examine the relationship between medical student self-efficacy and other relevant variables. These include attitudes toward patients who smoke, smoking cessation counseling, acquiring general communication skills, knowledge of smoking, MI skills, and year in training. This study focuses on medical students, while the existing research centers on medical residents and physicians. This research provides essential information 
for the foundation of this study. However it is important to clarify that while research about medical providers is included in this literature review, it is presented to support the rationale for examining these variables in medical students.

\section{Defining the Problem}

Medical professionals have a major role in addressing the foremost cause of preventable death in the United States-- tobacco use (U.S. Department of Health and Human Services, 2000). Seventy percent of patients who want to quit smoking report visiting their primary care physician within the previous year (CDC, 2000). The Centers on Disease Control have published the following statistics: (a) approximately 17 million people attempt to quit smoking each year, with success in only 1.2 million cases; (b) an estimated 438,000 deaths are attributed annually to tobacco and tobacco related illnesses; (c) smokers cost the healthcare system approximately $\$ 73$ billion annually (CDC, 2002). Medical providers must be prepared to offer smoking cessation counseling in an effective way so they can effect change in this population. To maximize training and implementation of skills, assessment during medical school might yield results that suggest curriculum changes to enhance the doctor-patient relationship. But this task is only further complicated by the daunting statistics about smoking cessation success rates. A majority of physicians believe smoking cessation is an important issue to address with patients (Smith et al., 2002). However, counseling rates to reduce or eliminate smoking are often low among providers (Swan et al., 2003). There are several potential explanations for lack of smoking screening or counseling for smoking cessation. 


\section{Status of Smoking Cessation Counseling by Medical Providers}

Vogt et al. (1998) identified four sources of physician reluctance to counsel for smoking cessation. First, physicians do not believe in the effectiveness of counseling patients to change this behavior, which likely affects provider self-efficacy. Second, they believe lifestyle-choice counseling is outside the scope of medical intervention. Third, they believe interventions are driven by patient complaints (only those smokers who want treatment will get it) and, finally they fear prevention services may not be covered by insurance companies. A potential further source of this reluctance was found by Chapman (1993), who suggested that physician frustration is related to high relapse rates for patients who smoke cigarettes and the significant amount of time spent on counseling patients to stop smoking. Frustration could be moderated by increased knowledge and skill in dealing with these patients and improvement in attitude toward patients who smoke. Determining if these factors are a component of medical student experience can aid in curriculum development and provide direction for future research. Psychologists can be instrumental in providing this necessary training to medical providers.

\section{The Role of Psychology in Addressing the Problem}

Healthcare teams are moving toward a multidisciplinary team approach in order to best treat patients. This team approach has become a national plan and is best highlighted by the Healthy People 2010 Project, which is a national initiative to promote healthy lifestyles and prevent disease processes (US Department of Health and Human Services, 2000). The goal of the Project is for $80 \%$ of all health care providers to routinely screen for smoking and counsel smokers on ways to quit. In addition, participant providers are expected to document and follow-up with patients about 
treatment plans. Psychologists are increasingly becoming members of these teams and have roles in treatment, education, and research (Robinson \& Baker, 2006; Tovian, 2006). Their inclusion can influence outcomes in this area as they have specific knowledge of the psychological and physical components of nicotine dependence. Thus the parameters of the Healthy People 2010 Project include psychologists as health care providers and suggest they have a primary role in teaching counseling techniques.

Psychologists often frame case conceptualizations and treatment strategies using the biopsychosocial model, especially in health care settings. The biopsychosocial model posits that biological, psychological, and sociological components of patient and environment should be considered when assessing the problem and creating a treatment plan. This model also lends itself especially well to a multidisciplinary team approach (Borrell-Carrio, Suchman, \& Epstein, 2004; Engel, 1977). The focus on health and prevention is central to the historical roots of counseling psychology because health problems affect anyone at any time, and this in turn can affect relationships, careers, and other areas of interest and concern to counseling psychologists (Hoffman \& Driscoll, 2000). The field of Counseling Psychology is based on working with people as they experience problems in normal life development. The problem of physicians not counseling patients to quit smoking may be a developmental issue within the context of their vocation, which fits naturally with the tenets of Counseling Psychology. Thus, counseling psychologists have a significant and vested interest in working with medical professionals to increase healthy behaviors of their patients.

The Counseling Psychology Division (17) of APA also works to promote counseling in health psychology education and practice (APA, 2009) for psychology 
graduate students and other students and practitioners in various healthcare fields. This section of the APA is dedicated to the advancement of research, teaching, and direct service to students and practitioners who deal with lifespan and developmental issues, prevention issues, adjustment to medical issues, as well as the incorporation of healthy lifestyle changes. These goals are all strongly connected to the issue of smoking, training, and smoking cessation counseling. As many referrals for therapy or behavior change come from medical providers, it also behooves counseling psychologists to understand how medical providers perceive personal self-efficacy as related to attitudes about smoking. This information will help facilitate changes in training and possibly smoking cessation counseling.

\section{Preparing Medical Students to Facilitate Smoking Cessation Counseling}

It is posited that if medical providers are introduced to patient behavior change interventions in medical school, actual interventions or referrals may increase, and in turn, positively impact patient behavior change. Physicians are often the primary contact person in the medical establishment for patients who smoke. They provide smoking cessation screening, counseling, and management of compliance rates, (Okuyemi, Nollen, \& Ahluwalia, 2006). The foundation for successful interventions is rooted in a solid doctor-patient relationship. Effective communication is the cornerstone of this open relationship (Rees, Sheard, \& McPherson, 2002). To facilitate patient change, physicians will benefit from effectively communicating with patients and assessing their own attitudes toward acquiring general communication skills. An assessment of attitudes may also have a direct bearing on effective doctor patient communication throughout their career. 
It is well known from research that smoking cessation counseling with a patient, though extremely important, is not a clear or easy discussion (Brown, Pfeifer, Gjerde, Seibert, \& Haq, 2004). Medical providers may feel a lack of confidence related to facilitation of smoking cessation when there are unsuccessful outcomes, such as when patients do not stop smoking. Generally, self confidence and confidence in one's abilities is based in the broader construct of self-efficacy, which is the perceived belief that a task can be accomplished (Bandura, 2002). If medical providers are to demonstrate selfefficacy, it is critical to assess how self-efficacy is developed and what the barriers are in achieving it.

\section{Self-Efficacy}

Self efficacy is a widely accepted theory of behavior acquisition, maintenance, and change and is best explained in the context of social learning theory as developed by Albert Bandura (Bandura, 1977). Bandura is well known for a ground breaking study he and others conducted related to patterns of behavior attributed to aggression (Bandura, Ross, \& Ross, 1961). In this study, boys and girls were divided into groups; one group where they observed an adult aggressively hit a "Bobo" doll and another group where they observed an adult playing in a non-aggressive manner with other toys. Children were then observed playing with either non-aggressive or aggressive toys in a different room. The researchers found that children who were exposed to the adults hitting the Bobo doll were more likely to play aggressively than children who did not witness aggressive behavior. His study opened a field of research related to aggression, differences in behavior based on gender, the influence of media and video games on children, and the 
role of modeling. It also inspired researchers to examine positive effects resulting from modeling.

Social learning theory suggests that learning is done within a social context and achieved through observational learning, imitation, and modeling. Bandura posited that learning has cognitive and affective components that attitudes and behavior (Ormrod, 1999). Further, aspects of a person's environment can serve as reinforcers for modeling, which can happen when a model reinforces the observer (a faculty member reinforces a medical student's behavior), when the observer is reinforced by another person (a medical student is reinforced by a patient), and the behavior leads to reinforcing consequences (smoking cessation counseling leads to positive outcomes for both patients and medical students) (Bandura, 1977). All of these factors are critical components in the development of self-efficacy, which ultimately moderates the behaviors in a targeted environment.

As noted earlier, self-efficacy, a central component of social learning theory, is the judgment a person has about his or her own abilities to accomplish a task or goal. An important facet of self-efficacy is not whether a person has the appropriate and necessary skills to accomplish a goal, but whether or not they believe that the goal can be accomplished (Bandura, 2002). If self-efficacy is not present, avoidant behavior likely ensues (Betz, 2004).

Development of self-efficacy. Self-efficacy begins in infancy when the relationship between cause and effect is first observed and is coupled with the development of the ability to regulate behavior in social contexts. It grows when a person exerts his or his influence and others in the environment respond. The development of 
self-efficacy is retarded when others are unresponsive (Bandura, 1977; Maddux, 2000). If people are able to develop high levels of self-efficacy, they may be more able to attain their goals (Maddux, 2005).

Self-efficacy is developed over time after achieving successes that support the belief that a goal can be accomplished. Four principles explain the development of selfefficacy. The first is the cognitive aspect that helps people increase self-observation and the regulatory processes that monitor behaviors. Self-observation and self-monitoring can aid in the facilitation of personal changes that affect the likelihood of successful outcomes. The second principle deals with the ability to adapt to environmental cues. People must be able to negotiate with others in order to communicate effectively. The third principle refers to the shaping of the self within social interactions. The feedback provided in social environments helps build personal identity and the sense of ability. Finally, how well one uses self-regulation skills can help predict expectations for outcomes of events. This skill is based on the previous three principles and is critical in interpersonal interactions (Maddux, 2005). Self-efficacy can be specifically applied to any area, such as playing a sport, engaging in social activities, or learning a new skill (Betz, 2004).

Self-efficacy is also central to understanding health behavior change. Expectations based on self-efficacy are very specific and are not global judgments of personal ability (Bandura, 1997). Self-efficacy supposes that people have the personal ability to accomplish a certain task or make a particular change (Dijkstra \& De Vries, 2000). Specifically, high self-efficacy related to the ability to quit smoking is significantly positively correlated with actual smoking cessation (DiClemente, 1981; 
Gulliver, Hughes, Soloman, \& Dey, 1995; Stuart, Borland, \& McMurray, 1994) and is predictive for abstinence later in life (DiClemente, 1981). An important factor in this process is how much self-efficacy the medical provider has about providing smoking cessation counseling to patients.

Therefore, if medical providers have high self-efficacy in their ability to help facilitate smoking cessation, it is then more likely that those providers will frequently engage patients in discussions about smoking behaviors and design ways to help patients quit. Because smoking is notoriously difficult to treat, medical providers who do not have the appropriate knowledge, skill, or positive attitude about their ability to help facilitate smoking cessation, are also unlikely to have high self-efficacy in providing this counseling.

Since self-efficacy develops over time, there are finer points that impact its development and require consideration. The strength of self-efficacy relates to a person's own certainty about performing a task, suggesting that self-efficacy can be measured as high or low. Performance capabilities require people to judge their own ability to complete a specific task and not judge how they feel about themselves in general. This factor relates to how medical providers feel about their ability to provide smoking cessation counseling specifically and not any self perception of their overall abilities.

People with high levels of self-efficacy often exhibit high levels of effort (the rate of performance on a task) and persistence (mental effort and achievement) on a task. In fact, in a meta-analysis of 70 studies of persistence and motivation, researchers found a positive and significant effect size of student self-efficacy (Multon, Brown, \& Lent, 1991). High effort and motivation to accomplish a task are associated with the 
completion of that task. They are also associated with learning a new skill. Self-efficacy also relates to assessment of future abilities and motivation to learn new tasks. When presented with learning a new skill, medical providers who put forth effort and persistence increase the likelihood that they will learn that skill (Zimmerman, 2000).

Social learning has a cognitive component, (belief about something), an affective component (emotional response), and is greatly studied in health psychology literature because it supports the link between thoughts and emotions and their effects on behavior. It is outside the scope of the present research to explore this literature fully, however it is critical to note that self-efficacy can affect outcomes and outcome expectancies (Bandura, Adams, \& Beyer, 1977).

Components of self-efficacy. An efficacy expectation has been met when people believe that they have the actual skill set to accomplish a task (Bandura, 1977; Bandura, 1997). Achieving self-efficacy is a four component process: 1) performance accomplishments (modeling, desensitization, exposure), 2) vicarious experience (live modeling, symbolic modeling), 3) verbal persuasion (suggestion, self-instruction), 4) emotional arousal (relaxation, biofeedback, desensitization). These processes are briefly outlined below.

First, performance accomplishments are experiences in an area that supports feelings of mastery or failure and represent efforts to manage the environment and its stressors (Maddux, 2005). An assessment of the degree of success in a situation will affect feelings associated with mastery or failure (Bandura et al., 1977). Successes will increase efficacy expectations while failures decrease efficacy expectations. For instance, if a medical student continues to counsel patients who use cigarettes and smoking rates 
remain the same, student self-efficacy in the ability to decrease smoking use may diminish. Performance accomplishments have the greatest influence on the development of self-efficacy (Bandura et al., 1977; Maddux, 2005).

Second, vicarious experiences are powerful mechanisms for developing efficacy expectations. When an individual observes someone else performing a task or accomplishing goal without adverse effects, the likelihood of the observing individual to successfully complete that task and the belief that the outcome will be successful, is increased (Bandura, 1997). When a medical student observes a physician successfully counsel patients on smoking cessation, the medical student will have more confidence he or she can do the same.

Third, verbal persuasion is the mechanism whereby people are led to believe that they have the knowledge or skills to complete a task via suggestions, self-instruction and interpretative treatments. If a physician imparts confidence to a medical student about the ability to counsel patients on smoking cessation and the student restates this information, verbal persuasion has been applied. It is a less powerful intervention than performance accomplishments and emotional arousal (Bandura et al., 1977; Bandura, 1997), yet has its place in attitude construction and knowledge base.

Finally, the emotional arousal component of self-efficacy subsumes the notion that levels of agitation or anxiety impact the self-efficacy construct. The level of anxiety related to task performance serves to inform an individual of how well personal coping strategies are operating. If a person is not agitated he or she may feel more able to handle a situation than if the agitation level is high (Bandura et al., 1977; Betz, 2004). Also, people with high self-efficacy tend to achieve more than those with low self-efficacy 
(Ormrod, 1999). When a medical student experiences success in smoking cessation counseling, it is likely that self-efficacy will increase, which will further reinforce that behavior.

For example, a patient who has been counseled about smoking cessation returns for a medical visit for recurrent medical complaints that are exacerbated by smoking. The medical student may become agitated or frustrated and believe that the patient will not comply, which in turn influences student self-efficacy related to the ability to reduce smoking rates in patients. If the student is aware of this factor and finds ways to cope with it, then self-efficacy may not be negatively impacted and may actually improve. Ultimately, the greater the medical professional's sense of self-efficacy, the greater the overall behavior change (Bandura et al., 1977; Bandura, 1997).

People will likely increase effort and persistence when engaged in activities and behaviors in which they achieve success (Ormrod, 1999). This is also true for medical students. If a medical student finds that smoking cessation counseling is effective with patients, he or she will likely continue to assess and counsel patients about their smoking behaviors. Knowledge and skills are acquired and attitudes are formed in medical school, and these serve as the basis for future practical clinical application with patients.

However, there are barriers to achieving self-efficacy and it is critical to recognize these obstacles as early in training as possible.

Medical students and self-efficacy. Self-efficacy is a necessary requirement for medical students as they build knowledge, refine practice techniques, and establish relationships with patients (Pololi \& Price, 2000). Self-efficacy is developed and fostered by a sense of mastery in an area. The belief that acquired knowledge can be successfully 
applied to medical patients builds self-efficacy (Ozer et al., 2004). As knowledge builds, additional skills can be applied, and self-efficacy can grow.

There is a reciprocal and analogous relationship between self-efficacy in a medical practitioner and his or her patients. It is likely that as medical student selfefficacy increases, so does the self-efficacy of the patient (Pololi \& Price, 2000). The student who feels confident in application of knowledge and acquired skill (smoking cessation counseling) can create an analogous environment with the patient to increase participation in the desired activity (quit smoking). Conversely, when medical students have low self-efficacy, avoidant behavior typically ensues (Betz, 2004). If the medical provider avoids a topic area, so might patients, despite the medical necessity.

As previously mentioned, behavior can also be acquired through vicarious experience and verbal suggestion (Bandura et al., 1977). One method that facilitates the development of self-efficacy is modeling. Modeling provides instruction and can assist in motivation because models can demonstrate successful and unsuccessful outcomes (Schunk, 2003). Medical students can model action taken by senior providers and if the relationship is strong, the likelihood is increased that the behavior will be learned and practiced, thereby increasing self-efficacy (Bandura et al., 1977). In a more recent study, researchers examined the types of relationships that exist between medical school year and student self-efficacy (Pololi \& Price, 2000). The researchers hypothesized that the relationship students have with faculty members is similar to the relationship that medical students have with medical patients.

In this study three cohorts of medical students at four sites completed a questionnaire at the end of each academic year. The researchers found a statistically 
significant decrease in the faculty-student relationship, medical student (doctor)-patient relationship, and in medical student self-efficacy in personal skill set as students progressed through school. This proposed parallel relationship (faculty-student: future doctor-patient) suggests that relationships deteriorate over time and so overall selfefficacy decreases. These deficiencies will likely impact doctor-patient relationships and health outcomes and need to be further explored. First, however, these relationships need to be established.

This study indicates that self-efficacy decreases significantly after each year in medical school. The results prompted the researchers to address issues related to professional relationships and self-efficacy. It is critical to understand why such a drop occurs and also if knowledge, skills, and attitudes play a role in this decline. One potential limitation to this study relates to the participant pool. Some students completed the measure one time (after Year 1), some completed the measure two times (after Years 1 and 2) and some students completed the measure three times (after Years 1, 2, and 3). Students in a particular cohort may have been influenced in either a positive or negative way by a confounding factor, such as the frequency of completing the measure. Additionally, a causal relationship between year in training and relationship status and self-efficacy cannot be determined. Finally, medical students at four medical schools in the southeastern part of the United States participated and it is unclear if this is a representative sample of all medical students and relationships between faculty and patients.

A decrease in self-efficacy among fourth-year medical students is not found in every research study. A cross-sectional study of first and fourth-year medical students at 
three medical schools examines the relationship between increased knowledge and selfefficacy. While knowledge about smoking and its health effects increased from year one to year four, students still reported a need for additional training. Despite the reported deficits, fourth-year medical students had increased self-efficacy scores on the ability to help facilitate patient smoking cessation, ease of discussion about smoking cessation, and an increase in the ability of medical professionals to be agents of change, as opposed to first year students (Schkrohowsky, Kalesan, \& Alberg 2007).

The discrepancy in the current literature necessitates further research to better understand the relationship of knowledge, attitudes, and self-efficacy in relation to the medical school academic year. These research studies examine variables that are assumed to have a relationship with self-efficacy, but a relationship was not established within the confines of either study. These relationships need to be confirmed. Additionally, the discrepancy highlights the need to better understand the type of influence that knowledge, skills, and year in medical school have on self-efficacy. The current study examines if such relationships exist prior to making assumptions about the proposed strength of the relationships.

\section{Contributing Factors that Influence the Development of Self-Efficacy}

Self-efficacy, as noted above, develops over time and with an appropriate level of guidance from others. It is an attribute that is achieved and not an absolute or guaranteed factor in life (Bandura, 1977). The study of the development of self-efficacy, knowledge, skills, and attitudes in medical students will hopefully guide curriculum changes with the intention of improving the practice of medicine. 
Medical students typically believe that offering support and providing guidelines for lifestyle and behavior change is an important facet of the physician's job. However, in a recent study, $43 \%$ of medical students did not believe that patients would likely change their negative health behaviors (Foster et al., 2002). Knowledge of behavior and lifestyle change is important for medical students for numerous reasons related to the development of self-efficacy in smoking cessation counseling. Students who are exposed to smoking cessation training are likely to screen for and counsel patients on smoking (Prochaska, Teherani, \& Hauer, 2006). This knowledge may serve as a foundation for the application of smoking cessation counseling and may increase self-efficacy related to this behavior change.

Research results indicate that the majority of medical students believe that patients will comply with directives to quit smoking. High rates of knowledge about smoking cessation counseling, however, are not associated with high rates of selfefficacy about providing actual smoking cessation counseling (Prochaska et al., 2006). Physicians typically report that patients are compliant with medical directives; however, physicians have low self-efficacy in their own abilities to provide the necessary guidance or support to patients to facilitate lifestyle changes. In fact, only $21 \%$ of physicians in a study thought that their formal medical training helped to prepare them to effectively assist patients quit smoking (Cantor et al., 1993). This is critical in understanding how medical students develop knowledge, attitudes, and skills and may be the most effective point in training for intervention and training.

Knowledge about smoking. It clearly behooves medical students to be aware of the frequency of smoking in their patients, as the health consequences of smoking 
comprise a national epidemic. There are several aspects to this body of knowledge. To increase this awareness, medical students must be taught how to assess smoking use in patients and second, medical students must be able to recognize obstacles for patients in quitting smoking. It is also paramount for medical students to acquire counseling skills to help facilitate patient smoking cessation (Nieman, Velasquez, Groff, Cheng, \& Foxhall, 2005). There are numerous ways that medical students learn counseling techniques, such as role- plays, observed structured clinical exams, didactic lessons, and use of standardized patients. Medical students must be able to recognize the symptoms associated with smoking prior to acquiring counseling skills. The research indicates, however, that knowledge among medical students about smoking, its effects, and the role of counseling interventions is not adequate (Spangler, George, Long Foley, \& Crandall, 2002).

Researchers found that when medical students were taught about smoking rates, intervention techniques, and counseling skills, they reported an increase in knowledge and application of information, as evidenced by engaging patients in smoking cessation discussions and counseling (Nieman et al., 2005). Fifty-four second-year medical students (pre-clerkship) participated in the Nieman et al., study, which focused on knowledge of smoking. The medical students completed a workshop related to smoking. After the workshop, smoking assessment of patients increased from $14.2 \%$ to $43.8 \%$. Nearly $91 \%$ of patients seen by these students were screened for smoking and $94 \%$ of patients were advised to stop smoking. Medical student self-efficacy to provide smoking cessation counseling, as measured by a self-report Likert-type form, increased 34\% after the workshop. 
A noted weakness of pre-post test design is that any changes made after an intervention are attributed to the effects of the intervention (Verma \& Mallick, 1999). In this study, the researchers attributed the increase in knowledge, frequency of assessment, and self-efficacy to the intervention provided. There are likely threats to internal validity, such as natural maturation, whereby participants change without regard to the intervention (Verma \& Mallick, 1999). There is no control group in this study, which also suggests that issues such as maturation, history, instrumentation used, or other extraneous variables cannot be ruled out as variables that affect the outcomes. It will be important to determine if these variables even have a relationship with one another, as it was assumed that these variables do, in fact, influence one another. The current study examines the presence of relationships among these variables while not manipulating the naturally occurring events within the medical school curriculum or within medical student experiences. Determining if these relationships exist will allow for future research to explore different dynamics of these connections.

Based on previous research, it is reasonable to suggest that medical student knowledge about smoking, its effects, and smoking cessation, has an effect on selfefficacy of smoking cessation counseling. However, these relationships must first be determined. When knowledge is low, self-efficacy may be low as well. Lack of knowledge can also be related to the negative attitudes of medical students (Tormala \& Petty, 2006). Research suggests that clinical application of smoking cessation counseling, based specifically on a learned skill set, increases self-efficacy to conduct smoking cessation counseling (Nieman et al., 2005). Medical student attitudes toward learning these skills should be examined because there is a possible association between attitudes 
and learned skill set. In turn, knowledge about smoking and counseling cessation skills, attitudes about smoking and smoking cessation, as well as general communication skills training, can affect self-efficacy.

Physician attitudes toward patients with addictive disorders. Patients with complicated medical complaints can pose a challenge to medical providers. Substance use and abuse can confound medical complaints, thereby increasing the challenge to effectively treat the patient. Those who are non-compliant with medical advice (e.g., those who do not quit smoking) are often considered “difficult patients,” and may increase physician frustration (Saper, 2006; Sharpe et al., 1994). This frustration likewise may influence attitudes about the likelihood that counseling for smoking cessation will be effective.

Psychological and physical dependency can create barriers to reduction or elimination of smoking. Smoking often coexists with and may exacerbate other psychological and physiological problems (Lasser, 2000; Sloane, Slatt, Ebell, Jacques, \& Smith, 2002). Although patients may seek assistance from their physician to stop smoking, there is no guarantee behavior will change. As previously discussed, medical providers find that patients who are non-compliant with medical treatment are often the most frustrating to treat (Saper, 2006; Sharpe et al., 1994). If medical providers feel frustrated and no longer believe the recommendations and assistance they offer are being integrated into patient lifestyle, it will likely affect provider sense of self-efficacy. These negative attitudes toward patients who smoke will likely have no positive effect on patient ability to quit smoking, and physicians will have little confidence that patients will actually stop smoking (Williams et al., 2003). As a result, the physician may no 
longer pursue counseling or referrals for smoking cessation, and self-efficacy to provide smoking cessation counseling may decrease. Avoiding these interventions will likely increase and may have dangerous consequences for the patient (Betz, 2004).

When medical providers feel an intervention may not be successful due to patient lifestyle choices, the intervention may not occur at all (Chapman, 1993). For example, in a recent study, $45.3 \%$ of medical residents stated that they felt frustrated treating a patient who was addicted to a substance, including nicotine, supporting the findings of Chapman (1993) (Karam-Hage, Nerenberg, \& Brower, 2001). Again, a pre-post test design was used in this study and it will be very important to determine if medical student attitudes about patients who smoke do actually have a relationship with self-efficacy, as this study explores.

These studies address physician attitudes, without any mention of knowledge, skill, or attitude development during medical school. In recognizing that medical school is a developmental model of knowledge and skill acquisition, acknowledging that the evolution of attitudes is also developmental in nature is necessary. That is why it is important to determine if a training intervention in medical school influences attitudes of medical professionals and if frequency of screening and smoking cessation changes. It may be that this variable has no impact on knowledge, attitudes, and skills, but it is an important variable to study until more definitive data can be obtained.

Previous research has found that these trainings do increase screening and smoking cessation counseling (Baerheim et al., 2007; Yedidia et al., 2003). However, the relationship among the variables is not yet clear. It is unclear at what point in medical education this training is most efficacious and therefore, the knowledge and attitudes that 
may be linked to medical student self efficacy of smoking cessation counseling are not yet fully understood.

Medical provider attitudes about screening for smoking. It is critical that medical providers screen for smoking in patients because smoking is correlated with multiple life threatening illnesses. Smoking is linked to emphysema, chronic bronchitis, chronic obstructive pulmonary disease, coronary artery disease, stroke, cancers of the lung, mouth, esophagus, and bladder; and in women who smoke while pregnant, to low fetal weight (Sloane et al., 2002).

Nicotine use typically evolves into nicotine dependence, which has both psychological and physiological components. Within mental health settings psychological disorders are diagnosed using the criteria given in the Diagnostic and Statistical Manual of Mental Disorders fourth edition- text revision (DSM-IV TR) (APA, 2000). This definition is used for purposes of this research study. According to the DSMIV, nicotine dependence is defined as tolerance to nicotine, withdrawal from nicotine, increased tobacco use, persistent efforts to reduce nicotine use, time spent in activities to obtain tobacco and social, occupational or recreational activities affected due to nicotine use. Finally, nicotine use is continued despite knowledge that tobacco use worsens either a physical or psychological problem (APA, 2000). Addiction to nicotine is based on pharmacology, learned set of behaviors, personality construct, and cognitive and genetic factors (Benowitz, 1999). As nicotine is physiologically addictive, quitting and maintaining abstinence can prove very challenging and frustrating for patients as well as medical providers. 
Smoking is also correlated with mental health problems, including mood, anxiety, and psychotic disorders (Lasser et al., 2000). While nicotine dependence itself is considered a psychiatric disorder, McNeill (2001) reviewed the amount of exacerbation inflicted by smoking on other symptoms of psychiatric disorders, including depression, panic disorder, and schizophrenia. There are a variety of hypotheses about the onset of a psychiatric disorder, smoking status, and the role of each in symptom presentation, but it is not within the scope of this study to examine these factors. However, tobacco use may be a form of self-medication for people with mental illness. Nicotine has been shown to reduce the attention deficits found in schizophrenics and in those with attention deficit/hyperactivity disorder (Dani \& Harris, 2005).

The brain receptors sensitive to nicotine are called nicotine acetylcholine receptors (nAChRs). When the nAChRs are enhanced, they release dopamine, norepinephrine, and serotonin, all of which are neurotransmitters with a role in depression and affective disorders. There is also an unknown substance in nicotine that mimics monoamine oxidase inhibitors, an antidepressant that suppresses the secretion of monoamine oxidase in the brain. It appears that nicotine has short and long-term mood enhancing effects, which supports the self-medication theory that people with mental illness smoke to produce like results of antidepressant medication (Quattrocki, Baird, \& Yurgelen-Todd, 2000).

It is not difficult to understand why people with mental illness use tobacco, despite its negative physical health effects. While it is outside the scope of this research to examine the possible correlational relationship between nicotine and other illnesses, it is reasonable to suggest that tobacco use exacerbates both physical and mental health 
conditions (McNeill, 2001). In turn, nicotine may produce beneficial effects in some patients, thus increasing their ambivalence about quitting smoking. An intervention by a professional is essential to facilitate behavior change because smoking is a complex, multi-system problem.

The majority of patients expect their medical providers to ask about lifestyle choices (Vogt et al., 1998). Researchers conducting a population-based survey of patient smoking behaviors discovered that less than $15 \%$ of patients who saw a medical professional were presented with quitting options, and only approximately $3 \%$ of these patients were scheduled for follow up appointments to discuss smoking cessation progress (Goldstein et al., 1997). Overall, research indicates that less than $70 \%$ of patients are screened for smoking by their physicians and approximately $30 \%$ of patients are provided with an intervention and counseling (Thorndike, Rigotti, Stafford, \& Singer, 1998). One likely reason for the decline in smoking cessation screening and counseling is physician concerns about length of time spent in an office visit and the frustration physicians feel about the efficacy of these interventions, as previously discussed (Cummings et al, 1989).

In a 1985 study researchers discovered that while medical students found smoking screening to be important, the majority of students indicated a low level of confidence in physician ability to provide such interventions due to skill deficits and knowledge about preventive care, including smoking cessation counseling (Scott \& Neighbor, 1985). This finding suggests screening is not done because the outcome is considered to be poor. Unfortunately, these findings continue to be consistent with the current literature. 
In a recent study, researchers asked first- and fourth-year medical students to complete a questionnaire reflecting knowledge and attitude on smoking and dependency (Schkrohowsky et al., 2007). The findings suggest that fourth-year medical students have low confidence that physicians have the ability and willingness to screen patients about smoking and cessation. This is particularly distressing because fourth-year medical students are about to enter into their residencies and begin practicing medicine.

Screening for smoking is different than providing smoking cessation counseling, although they are related. A medical provider must first have the knowledge, skills, and self-efficacy to successfully screen for smoking in patients. The next step is to engage the patient in smoking cessation counseling, which requires a different skill set.

Understanding these fundamental components may help illuminate the reasons why physicians make specific choices related to smoking cessation counseling.

Medical provider attitudes toward smoking cessation counseling. As has been discussed above, physician perception and attitude toward the patient may affect treatment. This may be due to a variety of factors, including personality conflicts between physician and patient, poor boundary setting, professional personal use of tobacco products, as well as other interpersonal factors. As previously noted, physicians do not consistently screen for smoking because they often do not believe that the patient will commit to smoking cessation. A recent research study examined an evidenced-based quality improvement smoking cessation intervention on physician likelihood to refer a patient to a smoking cessation program. Additionally, the researchers examined physician attitude toward smoking cessation counseling (Meredith, Yano, Hickey, and Sherman, 2005). 
The particular study included 280 physicians from several Veterans’ Affairs facilities. Data collected from this evidenced-based program assessed how frequently physicians counseled and referred patients to smoking cessation programs. Attitude did have a positive effect and showed a statistically significant association with smoking cessation counseling and referral. It is not surprising to find that physicians endorsing a more favorable attitude towards smoking cessation have a higher rate of counseling and referral. There was no difference between types of intervention, which further enforces the importance of attitude as a possible barrier to the development of self-efficacy (Meredith et al., 2005).

The previously reported information about skill and attitude development is associated with practicing physicians. When polled these physicians indicated that they did not have the appropriate skill set to feel confident about screening and counseling patients on smoking cessation (Richmond, 1999). If improvements in smoking screening and smoking cessation are to increase among medical personnel, knowledge and skill sets must begin in medical school. It is important to provide medical students with knowledge and skills to conduct screenings and counseling for smoking cessation. Medical school espouses a developmental model of knowledge acquisition and skill development. This model appears to suggest that the earlier in medical school a student is introduced to knowledge and skills, the more time there is for development of the skill set, appropriate attitudes, and ultimately, self-efficacy. However, there are some inconsistencies in this literature that will be more fully explored.

Some research indicates that medical student attitudes do change over the course of medical school (Cape, Hannah, \& Sellman, 2006; Price, Williams, \& Hoffenberg, 
1998). However other research reports no attitude change or negative change (Woloschuk, Harasym, \& Temple, 2002). It is important to explore this discrepancy because it can provide useful information that will likely improve education, preparation, communication, and ultimately train future medical students to be more skillful physicians. Because this process is, by definition, developmental, the timing of these interventions is at the crux of this discussion.

Researchers used a mixed cross-sectional and longitudinal study to examine medical student attitudes toward the role in smoking cessation counseling during medical school years 2, 4 and 6. These researchers found that as students progressed through medical school, scores of attitudes toward smoking cessation became more positive, indicating that medical students can affirmatively change their attitudes about psychosocial issues and behavior change as they gain more information and practice. Additionally, scores on knowledge and skills significantly increased across measurement intervals suggesting an interaction between attitudes, knowledge, and skills. This finding, however, has not been consistently replicated (Cape et al., 2005). One of the weaknesses of a longitudinal study is the effect of ongoing testing of the sample. A study comparing differences between year in training on variables possibly relating to self-efficacy may provide the information researchers need to change the curriculum and most effectively train medical students.

In summary, attitudes about patients who smoke and attitudes toward smoking cessation can increase or decrease the likelihood that a physician will screen or counsel patients on smoking cessation. Poor attitudes correlate with fewer referrals for smoking cessation counseling (Meredith et al., 2005) and may impact self-efficacy. In order to 
prevent medical students from becoming physicians with negative attitudes toward smoking cessation counseling and with few skills to provide such counseling, an intervention must be made. Due to the comorbid nature of smoking and medical problems, it is imperative that medical students learn the proper skills to screen for smoking, and examine their attitudes about smoking and patient ability to quit. Before this intervention is made, it is important to better understand differences in attitudes between clerkship and non-clerkship year medical students. As there are no consistent findings to suggest that medical student attitudes either change-and if so, when, this variable needs to be more closely examined.

In order to fully grasp the complex interaction of knowledge and attitudes, it is important to also examine attitudes toward communication training. Physicians typically state that they feel under prepared to screen for and counsel patients who smoke (Richmond, 1999; Spangler et al., 2002). This lack of preparation is likely related to physician self-efficacy about the ability to help facilitate patient change and should be monitored beginning in medical school. If medical provider self-efficacy is low, the ability to communicate lifestyle change counseling with patients is also likely to be low. When medical providers are not prepared to communicate effectively with patients, it is likely that attitudes will be affected. In this specific case, if the medical provider is under prepared to communicate well with a patient, a misunderstanding may affect compliance, and in turn may shape attitudes and self-efficacy, as previously discussed (Williams et al, 2003). Thus monitoring of attitude development and self-efficacy in medical school may offer different results when students earn their degrees. 
Medical provider attitudes toward general communication. It is the aim of most medical students to become the best physicians possible. The World Health Organization describes the best doctors as those who improve quality of care, use new technologies appropriately, promote healthful behaviors and lifestyles, employ medical interventions to benefit the individual and the entire community, and are able to excel in teams (Bolen, n.d.). Strong communication skills are a reliable avenue to achieve those markers. These communication skills can be learned in medical school. Key tenets to teach effective communication strategies to medical students include the application of communication theory into practice with patients. Practicing these newly-formed skills can be done in a variety of ways, including the use of standardized patients, selfobservation on video, and reading. Assessment is necessary to measure skill and progress (Deveugle et al., 2005).

Acquiring basic, solid communication skills is a mandatory requirement for medical students (Liaison Committee of Medical Education, 2008). They must understand how to communicate with patients in any situation. Researchers found that physicians who had higher scores on a scale that measured psychosocial beliefs (defined in this study as physician role in the life of the patient, beliefs about what patients do and do not want in the doctor-patient interaction, and beliefs about physician reactions toward patients) also used more empathy, more psychosocial support, and less biomedical information in their discussions with patients. In turn, these patients expressed more positive attitudes toward their physicians and asked more questions (Ashworth, Williamson, \& Montana, 1984). 
These basic communication skills are the foundation for acquiring additional skills, namely those involved in motivational interviewing, to be discussed later. Students must be well versed in basic communication skills, such as understanding the difference between opened and closed ended questions and the effect each may have on the doctorpatient relationship (Rollnick et al., 2008), using empathy, and providing appropriate responses to patient cues (Jenkins \& Fallowfield, 2002). Knowledge of communication skills and implementation of these skills will enhance medical student ability to use skills to create interventions.

Researchers have long known that effective communication between physician and patient has many positive effects. It creates an alliance that increases patient compliance with medical recommendations and treatment plans, lifestyle changes, and overall increase in relationship satisfaction (Brody, Miller, Lerman, Smith, \& Caputo, 1989; Wolliscroft, Clahoun, Billiu, Stross, MacDonald, Templeton, 1989).

The Liaison Committee on Medical Education (LCME) directed all medical schools in the United States to adopt a communication curriculum based on competencies identified by the Accreditation Council for Graduate Medical Education (ACGME) (Nierenberg et al., 2007). This policy supports the importance of communication training in medical schools. The members of the Medical School Objectives Project (MSOP) of the Association of American Medical Colleges (AAMC, 1999) published a report indicating that communication between physician and patient and other members of the medical team is a critical skill set. It is expected that medical students be adept at communicating with patients and the team (AAMC, 1999). As a result, medical schools have begun to incorporate communication skills training into their curricula. Numerous 
authors have described this new curriculum that is currently being taught in medical schools (Aspegren, 1999; Poirier, Clark, Cerham, Pruthi, Geda, \& Dale, 2002; Yedidia et al., 2003).

The members of the Amsterdam Conference on Communication in Healthcare (1998) identified several issues in communication training in medical school. The directives include achieving global knowledge of communication skills, the development of patient-centered communication, and teaching communication skills within this specific framework (AAMC, 1999). Learning communication skills is based on successful instruction, and teaching communication skills is most effective when it is offered in a structured manner (Fadlon, Pessach, \& Toker, 2004). Competency is gained when both didactic and experiential modules are employed during training sessions (AAMC, 1999). Role- plays with faculty, peers, and those trained to teach communication skills, as well as viewing oneself on videotape are two most effective training tools (AAMC, 1999). Providing this opportunity before residency may serve to improve medical student interpersonal skills and enhance doctor-patient communication.

The literature suggests that students exposed to communication skills training in medical school perform higher on patient satisfaction scales because these students were better able to create relationships with patients, organized time well, were sensitive in patient assessment, and negotiated decision making with patients (Baerheim et al., 2007; Yedidia et al., 2003). When patients have a strong rapport with their medical provider, compliance rates increase (Brody et al., 1989; Wolliscroft et al., 1989). Therefore, patients may be more amenable to smoking cessation counseling, which may in turn impact medical provider self-efficacy. 
The manner in which this critical information is presented is crucial to the value medical students place on it. For example, researchers found that if communication training is presented in a structured and formal setting, students benefit from instruction, as opposed to those students who participate in informal instruction (Fadlon et al., 2004). This data suggests that medical student attitude toward learning communication skills is an important factor in facilitating the doctor-patient relationship, which has far reaching implications for individual patients and for the healthcare system as a whole. Additionally, there is support for communication skills training provided throughout medical school as a mechanism to improve overall relationships with patients (Rider, Hinrich, \& Lown, 2006) and thus, ostensibly to increase self-efficacy.

When 93 physicians participated in a study to examine how their attitudes and beliefs toward psychosocial factors influenced their communication with patients, significant results were obtained (Jenkins \& Fallowfield, 2002). Researchers assessed physicians before and after a training intervention on communication skills that integrated cognitive, affective, and behavioral components with patient interaction. Participants exhibited statistically significant changes in the following areas: empathy, appropriate responses to patient cues, and psychosocial probing (which are key elements of MI). The researchers suggest these three skills must be gained in order to help facilitate patient change (Jenkins \& Fallowfield, 2002). It is, however, unclear whether the intervention had an impact on the change in attitudes due to participant maturation or other extraneous variables, due to the research design. A relationship between attitudes about communication training and self-efficacy must first be established. Due to the developmental model of learning in medical school, training needs to begin there, as 
opposed to residency or beyond, to ensure that students have the necessary communication skills to foster a therapeutic alliance.

Additionally, researchers suggest attitudes about receiving communication skills training vary across the academic year of medical students. In a qualitative study, researchers commissioned a focus group of medical students from each year, with similar representation of non-clerkship and clerkship year students (Rees et al., 2002). They found equal representation of positive and negative attitudes toward communication skills training among participants in each of the academic years. Some students who had low scores in interpersonal communication appreciated and had positive attitudes toward communication skills training in the hope of gaining additional skills. Other students with low scores in interpersonal communication had negative attitudes toward communication training and indicated that communication is not a necessary skill for the practice of medicine.

An important theme that has emerged from this research is the sequence of when communication skills training was provided to medical students. Students who had this training in pre-clerkship years exhibited more positive attitudes than students who received this training in clerkship years (Rees et al., 2002). This finding is inconsistent with existing outcomes in the literature. A meta-analysis was conducted to examine the most appropriate and meaningful time to teach communication skills to medical students. An examination of 83 studies found that there is no conclusive support for a consistent time to teach medical students communication training. However, teaching communications skills during the clerkship years appeared to have the most effect on medical student application of these skills (Aspergren, 1999). 
Changes in attitudes in medical students and the ability to communicate medical advice efficiently and effectively with patients were recently studied (Woloschuk et al., 2002). The researchers recruited three cohorts of medical students and asked them to complete two questionnaires related to attitudes at three intervals: at the beginning of year 1, and at the end of years 2 and 3. The Medical Skills Questionnaire consists of statements such as, "Society would be much more satisfied with the medical profession if physicians could communicate better with their patients,” and participants respond on a 5-point Likert-type scale. The Attitudes Toward Social Issues in Medicine (ATSIM) consists of 7 subscales, 5 of which were included in this study: social factors, paramedical cooperation, preventive medicine, doctor-patient relations, and social desirability. Again, participants responded using a 5-point Likert-type scale.

In this study, the researchers consistently found that attitudes in all areas became more negative from the beginning of medical school to the end of year 3. Specifically, the scores on variables of doctor-patient relations and preventive medicine (encouraging smoking abstinence) remained the same for the 2 non-clerkship years; however, attitude scores became more negative after the clerkship year. The subscale of doctor-patient relations measured the importance of psychological and interpersonal factors between doctors and patients and its effect on patient care. The preventive medicine subscale measured the importance of preventive health methods with patients (Woloschuk et al., 2002). This finding suggests that after clerkship years, medical students have poorer attitudes toward the importance of doctor-patient communication and relationships, and perhaps place less emphasis on preventive health perspectives, such as smoking cessation counseling. 
Additionally, the same study (Woloschuk et al., 2002) examined the relationship between attitudes and their effects on medical student education. The researchers in this study suggested that more studies are needed with focus on the relationship between attitude changes and clinical performance. A potential approach to accomplish this task is to examine the relationship between attitudes, knowledge, and skills on self-efficacy. In a related study, researchers looked at third-year medical student attitudes toward patients who smoke cigarettes (Griffith \& Wilson, 2001). When medical students completed measures about attitudes of different patient populations before the first clerkship year $27 \%$ of students believed that smokers could actually quit smoking. However, at the end of the clerkship year, only $23 \%$ of students believed patients could quit smoking. While these are not statistically significant results, it does suggest that more medical students at the end of clerkship year believe that patients will not quit smoking. This belief may be related to smoking assessment and smoking cessation counseling, but also, on selfefficacy to facilitate behavior change.

The results of the Woloschuk et al., (2002) and Griffith and Wilson (2001) studies also yielded inconsistent results related to the timing of the training. It is important to consider the differences in the timing of the interventions and the inconsistent results of these studies because it underscores a gap in the learning sequence of communication training. The importance of learning and using communication skills has been previously reported. Solid communication skills strengthen the doctor-patient relationship and increase the likelihood that patients will be compliant with treatment, as well as satisfaction in the doctor patient relationship, which is a safeguard against misdiagnosis and patient litigation (Brody et al., 1989; Wolliscroft et al., 1989). 
The goal of the medical professional is to understand patient health problems and facilitate behavioral and lifestyle change. As shown in the preceding discussion, there are significant obstacles that interfere with the development of self-efficacy to facilitate change in the patient. Yet there are numerous ways medical providers can provide this type of support and intervention. Motivational interviewing, which has its foundations in solid communication skills, is potentially a method for reducing the obstacles to acquiring self-efficacy, and is a widely used intervention for facilitating behavior change.

Motivational interviewing as an intervention skill. Motivational interviewing is a combination of theories, principles, and techniques that aim to help patients manage ambivalence about behavior change (Resnicow et al., 2002). Motivational interviewing is a "client-centered, directive method for enhancing intrinsic motivation to change by exploring and resolving ambivalence, (Miller \& Rollnick, 2002, p. 25).” It is an intervention method used to resolve patient ambivalence, increase discrepancy between current behavior and desired future outcomes, and create behavior change (Miller \& Rollnick, 2002).

The philosophy behind motivational interviewing suggests that motivation is a self-motivated, self induced, personal phenomenon; therefore the sources of motivation for behavior change cannot be persuaded, suggested, or displaced from practitioner to patient (Miller \& Rollnick, 2002). Motivation is an inherent value, not a personality trait, and it functions to clarify and reflect patient readiness for behavior change. Understanding that motivation is self-directed, facilitation of behavior change should be met with an approach lacking in either confrontation or advice giving (Britt et al., 2003). 
Motivational interviewing is comprised of a compilation of theories, including social psychology (attributions), cognitive theory (cognitive dissonance), Bandura's theory of self-efficacy, the transtheoretical model of change (Prochaska, DiClemente, \& Norcross, 1992) and Rogers’ humanistic therapy (Britt et al., 2003; Burke, Arkowitz, \& Menchola, 2003). While practitioners may employ each of these theories independent of one another, motivational interviewing allows practitioners to use the combined and integrated strengths of these differing theories to facilitate change. It is outside the scope of this paper to discuss how MI training is conducted. For additional resources the reader is referred to www.motivationalinterviewing.org.

The efficacy of motivational interviewing has been tested on several patient problems. It was first used in the 1980s in the treatment of substance-use disorders (Miller \& Rollnick, 2002). Following its introduction, it has been used in a multitude of disciplines and for numerous mental health and medical health problems including cardiovascular risk reduction (Brodie \& Inoue, 2005; Castaldo et al., 2005; Ogedegbe \& Chaplin, 2005), compliance in diabetes treatment (Sharp \& Lipsky, 2002; West, DiLillo, Bursac, Gore, \& Greene, 2007), improving compliance in an exercise program (Scales \& Miller, 2003), and for asthma and COPD treatment (Broers et al., 2005; deBlok, deGreef, tenHacken, Sprenger, Postema, \& Wempe, 2006), as well as many others. The results of these studies indicate that motivational interviewing is an intervention that is effective in treatment of health problems. However, the majority of MI empirical research has focused on substance use and smoking (Britt et al., 2003; Miller, Rollnick, \& Butler, 2007). According to the DSM-IV, substance dependence disorders incorporate a lifestyle component that maintains the addiction (APA, 2000). 
Just as MI is helpful to people who are addicted to nicotine because it addresses behaviors that sustain the addiction, $\mathrm{MI}$ is likewise helpful for practitioners who need to address their own professional behaviors that may or may not engender change in patients. This is a second-order intervention that promotes overall system change. Second-order change is change of the entire system and occurs over time. It typically occurs when the system is under normative or non-normative stress (Olson, 1999). In this case, if MI philosophy and interventions can influence medical providers to restructure their own attitudes about patient who smoke and smoking cessation counseling, then there is a chance for the whole relationship to change and facilitate a new approach to behavior change. Furthermore, this type of change has the potential to positively affect the entire health care system.

Empirical studies examining the efficacy of motivational interviewing began as early as 1988 when researchers used MI with people who excessively used alcohol. The researchers found that MI was an effective intervention (Miller, Sovereignm, \& Krege, 1988). The MATCH project was the first empirically based study that evaluated the use of MI as a single or primary treatment for problem drinkers. This study examined the outcomes for 1,726 alcohol-dependent participants who were randomly assigned to three treatment settings; namely, Motivational Enhancement Therapy (MET), Alcoholics Anonymous, and cognitive-behavioral coping skills training. The participants in the MET group abstained from alcohol at the same rates as those in the other two treatment groups (Project MATCH Research Group, 1993).

Motivational interviewing is designed to be brief in nature and can be used as a solitary intervention or as a precursor to another treatment modality (Hettema, Steele, \& 
Miller, 2005) with positive significant effects (Burke et al., 2002; Noonan \& Moyers, 1997). As this is a brief interaction, practitioners must be skillful in the administration of the spirit of motivational interviewing, which a distinctive feature of motivational interviewing.

Collaboration, evocation of patient goals, and respect for patient autonomy comprise the spirit of MI which addresses the "way" that a practitioner interacts with the patient (Rollnick et al., 2008). An established relationship between patient and practitioner is a strong indicator that the spirit of MI will be endorsed. This relationship is the cornerstone that builds behavior change. Motivational interviewing in its purest form follows the aforementioned philosophy and spirit; however, MI is not always practiced in this specific way. If some of the principles of MI are present in an interaction, but the practitioner uses techniques inconsistent with MI, such as significant advice giving or confrontation, then MI in its purest form is not being conducted (Dunn, Deroo, \& Rivara, 2001). Many interventions resemble MI, but vary in ways that differentiate them from the traditional form of MI. Additionally, the practice of MI is often more effective if the practitioner has a solid understanding of the individual patient's process of change (Prochaska et al., 2006). The process of change is described in the Transtheoretical Model of Change (TTMC), which houses some of the theoretical underpinnings of MI.

The Transtheoretical Model of Change (TTMC) was developed by Prochaska, DiClemente, and Norcross (1992) to improve understanding about how a person makes changes. The focus of this model is on patient readiness to change, which is critical information so the physician best understands how to intervene. The intervention will be associated with the stage of change the patient endorses. The four stages of readiness to 
change are a) Precontemplation, b) Contemplation and Preparation, c) Action, and d) Maintenance. In the Precontemplation stage, the patient is unaware that a change needs to be made. In the contemplation and preparation stage, the patient may be aware that a change needs to be made and makes arrangements to do so. In the action stage, the patient engages in behavior modification and recognizes the cognitive and affective components of the process. Finally, in the maintenance stage, patients have made a change and now must engage in behaviors that sustain the change.

Recognizing the stage of an individual's readiness process allows the provider to tailor the interventions necessary to facilitate behavior change (Velicer et al., 2000). Establishing the stage of change that characterizes a given patient is central to the success of motivational interviewing and allows the practitioner to intervene at the appropriate level, increasing the likelihood of change behavior (Miller \& Rollnick, 2002). Again, there are two central components to motivational interviewing, examining and resolving ambivalence. Recognizing the stage of change which best represents the patient will allow for the appropriate MI intervention. Understanding the theory of change will only enhance the application of a model to facilitate change (DiClemente and Velasquez, 2002). Working through the stages of change is a gradual process and requires multiple steps to get to the maintenance stage. Recognizing the stage is largely related to TTMC and the motivation to move through these stages is largely related to MI (DiClemente \& Velasquez, 2002).

In a review of 6 studies, researchers found that specific interventions were most appropriate depending on the stage of change adopted by a person at a certain time. For instance, people who were identified as in the contemplation stage increased awareness 
of problem behaviors and responded well to the MI strategy of developing discrepancy between current behavior and future goals. For those in the action stage, interventions based on the development of self-efficacy and continuing to develop discrepancy helped people make changes (Prochaska \& DiClemente, 1992). It appears that TTMC identifies the stage of the individual considering change and MI is the motivation and behavior associated with each particular stage.

Adopting motivational interviewing techniques and points of the Transtheoretical Model of Change can reduce frustration and improve the self-efficacy of the medical professional because it removes the responsibility from the medical provider to make the patient stop smoking and places the impetus for change on the patient. The medical professional is then responsible for helping patients move through the stages of change, rather than "fixing" them. As previously discussed, the likelihood that the medical provider will screen for smoking use, refer for smoking cessation counseling, and utilize communication skills training is associated with his or her knowledge, skill, and attitude. Provider control over these variables will affect his or her belief that these interventions will ultimately influence behavior change.

Role of self-efficacy in motivational interviewing. Motivational interviewing is an integrated theory which aims to encourage the development of self-efficacy, encouraging the belief that accomplishing a task is possible. In a meta-analysis of 19 studies, researchers found that physician self-efficacy was predictive of attitude and behaviors. Seventy-nine percent of the physicians in this study indicated that lack of professional self-efficacy was a barrier to patient care (Cabana et al., 1999). Physicians often experience frustration with addicted patients which in turn decreases self-efficacy 
in their ability to assist patients in making changes. External events can influence personal emotions and behaviors. Social learning theory offers an explanation for the relationship between external and internal factors and the influence on behavior (Bandura, 1997), and has been used in several studies to explain why people behave in particular ways and how psychologists can treat the cognitive processes that negatively impact behavior (Bandura \& Locke, 2003; Michie \& Abraham, 2004; Rosenstock, Stretcher, \& Becker, 1988). Although social learning theory stands on its own, it also has a significant role in the application of motivational interviewing.

As discussed previously, social learning theory posits that individual self-efficacy affects the likelihood of engaging in a particular behavior. In motivational interviewing, self-efficacy is critical because the patient is credited with having the resources to solve problems, complete tasks, or achieve goals. Patients must believe in their own skills to create that change, complete that task, or achieve that goal (Britt et al., 2003). In turn, medical providers who share these beliefs with their patients can facilitate change. The use of MI allows patients to recognize their own abilities, which further strengthens the belief in their capabilities. Acknowledging one's abilities is a success in itself. This in turn fosters the belief that success is sustainable by behavior, hence, increasing selfefficacy.

Motivational interviewing and smoking cessation. Smoking cessation is one area researchers have been exploring to determine the usefulness of MI techniques in facilitating patient behavior change. The results of a meta-analysis review suggest that among a range of disorders, the use of motivational interviewing has shown the greatest efficacy on smoking cessation, as compared to other interventions (Britt et al., 2003). 
This is critical information because when an intervention proves efficacious, it can be tested in myriad settings to increase its range of application. In this case, motivational interviewing is a promising tool for training medical students to assist in smoking cessation among their patients. Also, as discussed above, because physicians often experience frustration with patients who are non-compliant with treatment recommendations this in turn may affect physician self-efficacy, potentially leading to less effective treatment. This makes using MI and the transtheoretical model of the stages of change a very powerful tool for developing and increasing self-efficacy among medical providers.

The understanding that motivation is an intrinsic, person-centered process may positively affect practitioners, particularly those who treat patients with non-compliance issues. The majority of smokers surveyed state that they have no intention of quitting smoking within the next month, which suggests they may need several contacts with a medical professional in order to process and progress through the stages of change (Velicer et al., 1995). This fact becomes especially salient because, as noted above, motivational interviewing focuses on resolving ambivalence, increasing discrepancy, and rolling with resistance—all techniques that would likely be of considerable benefit to non-compliant patient populations, including smokers (Miller \& Rollnick, 2002).

The stage of change the patient endorses will indicate which intervention is necessary for the physician to pursue. In a study conducted by Prochaska et al. (1994), the authors recruited 3,858 people to participate in an integrative study that examined stages of change and 12 problem behaviors, including smoking. In this group, 764 current and previous smokers completed a 5-point Likert-type scale survey to determine their 
perceived stage of change (precontemplation, etc.). They were asked to indicate 'pros' and 'cons' for their current behavior and for reasons to change behavior. There were 108 participants in the precontemplation stage, 187 in the contemplation stage, 134 people in the action stage and 247 in the maintenance stage. The results indicated that pros for changing behavior were higher for participants who endorsed the contemplation stage over the precontemplation stage. The cons for changing were lower for participants in the action stage as opposed to the contemplation stage.

These results suggest that participants who endorse more advanced stages of change will be more likely to see a positive to change behavior than participants from earlier stages, who are less likely to see a positive to change behavior. These results provide evidence for the efficacy of motivational interviewing. Further, the findings suggest that when physicians know how to help facilitate behavior change using these parameters or using this model, from precontemplation to action stages, they will likely see more improvement in patients who quit smoking.

The research suggests that the use of motivational interviewing is an effective intervention to reduce smoking. Although most physicians believe that smoking cessation is important in their practice, actual counseling rates remain low (Meredith et al., 2005). As already discussed, physician attitudes toward smoking and smoking cessation interventions are often cited as one cause for these low rates.

Medical students who are exposed to smoking cessation training are likely to screen for and counsel patients on smoking use (Fadlon et al., 2004). Other research indicates that the majority of medical students believe that patients will comply with 
directives to quit smoking. However, this knowledge does not correlate with confidence about providing smoking cessation advice (Prochaska et al., 2006).

Motivational interviewing and medical students. Motivational interviewing has been an intervention taught to many professionals in a variety of fields. However only in recent years has MI been used to teach medical students how to intervene and encourage behavior change. Early research done in medical settings included medical residents as participants. In two studies, researchers instructed medical students in their first and third years on the use of MI (Poirier et al., 2002; White, Gazewood, \& Mounsey, 2007).

Overall, in both studies, medical students reported that learning MI was an important skill that improved their ability to speak with patients about behavior change.

The findings suggest that students in clerkship years are able to learn how to use MI techniques, such as reflective listening and asking permission before advising (White et al., 2007). Additionally, after general training in MI, students experienced more confidence in counseling patients with nicotine dependence than counseling those with other substance abuse disorders and obese patients (Poirier et al., 2002).

In a separate study, researchers taught 53 third-year medical students about MI and its applications (Bell \& Cole, 2008). Changes in skills and knowledge were measured by the Video Assessment of Simulated Encounters-Revised (VASE-R), which measures specific MI skills using three video-taped vignettes that precede questions, such as, "Write a statement that shows you are listening.” The results indicate medical student scores on MI skills and knowledge significantly increased after the training. The researchers also measured confidence, which is related to self-efficacy, and found that 
medical student confidence to implement MI tools with patients increased significantly with the training.

After an instructional course in motivational interviewing, first-year medical students reported an increase in responsibility for facilitating patient behavioral change, and a decrease in pejorative attitudes toward patients with unhealthy behavior choices (Brown et al., 2004). These findings demonstrate that gaps exist in this literature. The literature does not provide definitive evidence concerning if and when communication skills training, knowledge on smoking, and behavior change training interventions during pre-clerkship or clerkship years, will have a significant effect. Brown et al. (2004) further suggest that future research should examine differences between pre-clerkship and clerkship year medical students to better understand the sequence for the development of the most efficacious training model.

An increase in self-efficacy in medical students related to smoking cessation screening and counseling is also echoed in a study conducted by Nieman et al., (2005). The researchers created a two-year module for medical students between the first and second years of their program. 78 medical students participated in this study. Didactic and experiential sessions were offered to the students, and included instruction on behavior change, effects of smoking use, smoking cessation counseling techniques, and role-plays that incorporated MI techniques. The students were evaluated prior to the intervention, after the intervention, and after the preceptorship (the time when students present cases to an attending physician and receive feedback) ended.

Student perceived knowledge and self-efficacy in ability to counsel patients about smoking increased $61 \%$ and $34.4 \%$, respectively, after the intervention. At the end of the 
preceptorship, student knowledge significantly increased a total of $98 \%$. Interestingly $44 \%$ of preceptors decided to integrate this model of smoking assessment and cessation counseling into their own practices. Perhaps even after exposure to brief motivational interviewing skills training, medical students may change their attitudes and will increase their self-efficacy to counsel patients about smoking cessation.

As already noted, there are some inconsistencies in the literature about attitude changes, skill development, and development of self-efficacy in medical school cohorts. First-year medical students are in the position to learn about behavior change early in the medical school curriculum, which can be reinforced later when working with patients. Again, MI is a helpful tool that facilitates such change. In one study, researchers asked first-year medical students to participate in a workshop that taught MI skills and examined their attitudes toward smoking cessation (Brown et al., 2004). One hundred forty-seven first-year medical students completed the protocol, which included attending workshops, reading manuals, taking tests, and completing questionnaires.

Significant differences before and after the completed protocol were found in MI skills and knowledge, including an increase in applying these techniques, and more positive and therapeutic attitudes toward patients who smoke. The findings of this study indicate an interaction between changes in knowledge and skills, attitudes, and selfefficacy. However, the results of the Woloschuck et al. (2002) and Griffith and Wilson (2001) studies, as reviewed above, yielded inconsistent results about the timing of training medical students in MI during their educational tenure. Further study to explore the inconsistencies in responses in pre-clerkship and clerkship year medical students is needed. 
The effective practice of MI is contingent upon learning basic communication skills, such as using open and closed questions, expressing empathy, setting agendas, and responding appropriately to patient cues (Jenkins \& Fallowfield, 2002). These skills are imperative in demonstrating to patients that they are understood. When patients feel understood, they typically feel a stronger connection with their provider, thus improving the relationship. There is a long history of literature that supports the hypothesis that relationships between people are shaped by how well a person feels heard and understood by another (Rogers \& Kramer, 1995). When the relationship is strong, patients are more likely to feel supported by physicians and are more likely to comply with physician recommendations. This is exactly the type of relationship that is necessary in order for MI interventions to be successful.

Researchers found that when patients report high rates of satisfaction within the doctor-patient relationship, medical compliance increases (Kerse, Buetous, Mainous, Young, Coster, \& Arroll, 2004). As previously discussed, the provider must also understand how to use MI based on the level of patient motivation to quit smoking. This skill set may alter physician attitudes about smoking, smoking cessation, and communication skills training, and in turn, affect self-efficacy.

\section{Instrumentation and Study Methodology}

The study of attitudes has been a popular area of research in the field of psychology, but the study of attitudes specifically related to communications skills training is a relatively new occurrence. Prior to 1999, only 83 empirical studies were conducted with medical students attitudes about communication skills training (Aspergren, 1999). Attitudes about patients who use addictive substances is also a 
relatively new area of study within the field. Researchers have attempted to create valid and reliable measures to study these variables (Aspergren, 1999; Cape et al., 2006, Karam-Hage et al., 2001; Meredith et al., 2005, Rees et al., 2002; Rider et al., 2006; Woloschuk et al., 2002). After an exhaustive and careful review of the literature, the measures for this study were selected based on relevance to the study and also validity and reliability. The study of medical student attitudes is not new, but focusing on their communication skills is a relatively new area to explore. As measures continue to be constructed, it is important to recognize that the measures selected for this study are currently the most robust available, even though they fall marginally below the standard of measure of validity.

The research studies critiqued in this review have both strengths and weaknesses. The current study attempts to avoid some of the problems of other studies through the use of a correlational design, which first addresses whether or not relationships exist among variables, before making any assumptions about these relationships. While the participant sample was low and thus limited the types of statistical analyses chosen, participants were not required to participate as part of a course or due to faculty member involvement. (Additional limitations are discussed in Chapter 4). Additionally, these variables were not manipulated in any way, which may offer helpful information about medical student knowledge, attitudes, and skills to faculty, curriculum development teams, and other researchers.

\section{Statement of the Problem}

As previously stated, tobacco use is a national health care crisis in which health care professionals are keenly poised to intervene. Physicians repeatedly state that 
assessing for smoking is critical (Smith et al., 2002). However, at the same time, they frequently indicate that counseling patients for smoking cessation is not feasible or even helpful (Swan et al., 2003). The research suggests medical students believe counseling on lifestyle and behavior change is an important function of their jobs, but many believe patients will not make the advised changes (Foster et al., 2002). Coupled with this attitude, medical students also often exhibit low confidence about the efficacy of medical professionals to intervene at this level (Schkrohowsky, et al., 2007).

Although medical students are mandated to learn communication skills before they graduate from medical school (LCME), practicing physicians report that they are underprepared to screen for and counsel patients who smoke (Richmond, 1999; Spangler, et al., 2002). This factor is directly related to their self-efficacy in fostering change. Presumably, medical students will be expected to counsel patients about smoking cessation, but if self-efficacy about their abilities to facilitate change is low, then it is reasonable to assume that appropriate interventions may not occur.

Certainly there is no consensus among researchers on the relationships connecting knowledge, attitudes, medical student year in training, and self-efficacy. There are different ways to address these variables and it is important to know if any of them can predict medical student self-efficacy. It is equally important to know if there are differences in these variables between medical students in pre-clerkship years and medical students in clerkship years, as shown above. The inconsistent findings reported in this study require further evaluation to explore interactions between factors. The inconsistent findings among studies measuring similar variables may also relate to limits in statistical design. It is important to more fully understand which variables are related to 
self-efficacy, as opposed to only measure changes in them. Developing an awareness of these relationships will likely lead to future research that can more fully explore the dynamics of these relationships.

\section{Purpose of the Study}

This research aims to investigate the strength of relationships between knowledge of smoking cessation, attitudes toward smokers, attitudes toward smoking cessation counseling, attitudes toward general communication training, motivational interviewing skills, and year of medical school on medical student self-efficacy related to smoking cessation counseling. Additionally, the differences between medical students in nonclerkship years and medical students in clerkship years in knowledge and attitudes will be explored between both groups.

\section{Definitions of Important Concepts}

Attitude. The learned, relatively stable tendency to respond to people, concepts, and events in an evaluative way (APA, 2002).

Clerkship years. "The clinical phase of the curriculum usually occurs during the last two years of medical school and is devoted to education in the clinical setting. The periods of instruction are called clerkships, and may range in length from approximately 4 to 12 weeks. During clerkships, students work with patients and their families in inpatient and outpatient settings.” (AAMC, 2009).

Communication Skills Training. Gaining the ability to provide advice and explanations to patients in a way that is understood (Rees, et al., 2002).

Knowledge. "The fact or condition of knowing something with familiarity gained through experience or association.” (Webster’s Dictionary, 2009). 
Motivational Interviewing. A directive, client-centered counseling style for eliciting behavior change by helping clients to explore and resolve ambivalence. (Miller \& Rollnick, 2002).

Preceptorship. Medical providers who are teaching faculty and guide medical students and residents with clinical decision making. (The Association of Professors of Gynecology and Obstetrics, 2009).

Preclerkship years. "The preclinical phase typically occupies the first two years after matriculation. The basic science departments are largely responsible for the content of the preclinical curriculum.” (AAMC, 2009).

Self-efficacy. The judgment a person has about his or her own abilities to accomplish a task or goal (Bandura, 1977).

Smoking cessation counseling. "The preventive measure consists of tobaccocessation counseling provided by physicians and other health care professionals. Key elements of effective counseling include identifying tobacco users, offering consistent and repeated cessation advice that is of personal medical relevance, adjuncts such as nicotine replacement therapy (NRT), follow-up contact, and advice regarding intensive cessation therapy. For patients who are unwilling to quit, motivational interventions, including information regarding personal risks associated with smoking and rewards resulting from cessation may be offered.” (Kattapong, Locher, Secker-Walker, \& Bell, 1998).

Social Learning Theory. Learning that occurs within a social context. It suggests that people learn from each another via observational learning, imitation, and modeling. (Ormond, 1999) 


\section{CHAPTER 2}

\section{Methodology}

This study explored the relationship between knowledge about smoking, attitudes toward patients who smoke, attitudes toward communication skills training, attitudes toward smoking cessation counseling, use of motivational interviewing (MI) skills, and year in medical school and the effects of medical student self-efficacy on smoking cessation counseling. The differences between medical students in non-clerkship years (years one and two consisting of didactic work) and medical students in clerkship years (years three and four consisting of clinical work with actual patients) were examined in the following areas: knowledge about smoking, attitudes toward smokers, attitudes towards smoking cessation counseling, attitudes toward basic communications training, and use of MI skills.

The outcome of this study is intended to provide psychologists and medical school faculty with a greater understanding of the relationship between self efficacy and the following variables: year in medical school, tobacco use knowledge, attitudes toward smokers, smoking cessation counseling, and general communication skills training. This information is aimed to provide the rationale to include training and education during the appropriate time in the course of medical school.

\section{Participants}

Participants for this study were recruited from the body of medical students at a large university in the mid-Atlantic region. All demographic information is listed in Table 1. 
Table 1.

Demographic Characteristics of the Sample (N)

Variable

n Percent of Sample

Gender

Male

Female

Year in Training

MSI

MSII

MSIII

MSIV
19

16

8

11

7

9

Smoked Cigarettes in Past

Yes

No

Currently Smoke

Yes

No

Parents/Caregivers Smoke

Yes

No

Yes

No

30

27

3

32

8

27
Exposed to Motivational Interviewing

$54.3 \%$

$45.7 \%$

$22.9 \%$

$31.4 \%$

$20 \%$

$25.7 \%$

$22.9 \%$

$77.1 \%$

$8.6 \%$

$91.4 \%$

$22.9 \%$

$77.1 \%$

$14.3 \%$

$85.7 \%$

If YES, how

Seminar

Class

Brochure

Personal Reading

Other

0

4

0

1

1

$0 \%$

$11.4 \%$

$0 \%$

$2.9 \%$

$2.9 \%$

Smoking Cessation Interventions

Yes

9

25

$25.7 \%$

$71.4 \%$

Communication Skills Training

Yes

14

21
$40 \%$

$60 \%$ 
Table 1 continued

Demographic Characteristics of the Sample $(N)$ continued

Variable

Specialty

No answer

Anesthesiology

Family Medicine/OBGYN

Emergency Medicine

General Surgery

Internal Medicine

Medicine-Pediatrics

Neurology

Neurosurgery

Orthopedic Surgery

Pediatrics

Primary Care n Percent of Sample

$\begin{array}{ll}1 & 2.9 \% \\ 1 & 2.9 \% \\ 1 & 2.9 \% \\ 1 & 2.9 \% \\ 2 & 5.7 \% \\ 1 & 2.9 \% \\ 1 & 2.9 \% \\ 1 & 2.9 \% \\ 1 & 2.9 \% \\ 1 & 2.9 \% \\ 1 & 2.9 \%\end{array}$

Frequency of Screening Pts

Always

30

$85.7 \%$

Sometimes

5

Never
$14.3 \%$

$0 \%$

Offer Smoking Cessation Counseling

Always

Sometimes

Never
23

11

1
$65.7 \%$

$31.4 \%$

$2.9 \%$ 
Participants were divided into two groups: pre-clerkship and clerkship year medical students. Students in years 1 and 2 were grouped together as "pre-clerkship year participants" and students in years 3 and 4 were grouped together as “clerkship year participants." (See Table 1) The national average of matriculated women medical students is 48.3 percent (Association of American Medical Colleges, 2008) so this sample size, at $45 \%$ females is slightly less than the national average. The gender distribution was computed at the completion of data collection and is reported in the Results section. Participant gender distribution generally reflected the overall gender distribution of students at this university, as this is the population to which the data will be generalized. 
Table 2.

Medical Student Demographics

\begin{tabular}{|c|c|c|c|c|c|}
\hline \multirow[b]{3}{*}{ Medical Student Cohorts ${ }^{a}$} & \multicolumn{2}{|c|}{$\underline{\text { Males }}$} & \multicolumn{2}{|c|}{ Females } & \multirow{3}{*}{$\frac{\text { Totals }}{\mathrm{N}}$} \\
\hline & $\overline{\mathrm{N}}$ & $\%$ & $\mathrm{~N}$ & $\%$ & \\
\hline & & & & & \\
\hline MSI & 65 & 57 & 50 & 43 & 115 \\
\hline MSII & 60 & 52 & 55 & 48 & 115 \\
\hline MSIII & 71 & 69 & 31 & 31 & 102 \\
\hline MSIV & 62 & 61 & 40 & 39 & 102 \\
\hline Preclerkship year totals & 125 & 54 & 105 & 46 & 230 \\
\hline Clerkship year totals & 133 & 65 & 71 & 35 & 204 \\
\hline Totals & 263 & 60 & 171 & 39 & 434 \\
\hline
\end{tabular}

Note. ${ }^{a}$ MSI-First year students, MSII-Second year students, MSIII-Third year students, MSIV-Fourth year students 
Preparing Medical Students 59

\section{Procedures}

All medical students at the university were asked to participate in this research study. They were recruited by e-mail and flyers posted by medical school administrators beginning in May 2009. A second round of recruitment began in June 2009 and medical school faculty recruited medical students during classes and seminars. Incentives offered for participation in this study were outlined in the contact information and informed consent form. Medical students accessed a website to participate in this study. The website link was included in the Internal Review Board (IRB) approval form, as was participant informed consent, study directions, and all questionnaires. Each participant responded confidentially. At the completion of the questionnaire, a hyperlink allowed the participant to e-mail the researcher to verify participation for distribution of the incentives. There was no way to link individual participants to their completed questionnaires. At no time will the individual scores on any of the questionnaires be released to members of their medical school faculty, therefore there will be no potential penalty for incorrect answers. The responses and scores were housed electronically and password protected to maintain confidentiality. Participants completed the study in May and June 2009, after two rounds of participant recruitment.

Participants had a chance to win one $\$ 50$ gift card to Starbucks Coffee House or a \$50 gift card to the medical school bookstore. Participants who e-mailed the researcher provided their e-mail address. The two participants who were selected to receive one of the incentives were notified via e-mail in July 2009. One participant has not responded to e-mails from the researcher, perhaps due to use of university e-mail account which may not be used during summer months. A mailing address was obtained so that one 
participant could receive the gift card. At this time, the winning participant has not responded to e-mails about the incentive.

Data was collected through a web-based survey using Secure Online Environment (SOLE), a web-based portal for students, faculty, and staff at the West Virginia University Health Sciences Center. SOLE was created by Academic Technologies as an open, online system for course development and management, and is a portable system that can be accessed anywhere. Using SOLE allowed participants to complete the questionnaires at a convenient time and place. Additionally, it allowed for confidential and secure responses that were accessible to this researcher.

Participants were provided with the url address to access SOLE in order to complete the study. All documents were accessible via SOLE and answers were marked electronically. The Video Assessment of Simulated Encounters-Revised (VASE-R), an interactive method of data collection, was available to participants on an additional screen while viewing the recorded vignettes. Instructions to complete the VASE-R were provided as the questionnaire was in progress.

\section{Instruments}

Seven published questionnaires and a demographic questionnaire created for this study were combined into a 96 total item web-based questionnaire tailor-made for the purposes of this study. Each questionnaire appeared in total, with the exception of the Provider Self Efficacy Questionnaire, which will later be explained in full. Questionnaires are included in Appendix A. The informed consent letter appears as Appendix B. After the IRB process was completed, the IRB approval letter was included 
on the study hyperlink. The questionnaires that follow served as content for the tailormade questionnaire completed by the study participants

Demographic questionnaire. Participants were asked to respond to 11 items designed by the researcher to gather demographic data. It included the following categories: gender, year in medical school, past and present smoking status, parental smoking status, previous exposure to MI, smoking cessation, exposure to communication skills training, medical specialty selection, frequency of screening for smoking, and frequency of providing smoking cessation counseling.

Provider Self-Efficacy Questionnaire (Ozer et al., 2004). (PSEQ). This instrument measures pediatrician self assessment of confidence in the ability to screen for and offer smoking prevention information to teenage patients. This questionnaire has 35 items listed and measured on an 11-point Likert-type scale; $0=$ not at all confident, $10=$ extremely confident. There are seven categories, each with several questions such as “How confident are you that you can: (a) ask teens about tobacco use?” There are five subscales of risk behaviors—-tobacco use, alcohol use, sexual behavior, seatbelt use, and helmet use. The other subscales of this questionnaire, alcohol use, sexual behavior, seatbelt use, and helmet use, measure behavior that is unrelated to the present research study and so were not included in this research study. Calculating the mean of the items determined the self-efficacy score. The higher the score, the higher the level of selfefficacy.

This questionnaire included the 4 items on the Tobacco Efficacy Scale and with the author's permission, the language was changed from "teens" to "patients" to reflect the participant group. The subscale Tobacco Efficacy Scale had an alpha reliability score 
of .80. Other variables were studied on this measure, but are not relevant to the current study, and therefore not reported here.

Tobacco Use in American Medical Schools. (Schkrohowsky, Kalesan, \& Alberg, 2007). The questionnaire assessed medical student knowledge and attitudes toward tobacco use, smoking cessation, and the role of physicians in smoking-related issues. This questionnaire was self-administered and consists of 49 total questions, including a 7item demographic questionnaire, which was eliminated from this study because a studyspecific demographic questionnaire had already been included. The measurement used in this study consisted of 42 questions.

There were four domains of questions in this questionnaire; morbidity/mortality (questions 9, 10, 11, 12, 28, 29), smoking cessation (questions 15, 16, 17, 18, 21, 24, 27), physician role $(8,14,19,20,22,23)$, and pharmacology $(13,25)$. Questions were answered as true/false. Examples of questions from each domain include, "Cigarette smoking is the single most preventable source of premature morbidity and mortality,” “Evidence suggests that providing written information, i.e. pamphlets, during the consultation significantly improves the efficiency of smoking cessation advice,” "Nicotine gum is contraindicated in all patients with heart disease," and "Nicotine’s pharmacological effects include: a) Increased vasopressin release”, etc. Attitude questions were answered on a 7-point Likert-type scale with a range of -3 to 3 (Very Difficult to Very Easy) and included such questions as, "How difficult is it to help patients stop smoking?”

In the published study (Schkrohowsky et al., 2007), a total of 198 medical students (136 MSI and 162 MSIV) participated and means were calculated, with a chi- 
square used to examine differences. The researchers found that medical students only answered $64 \%$ of questions on tobacco use and cessation correctly, which is considered a deficient score. Also, attitudes about smoking cessation success became more negative from non-clerkship to clerkship years. Medical students were more positive about the success of smoking cessation counseling and their role in facilitating that for patients at the beginning of medical school than they were at the end of medical school. The reliability and validity scores were not available and so were then calculated for the purposes of this study. The procedure to determine reliability and validity will be discussed in a separate section.

The knowledge section of this measure was scored by the researcher based on the answer sheet for the measure. The raw data was then calculated to find a percentage score, which is consistent with the manner of scoring in the published article.

Attitude toward Smoking Cessation Counseling (Meredith et al., 2005). This questionnaire had 9 items addressing medical provider attitudes toward patients who smoke and their smoking intervention. An example of the questions is, "Smokers are unlikely to quit when counseled.” The questionnaire used a Likert-type scale ranging from, $1=$ strongly disagree, $2=$ disagree, $3=$ neutral, $4=$ agree, $5=$ strongly agree. The higher the score, the higher the level of self-efficacy. The researchers developed this questionnaire using factor analysis $(\alpha=0.65)$ and using a review of other questionnaires that measured provider attitude toward depression. The Cronbach’s alpha of the scale, 0.65, was below the standard .70 and this information was taken into consideration when results were analyzed. 
Communication Skills Attitude Scale (Rees, Sheard, \& Davies, 2002) (CSAS). The CSAS was a 26-item self-administered questionnaire designed to assess the attitudes of medical students toward learning communication skills. Examples of questions include “In order to be a good doctor I must have good communication skills,” and "Learning communication skills is too easy.” The CSAS was developed in the United Kingdom and was normed on first- and second-year medical students. These students only received didactic training, which is consistent with pre-clerkship year medical students in the United States. The questionnaire used a Likert-type scale to measure responses as follows 1 = strongly disagree, $2=$ disagree, $3=$ neutral, $4=$ agree, $5=$ strongly agree Thirteen of the questions were positively scored and 13 items were scored in the reverse direction. The score of the measure related to the type of attitude about communication skills; the higher the score, the more positive the attitude.

Internal consistency for the positively scored items was $\alpha=0.873$ and internal consistency for the reverse scored items was $\alpha=0.805$. The threshold for establishing internal consistency was set at .80. The scores for the CSAS exceeded this level (Bland \& Altman, 1997). The kappa coefficients, which measured the agreement of scores between two raters taking into account the agreement occurred by chance, were found to be moderate, (69.2\%). This statistic indicates sufficient test-retest reliability for this study (Landis \& Koch, 1977).

The Video Assessment of Simulated Encounter- Revised (Rosengren, Hartzler, Baer, Wells, \& Dunn, 2008). This questionnaire, which included an interactive video questionnaire, was developed because of burgeoning interest in measuring individual skill in conducting motivational interviewing-style interventions (Rosengren, Baer, 
Hartzler, Dunn, \& Wells, 2005). The researchers reviewed the related literature and identified measurable central MI skills. They then created three scripted case vignettes in which actors familiar with substance use issues played patients with different substance use problems. A pilot study was conducted with addiction treatment providers to assess for clarity, authenticity, and to provide feedback on length of answers required of participants. Originally there were 24 questions with 7 subscales included on this questionnaire. The coding reliability varied from 71.2\%-98.5\%, and therefore 6 questions and 2 subscales were dropped from the questionnaire due to low reliability, thus creating the Video Assessment of Simulated Encounters- Revised (VASE-R) questionnaire.

The VASE-R consists of 18 questions which were completed as the participant viewed the interactive video and responded to each question using paper and pencil. It measures participant ability to create and recognize MI responses. The three vignettes were played on a DVD player and as each vignette played, the commentator instructed the participant to write a MI-consistent response such as, "Write a response that indicates that you are listening.” Depending on the prompt, the participant had between 30 and 90 seconds to respond and then the vignette resumed. Participant responses were coded on a 3-point system, $0=$ confrontational or likely to engender resistance, $1=$ neutral or inaccurately represents the content of the client's speech, and $2=$ accurately reflects the content of the client's speech and represents the intended MI skill. There were 5 subscales; (1) reflective listening, (2) summarizing, (3) responding to resistance, (4) eliciting change talk, and (5) developing discrepancy. These subscales are directly related to skills consistent with MI. An administrator manual, which provided examples of responses and the scores of each response, was used to score the responses. 
Recently, the researchers conducted two studies to further evaluate the psychometrics of the VASE-R (Rosengren et al., 2008). In one study 1,144 substance abuse treatment personnel participated. Each participant completed a self-report demographic survey, the group administration of the VASE-R, the Helpful Responses Questionnaires (Miller, Hedrick, \& Orlofsky, 1991) and audio-recorder interviews with a standardized patient, which were then scored using the Motivational Interviewing Treatment Integrity (Moyers, Martin, Manuel, \& Miller, 2004). Three independent raters randomly selected $20 \%$ of the protocols. The internal consistency was high using Cronbach's $\alpha$ coefficient $(\alpha=.85)$. Concurrent validity scores indicated that VASE-R is correlated to the scores on the Helpful Response Questionnaire and the Motivational Interviewing Training Inventory, which were two independent measures that assessed for MI skills. These are the "gold standards” in the area of MI (Rosengren et al., 2005). For the purposes of this study, the researcher reviewed each response and scored it based on the scoring manual. This researcher has studied Motivational Interviewing for four years, attended several seminars on the subject, given lectures and seminars on the use of MI for different problem sets, had MI skills used in counseling sessions evaluated by supervisors, and contacted the authors of the VASE-R about scoring the responses. There were no questionable responses provided by participants and the scoring was straightforward. The VASE-R was scored out of a possible 36 points. Participants who scored above 27 were deemed proficient in MI. The responses were summed and determined to be proficient or not proficient, based on the cut off score. 


\section{Research Design}

This study was a causal-comparative research design because participants were not randomly selected or randomly assigned into groups; academic year was a naturally occurring grouping that served as the independent variable. There were potential limitations to employing this research design. Since this is a sample of convenience, it is impossible to predict if the results can be generalized to other populations. An additional limit to this research design is drop out rate. As a way to increase participation and provide information that would make an informed decision to participate in this study possible, participants were notified of the anticipated time commitment and incentives offered.

\section{Data Analysis}

This study posits that there is a non-directional correlational relationship between (1) knowledge of smoking and medical student self-efficacy, (2) attitudes toward smokers and medical student self-efficacy, (3) smoking cessation counseling and medical student self-efficacy, (4) general communication skills training and medical student self-efficacy, (5) use of MI skills and medical student self-efficacy, and (6) year in medical school on medical student self-efficacy. As previously stated, there are gaps in the literature related to year in medical school when students most benefit from exposure to knowledge and skills training, which may affect self-efficacy. This study aims to address these potential relationships and any differences in knowledge, attitudes, and MI skills between nonclerkship and clerkship year medical students. This study could have also been analyzed by using a regression analysis to determine the predictive nature of variables on others. The limited sample size, however, did not allow for the use of a regression analysis. This 
is a limitation in the study, which will be further examined in Chapter 4. The study was guided by the following research questions.

Research question one. Does a relationship exist between medical student knowledge of smoking, attitudes regarding patients who smoke, communication skills training and motivational interviewing skills, and year in training on medical student selfefficacy in smoking cessation counseling? The variables are self-efficacy knowledge about smoking, MI skills, attitude toward smokers, attitude toward communication skills training, attitude toward smoking cessation counseling, and year in medical school.

The relationship among the variables (1) knowledge about smoking, (2) MI skills, (3) attitude toward smokers, (4) attitude toward communication skills training, (5) attitude toward smoking cessation counseling and self-efficacy were analyzed using the Pearson correlation because the measures of these variables are considered continuous. The Pearson product-moment correlation statistic addresses the strength of association between two variables (Tabachnick \& Fidell, 2001). Additionally, the coefficient of determination measures the variability shared by the two variables. The equation for the coefficient of determination is:

$$
r=\frac{n \sum x y-\left(\sum x\right)\left(\sum y\right)}{\sqrt{n\left(\sum x^{2}\right)-\left(\sum x\right)^{2}} \sqrt{n\left(\sum y^{2}\right)-\left(\sum y\right)^{2}}}
$$

Correlations were calculated to examine the proportion of variance shared between the independent variables and self-efficacy. The strength of relationships was calculated. A Pearson correlation satisfies the research question because the results are 
informative for the strength of the association between each independent variable and the dependent variable of self-efficacy.

A Spearman rank-order correlation analyzed the relationship between the variable, year in medical school, and the other variables because participants were not equally distributed between pre-clerkship and clerkship year groups (Field, 2005). The Spearman rank-order correlation is a nonparametric statistic that is used when there is a violation of the parametric assumptions or when the assumptions underlying parametric statistics are not met. In this case the non-normally distributed data was found in the variable of students in pre-clerkship and clerkship years. Additionally, pre-clerkship or clerkship year exhibits a meaningful ordinate structure; students in years 1 and 2 were predetermined to be in the pre-clerkship year and students in years 3 and 4 were predetermined to be in clerkship years. This satisfied requirements for the use of a Spearman rank-order correlation. There are no previous published studies that examine the relationships between these independent variables.

Research question two. How does knowledge about smoking, attitude toward smokers, attitude toward smoking cessation counseling, and attitude toward communication skills training differ by year in medical school? In research question two, the independent variable was year in medical school (pre-clerkship year and clerkship year) and the dependant variables were (1) participant attitude toward smoking cessation, (2) scores of MI skills (3) scores of participant attitude toward communication training (4) participant knowledge, (5) and attitudes toward smoking. Descriptive statistics (mean and standard deviations) were conducted to examine these differences and to explore findings. The Mann-Whitney test is a non-parametric equivalent of an independent t-test and 
compared the possible statistical significance between the means of the multiple dependent variables on the two groups of participants (year in training) (Fields, 2005).

The Mann-Whitney test is calculated when there are no assumptions about the distribution of data. Because the pre-clerkship and clerkship groups were not equal in size, the Mann-Whitney test calculated the median of each group to determine if they were significantly different from each other. The two groups were ranked based on participant number. For example, there were more participants in the pre-clerkship group than the clerkship group and therefore the pre-clerkship group is ranked higher than the clerkship group. Effect sizes were calculated by converting the calculated $z$ score into the effect size estimate, $r$. The equation for the Mann-Whitney statistic is the following:

$$
U=n_{1} n_{2}+\frac{n_{2}\left(n_{2}+1\right)}{2}-\sum_{i=n_{1}+1}^{n_{2}} R_{i}
$$

\section{Obtaining Reliability and Validity for the Tobacco Use in American Medical Schools Questionnaire}

The reliability and validity for the Tobacco Use in American Medical Schools (Schkrohowsky et al., 2007) questionnaire was not calculated by the authors and is not published. In this study, Cronbach's alpha was calculated across the items to examine reliability (Tabachnick \& Fidell, 2001). Knowledge of and attitude toward tobacco use and smoking cessation and the role of physicians in smoking related issues comprise the 49 items on this measure. These items are similar to items in the Attitude toward Smoking Cessation Counseling (Meredith et al., 2001) questionnaire. It was expected that the scores on the Tobacco Use in American Medical Schools would be similar to the scores on the Attitude toward Smoking Cessation Counseling questionnaire. If the scores 
were dissimilar, it would be likely that the questionnaire lacked validity. A more complete discussion of this computation can be found in Chapter 3. 


\section{CHAPTER 3}

\section{Results}

The purpose of this exploratory study was to examine the relationships among knowledge about smoking, attitude toward patients who smoke, attitude toward communication skills training, attitude toward smoking cessation counseling, use of motivational interviewing (MI) skills, and year in medical school on the effects of medical student self-efficacy on smoking cessation counseling. The published research yielded inconsistent results related to the relationship between these variables (Cape et al., 2006; Nieman et al., 2005; Schkrohowsky et al., 2007; Woloschuk et al., 2002) and there is no published study that examined all of the aforementioned variables together.

Two research questions aimed to examine the strength of the relationship between the variables. The first research question examined the relationship between factors related to medical student knowledge and attitudes regarding smoking, specific training and interviewing skills, and level of schooling in predicting self-efficacy in smoking cessation counseling. The second question examined any potential differences between pre-clerkship and clerkship year students on measures of knowledge about smoking, attitude toward smokers, attitude toward smoking cessation counseling, and attitude toward communication skills training.

Thirty-five medical students participated in the study. All incentives for participation in the study, including acquiring hours for mandatory community service, were first proposed to a medical school faculty member. This incentive, however, was denied by IRB because it too closely resembled opportunities for extra credit and the medical school was not on file with IRB to offer this specific incentive for study 
participation. Therefore, it was omitted from the study and consent form. The initial request for participation was issued in May 2009. The same medical school faculty member sent weekly e-mails to students to participate in the study. Additionally, during clinical seminars taught by this faculty member, students were encouraged to participate in the study. An administrator hung flyers advertising the study in heavily traveled areas. This effort yielded 30 participants, despite many efforts to recruit more participants.

A second attempt to recruit participants began in June 2009 by other medical school faculty members who invited students to participate in the study during seminars, classes, and via e-mails. At that time, faculty provided students with the appropriate URL link to the study. An additional 5 students were recruited after the second effort.

\section{Participant Characteristics}

All participant characteristics are found in Tables 1 and 2 in Chapter 1. A Chi-Square goodness of fit test was conducted to determine if the sample size is consistent with medical students within this university (See Table 3). Gender differences between the sample size and national averages of matriculated medical students were not significant, $\square^{2}(1)=.073, p<$ ,005. There were also no significant differences between the students in each cohort in this study as compared to medical students in the university population, $\square^{2}(1)=.803, p<.005$. The results of this analysis suggest that the sample size is consistent with the population and that this pilot study represents the demographics of the population. 
Table 3. Chi-Square Goodness of Fit Test

Gender

Frequency Percent

Valid

\begin{tabular}{lll} 
Male & 19 & 54.3 \\
\hline Female & 16 & 45.7 \\
\hline Total & 35 & 100.00 \\
\hline
\end{tabular}

Chi-Square Test: Comparison to Nation Numbers, (Males 52\%, Female 48\%)

\begin{tabular}{lrrr} 
& Observed N & Expected N & Residual \\
\cline { 2 - 4 } Male & 19 & 18.2 & .8 \\
\hline Female & 16 & 16.8 & -.8 \\
\hline Total & 35 & &
\end{tabular}

Test Statistics

\begin{tabular}{ll} 
Chi-Square & $\frac{\text { Gender }}{.073^{\mathrm{a}}}$ \\
\hline $\mathrm{df}$ & 1 \\
\hline Asymp. Sig. & .787 \\
\hline
\end{tabular}

${ }^{a} 0$ cells $(0 \%)$ have expected frequencies less than 5 . The minimum expected cell frequency is 16.8 .

Year in Training

\begin{tabular}{cccc}
\hline \multirow{2}{*}{ Valid } & \multicolumn{1}{c}{ Frequency } & Percent \\
\cline { 2 - 4 } & MSI & 8 & 22.9 \\
\hline MSII & 11 & 31.4 \\
\hline MSIII & 7 & 20 \\
\hline MSIV & 9 & 25.7 \\
\hline Total & 35 & 100 \\
\hline
\end{tabular}

Chi-Square test: Comparison to WVU Medical Students (MSI 26\%, MSII, 26\%, MSIII, 24\%, MSIV 24\%)

Year in Training

\begin{tabular}{llcl} 
& Observed N & Expected N & Residual \\
\cline { 2 - 4 } MSI & 8 & 9.1 & -1.1 \\
\hline MSII & 11 & 9.1 & 1.9 \\
\hline MSIII & 7 & 8.4 & -1.4 \\
\hline MSIV & 9 & 8.4 & .6 \\
\hline Total & 35 & &
\end{tabular}


Table 3. Chi-Square Goodness of Fit Test continued

\section{$\underline{\text { Test Statistics }}$}

\begin{tabular}{ll} 
& $\frac{\text { Year in Training }}{.806^{\mathrm{a}}}$ \\
\hline $\mathrm{df}$ & 3 \\
\hline Astmp.Sig. & .848 \\
\hline a cells (0\%) have expected frequencies less than 5. The minimum expected cell \\
frequency is 8.4
\end{tabular}




\section{Instrumentation}

It is necessary to report the reliability and validity of a measure because this allows researchers to evaluate the consistency of the measure itself and how well it relates to similar measures (Tabachink \& Fidell, 2001). Both reliability and validity of a measure are needed to accurately interpret statistical results. As previously stated, the reliability and validity of one measure used in this study was not reported in the published study. However, the reliability and validity of that measure were assessed in this study for accurate interpretation.

\section{Reliability and Validity of Tobacco Use in American Medical Schools}

Questionnaire. The authors of the Tobacco Use in American Medical Schools (Schkrohowsky et al., 2007) questionnaire did not calculate the reliability of the measure. Cronbach's alpha was calculated across the attitude items to examine reliability in this study to address this deficit in information (Tabachnick \& Fidell, 2001). Attitude about people who smoke had a high reliability, Cronbach's $\alpha=.810$, which is within the acceptable range. It can be inferred that the results of the data analysis are interpretable and reliable.

The items on the attitude scale are similar to items in the Attitude toward Smoking Cessation Counseling (Meredith, et al., 2001) questionnaire, which has a Cronbach’s $\alpha=.65$. To determine concurrent validity of the Tobacco Use in American Medical Schools questionnaire, a correlation was used to assess the relationship between the two measures. The Attitude toward Smoking Cessation Counseling questionnaire and the Tobacco Use in American Medical Schools questionnaire are significantly correlated, 
$r=.359, p<0.01$, with a moderate effect size. While this is a moderately related relationship, the Tobacco Use in American Medical Schools questionnaire has a higher Cronbach's $\alpha=.810$ than the Attitude toward Smoking Cessation Counseling, with a Cronbach's $\alpha=.65$. Since the reliability and validity appear to be high, the results of the analyses that involve this measure can be reliably interpreted.

\section{Results of Data Analysis}

Two research questions were formulated based on a thorough review of the literature. The research questions addressed the strength of relationship between knowledge, attitude, and skills on self-efficacy of medical students to counsel for smoking cessation and any differences in these relationships between pre-clerkship and clerkship year students.

Research question one. The first research question examined the relationship between factors related to medical student knowledge and attitudes regarding smoking, specific training and interviewing skills, and level of schooling in predicting self-efficacy in smoking cessation counseling. The variables, as previously noted, were self-efficacy, knowledge about smoking, MI skills, attitude toward smokers, attitude toward communication skills training, attitude toward smoking cessation counseling, and year in medical school. Due to the inconsistencies in the published literature, a non-directional hypothesis was chosen in order to allow the data to direct future research questions.

The relationship between self-efficacy to provide smoking cessation counseling to patients $(M=31.09, S D=7.22)$, percentage of correct responses related to knowledge about smoking $(M=58.45, S D=9.37)$, attitudes toward smokers $(M=29.06, S D=6.25)$, attitudes toward communication skills training $(M=80.83, S D=10.86)$, attitude toward smoking cessation counseling $(M=67.91, S D=9.63)$ and proficiency on Motivational Interviewing skills $(M=1.03, S D=.174)$ are detailed in Table 4 . 
Table 4.

Mean and Standard Deviations of Correlations

Variable Mean Standard Deviation

Self-efficacy

31.08

7.22

Percent correct on test of knowledge of smoking

Attitudes about people who smoke

Attitudes about communication skills

80.83

10.86

Attitudes about smoking cessation counseling

Motivational Interviewing skills 
The correlation between self efficacy score and the percentage of correct responses on knowledge about smoking use was significant, $r=.469, p<.001$, with a moderate effect size. The correlation between self efficacy and attitudes about patients who smoke was also found to be statistically significant, $r=.361, p<.05$, with a moderate effect size. A significant difference was additionally found between self efficacy and attitudes toward communication skills learning, $r=.601, p<.001$, with a moderate effect size. Furthermore, a statistical significance was found between selfefficacy and attitudes toward smoking cessation counseling, $r=.695, p<.001$, also with a moderate effect size. A Pearson Correlation was not run on the relationship between self-efficacy and Motivational Interviewing skills due to the lack of variability in the MI variable. This is detailed in Table 5. 
Table 5.

Correlations for Self-Efficacy, Knowledge, Attitudes, and Skills

\begin{tabular}{|c|c|c|c|c|c|c|}
\hline TobAtt $^{\mathrm{a}}$ & \multirow{2}{*}{$\begin{array}{l}\text { SE score } \\
.361^{\text {b }}\end{array}$} & \multirow{2}{*}{$\begin{array}{l}\% \text { Knowledge } \\
.263\end{array}$} & TobAtt & \multirow{2}{*}{$\begin{array}{l}\text { CSAS }^{\mathrm{d}} \\
.338^{*}\end{array}$} & \multirow{2}{*}{$\begin{array}{l}\text { SmokCess } \\
.359^{*}\end{array}$} & \multirow{2}{*}{$\begin{array}{l}\mathrm{MI}^{\mathrm{f}} \\
.107\end{array}$} \\
\hline Pearson Correlation & & & 1 & & & \\
\hline Sig. (2-tailed) & .033 & .127 & & .047 & .034 & .554 \\
\hline $\mathrm{N}$ & 35 & 35 & 35 & 35 & 35 & 35 \\
\hline CSAS & SE score & \% Knowledge & TobAtt & CSAS & SmokCess & MI \\
\hline Pearson Correlation & $.601^{* *}$ & .320 & $.338^{*}$ & 1 & $.638^{* *}$ & .057 \\
\hline Sig. (2-tailed) & .000 & .061 & .047 & & .000 & .751 \\
\hline $\mathrm{N}$ & 35 & 35 & 35 & 35 & 35 & 35 \\
\hline SmokCess & SE score & \% Knowledge & TobAtt & CSAS & SmokCess & MI \\
\hline Pearson Correlation & $.601^{* *}$ & .320 & $.338^{*}$ & 1 & $.638^{* *}$ & .057 \\
\hline Sig. (2-tailed) & .000 & .061 & .047 & & .000 & .751 \\
\hline $\mathrm{N}$ & 35 & 35 & 35 & 35 & 35 & 35 \\
\hline SmokCess & SE score & \% Knowledge & TobAtt & CSAS & SmokCess & MI \\
\hline Pearson Correlation & .048 & .047 & .107 & .057 & .107 & 1 \\
\hline Sig. (2-tailed) & .793 & .796 & .554 & .751 & .552 & \\
\hline $\mathrm{N}$ & 33 & 33 & 33 & 33 & 33 & 33 \\
\hline $\begin{array}{r}{ }^{\mathrm{a}} \text { Tobacco Use in An } \\
{ }^{\mathrm{c}} \text { Tobacco Use in Am } \\
{ }^{\mathrm{e}} \text { Attitude toward Sm } \\
{ }^{* *} \text { Correlation is significant a }\end{array}$ & $\begin{array}{l}\text { Medical Scl } \\
\text { Medical Sch } \\
\text { essation Co } \\
1 \text { level (2-t }\end{array}$ & $\begin{array}{l}\text { s, Attitude Scale' } \\
\text { s, Knowledge Scale } \\
\text { eling } \\
\text { d). }\end{array}$ & ${ }^{*} \mathrm{C}$ & $\begin{array}{l}\text { ider Attit } \\
\text { nunicatio } \\
\text { vational } \\
\text { ation is } \mathrm{s}\end{array}$ & $\begin{array}{l}\text { scale } \\
\text { ls Attitude Sc } \\
\text { ewing, VASF } \\
\text { ant at the } 0.0\end{array}$ & -tailed) \\
\hline
\end{tabular}


The analyses also yielded additional significant results. Attitudes about patients who smoke is significantly correlated to attitudes about communication skills, $r=.338$ and attitudes about smoking cessation counseling, $r=.359(p s<.05)$. Attitudes about communication skills also significantly correlate with attitudes about smoking cessation counseling, $r=.638, p<.01$.Attituides about smoking cessation counseling are further significantly correlated to percent of correct responses on knowledge about smoking, $r=.442, p<.01$.

The Spearman rank-order correlation was used to analyze the relationship between year in training (pre-clerkship v. clerkship) and self-efficacy due to the discrepancy between group sizes. Year in medical school was not significantly correlated to self-efficacy, $r_{s}=.093, \mathrm{p}<.001$. Nonparametric correlations can be found in Table 6 . 
Table 6.

Nonparametric Correlations

\begin{tabular}{|c|c|c|c|c|}
\hline & & & Year in Training: & $S E^{\mathrm{a}}$ \\
\hline \multirow[t]{6}{*}{ Spearman's rho } & \multirow[t]{3}{*}{ Year in Training: } & Correlation Coefficient & 1.000 & .093 \\
\hline & & Sig. (2-tailed) & & .594 \\
\hline & & $\underline{\mathrm{N}}$ & 35 & 35 \\
\hline & \multirow[t]{3}{*}{ SE } & Correlation Coefficient & .093 & .1 .000 \\
\hline & & Sig. (2-tailed) & .594 & \\
\hline & & $\underline{\mathrm{N}}$ & 35 & 35 \\
\hline
\end{tabular}

${ }^{\mathrm{a}}$ Provider Attitudes Scale 
Research question two. How does knowledge about smoking, attitude toward smokers, attitude toward smoking cessation counseling, and attitude toward communication skills training differ by year in medical school? In research question two, the independent variable was year in medical school (pre-clerkship year and clerkship year) and the dependant variables were (1) participant attitude toward smoking cessation, (2) scores of MI skills (3) scores of participant attitude toward communication training (4) participant knowledge, (5) and attitudes toward smoking. The Mann-Whitney test addressed possible differences among dependent variables on the year in training. There were no significant differences found among the variables. This information is also found in Table 7 and Table 8. 
Table 7.

Mann-Whitney Test Statistics

\begin{tabular}{|c|c|c|c|c|c|c|}
\hline & $\underline{\text { SE score }}{ }^{\mathrm{c}}$ & $\%$ Knowledge ${ }^{\mathrm{d}}$ & TobAtt ${ }^{\mathrm{e}}$ & CSAS $^{\mathrm{f}}$ & SmokCess $^{\mathrm{g}}$ & $\mathrm{MI}^{\mathrm{h}}$ \\
\hline Mann-Whitney U & 134.000 & 143.000 & 106.500 & 119.000 & 113.000 & 126.000 \\
\hline Wilcoxon W & 324.000 & 333.000 & 242.500 & 255.000 & 249.000 & 231.000 \\
\hline $\mathrm{Z}$ & -.599 & -.300 & -1.510 & -1.096 & -1.295 & -.858 \\
\hline Asymp. Sig. (2-tailed) & .549 & .764 & .131 & .273 & .195 & .391 \\
\hline Exact Sig. [2 ${ }^{*}(1$-tailed Sig.)] & $.567^{\mathrm{a}}$ & $.781^{\mathrm{a}}$ & $.133^{\mathrm{a}}$ & $.286^{\mathrm{a}}$ & $.205^{\mathrm{a}}$ & $.815^{\mathrm{a}}$ \\
\hline Effect size, $r$ & -.10 & -.05 & -.255 & -.185 & -.218 & -.145 \\
\hline
\end{tabular}

${ }^{a}$ Not corrected for ties

${ }^{\mathrm{b}}$ Grouping Variable: Pre-clerkship years v. Clerkship years

c Tobacco Use in American Medical Schools, Attitude Scale

${ }^{\mathrm{d}}$ Provider Attitudes Scale

e Tobacco Use in American Medical Schools, Knowledge Scale

${ }^{\mathrm{f}}$ Communication Skills Attitude Scale

${ }^{g}$ Attitude toward Smoking Cessation Counseling

${ }^{\mathrm{h}}$ Motivational Interviewing, VASE-R 
Table 8.

Mann-Whitney Descriptive Statistics

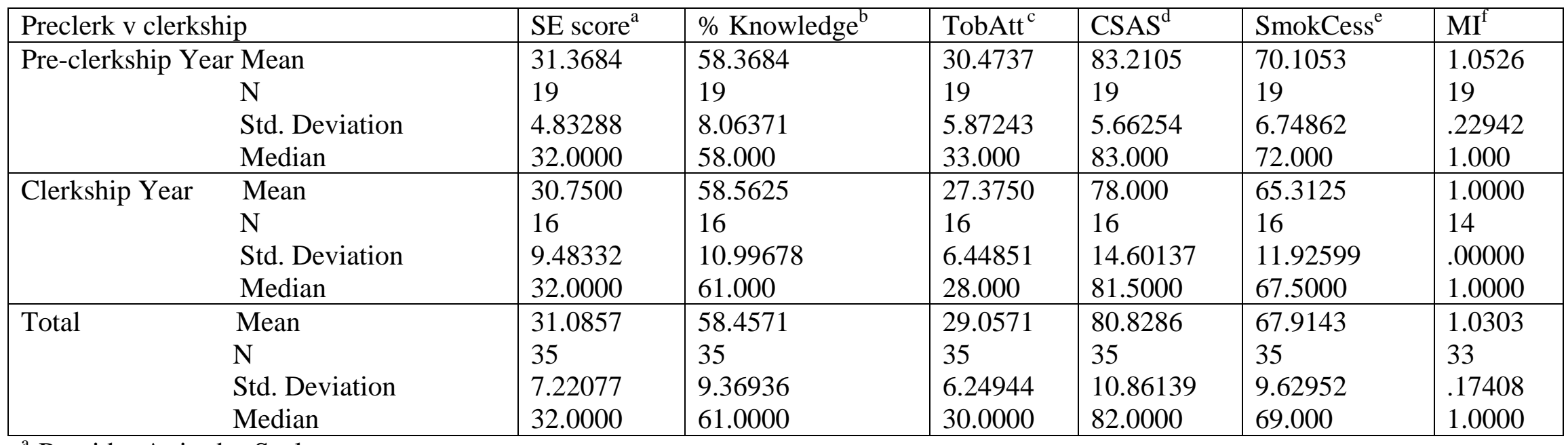

\footnotetext{
Provider Attitudes Scale

b Tobacco Use in American Medical Schools, Knowledge Scale

${ }^{\mathrm{c}}$ Tobacco Use in American Medical Schools, Attitude Scale

${ }^{\mathrm{d}}$ Communication Skills Attitude Scale

e Attitude toward Smoking Cessation Counseling

${ }^{\mathrm{f}}$ Motivational Interviewing, VASE-R
} 
The pre-clerkship and clerkship groups were not equal in size; therefore the Mann-Whitney test calculated the median of each group to determine if they were significantly different from each other. No difference was found among the groups and Table 9 details these findings. While no significance was found, it was determined that students in pre-clerkship years had more positive attitudes about people who smoke, attitudes about communication skills training, attitudes about smoking cessation counseling, and on demonstrating Motivational Interviewing skills than students in clerkship years. This may be due to distribution of sample size or an emerging trend that should be examined through future research. 
Table 9.

Mann-Whitney Test

Ranks

\begin{tabular}{|c|c|c|c|c|}
\hline & Preclerk v clerk & $\mathrm{N}$ & Mean Rank & Sum of Ranks \\
\hline \multirow[t]{3}{*}{ SE score ${ }^{a}$} & Pre-clerkship Year & 19 & 17.05 & 324.00 \\
\hline & Clerkship Year & 16 & 19.13 & 306.00 \\
\hline & Total & 35 & & \\
\hline \multirow[t]{3}{*}{ \% Knowledg } & Pre-clerkship Year & 19 & 17.53 & 333.00 \\
\hline & Clerkship Year & 16 & 18.56 & 297.00 \\
\hline & Total & 35 & & \\
\hline \multirow[t]{3}{*}{ TobAtt ${ }^{\mathrm{c}}$} & Pre-clerkship Year & 19 & 20.39 & 387.50 \\
\hline & Clerkship Year & 16 & 15.16 & 242.50 \\
\hline & Total & 35 & & \\
\hline \multirow[t]{3}{*}{ CSAS $^{\mathrm{d}}$} & Pre-clerkship Year & 19 & 19.74 & 375.00 \\
\hline & Clerkship Year & 16 & 15.94 & 255.00 \\
\hline & Total & 35 & & \\
\hline \multirow[t]{3}{*}{ SmokCess $^{\mathrm{e}}$} & Pre-clerkship Year & 19 & 20.05 & 381.00 \\
\hline & Clerkship Year & 16 & 15.56 & 249.00 \\
\hline & Total & 35 & & \\
\hline \multirow[t]{3}{*}{$\overline{\mathrm{MI}^{\mathrm{f}}}$} & Pre-clerkship Year & 19 & 17.37 & 330.00 \\
\hline & Clerkship Year & 14 & 16.50 & 321.00 \\
\hline & Total & 33 & & \\
\hline $\begin{array}{l}\text { a Provider At } \\
\text { b Tobacco Us } \\
{ }^{\mathrm{c}} \text { Tobacco Us } \\
{ }^{\mathrm{d}} \text { Communica } \\
{ }^{\mathrm{e}} \text { Attitude tow } \\
{ }^{\mathrm{f}} \text { Motivationa }\end{array}$ & $\begin{array}{l}\text { itudes Scale } \\
\text { in American Medica } \\
\text { in American Medical } \\
\text { ion Skills Attitude Sc } \\
\text { ard Smoking Cessatio } \\
\text { Interviewing, VASE- }\end{array}$ & $\begin{array}{l}\text { ls, Kı } \\
\text { s, At } \\
\text { eling }\end{array}$ & $\begin{array}{l}\text { vledge Scale } \\
\text { de Scale }\end{array}$ & \\
\hline
\end{tabular}




\section{Summary of the Results}

The results of the exploratory study suggest that knowledge and attitudes do relate to self-efficacy in medical students. These results may provide important information for curriculum developers, medical school faculty, and mental health professionals who work in medical settings. The data suggests that there are significant relationships between medical school student self-efficacy scores and the percentage of correct responses on knowledge about smoking, attitudes about patients who smoke, attitudes toward communication skills learning, and attitudes toward smoking cessation counseling. There was no difference between pre-clerkship and clerkship year students on the variables, which also has important ramifications for those involved in curriculum development and medical school instruction. 


\section{CHAPTER 4}

\section{Discussion}

The overall purpose of this study was to investigate the strength of relationships between knowledge, attitudes, and skills on self-efficacy of medical students to counsel patients on smoking cessation and to explore potential differences between pre-clerkship year medical students and clerkship year medical students on measures of knowledge, attitudes, and skills. Several variables have the potential to influence the issue, all related to attitudes, knowledge and, treatment skills of the medical profession regarding the serious health issue of smoking. Previous research revealed that knowledge, attitudes, and skills were related to self-efficacy and this study is the result of a review of existing literature, an understanding of gaps in the current literature, and inconsistencies that require further exploration. The recommendations for future research are based both on the outcomes of this exploratory study and on the literature that supported the rationale for this particular study.

Medical training provides the foundation for physician management of the doctorpatient relationships, prevention services, and the cross section of lifestyle and medical problems. The findings may help medical school faculty know how to tailor curriculum to include training in knowledge areas, attitudes, and skills because of the potential impact on self-efficacy. The findings may further help to identify students who need remediation or extra support related to the variables examined. These implications will be more fully discussed below.

The participants in the study were medical students. The first objective of the study investigated the strength of the relationship between knowledge, attitudes, and 
skills on their perception of their ability, or self efficacy, to counsel patients on smoking cessation. The second objective was to explore the differences between medical students in these areas before and after the start of clinical clerkship experiences. The intent was to investigate which variables relate most closely to self-efficacy and if any differences between years in training were observed.

\section{Limitations}

This study has several limitations that must be considered when examining the outcomes. First, 35 participants completed the study, which makes the participant pool small. As a sample of convenience, there is no way to know if the participants represent the demographics or behaviors of others within this population. There may be information about this population which is not represented in this study. One hypothesis is that only students who had a strong professional or personal interest in smoking and smoking cessation counseling opted to participate in the study. This may have skewed the data.

The sampling technique and sampling size also limited the options for research question formulation. With this sample size, it was only possible to ask these research questions. The small number of participants also limited the types of statistical analyses available for this study, which limited the range of possible outcomes. While the findings do provide important information, additional research questions and analyses could provide faculty and researchers with more specific information about curriculum development and development of needed knowledge, skills, and attitudes. For example, regression analyses may provide information about the predictive value of variables, which stand to make an impact on this field of study. 
Several other studies cited in the literature search also had low participant numbers (Bell \& Cole, 2008; Martino et al., 2007; Pederson et al., 2006; Poirier et al., 2004; Yeddida et al., 2003). Recruiting students outside a class requirement tends to yield low participant sampling, such as was experienced in this study. This trend is important for researchers to understand when creating research designs for future studies.

An extensive literature search was conducted prior to selecting the measures in this study. While the measures were evaluated closely and were the best available, they vary in the robustness of reliability and validity. The Attitude toward Smoking Cessation Counseling (Meredith, et al., 2005) Questionnaire addressed medical providers’ attitudes toward patients who smoke and had a Cronbach's $\alpha=.65$. A Cronbach's alpha score of .70 is widely considered the cut off between a reliable and unreliable test. This measure falls below and therefore the outcomes must be cautiously interpreted due to the low reliability score. It was determined that a significant relationship existed between self-efficacy and attitudes toward patients who smoke $(r=.361, p<.05$,). However, due to the low reliability scores of the attitudes measure, care must be taken not to extrapolate too much information from this finding.

The study design may also lend itself to an inherent limitation due to the nature of data collection. Participants completed self-report questionnaires and the issue of social desirability may have interfered with the integrity of responses. Participants may have responded in what was perceived as the socially appropriate or positive response despite other personal answers to the question (Heppner et al., 2008). While confidentiality was clearly described in the informed consent letter, it cannot protect against participant responses that may be perceived as socially undesirable. Additionally, participants self- 
selected to participate in the study and that therefore may further impact the sample of participants.

This was an exploratory study and therefore generalizeable to medical students at West Virginia University Medical School. The results may not be transferable to medical students at other medical schools. Additionally, West Virginia has the third highest smoking prevalence rate at 26.7\% (WVDHHR, 2009) and this fact may also impact medical students as they learn about health and disease.

While there was no significant relationship between year in training on the variables measured, a causal comparative relationship does have limitations. Participants were grouped based on year in training, but in fact another grouping mechanism may have been more appropriate for the study. Because there were no differences between pre-clerkship and clerkship year students, it is difficult to elicit information about the meaning of this potential grouping.

Previous studies recruited participants directly from classes or faculty- directed research projects (Cape et al., 2006; Nieman et al., 2005; Woloschuck et al., 2004). These studies included higher numbers of participants than this study. Studies wherein researchers recruited students from other venues (and not in classes) saw similarly low participant numbers as in this study. It appears that when research is not associated with a faculty member or is not a requirement of a course, participant recruitment is low and the process of recruitment is cumbersome. The options for incentives to participate in this study were few and may also have affected the recruitment process. 


\section{Findings}

The study yielded both significant and non-significant results that have important implications for future research and clinical practice. An exploration of these results will help focus curriculum to address the needs of students and patients and help students monitor their own attitudes so that patient interaction is suited to facilitate change. Any tools or training that can increase medical student beliefs that they can accomplish a task will likely lead to more effective treatment and management of patient problems. A brief overview of the results is reported below.

Knowledge and self-efficacy. The knowledge explored in this study focused on issues related to the effects of smoking and aspects of smoking cessation. The level of knowledge that existed in medical student participants was related to their belief in the ability to counsel patients to stop smoking $(r=.469, p<.001)$. This knowledge included facts about morbidity/mortality of smoking, smoking cessation counseling strategies, potential obstacles to quitting, physician role in helping patients to stop smoking, and pharmacology of tobacco and smoking. The more knowledge, the more the medical students believed they could help patients stop smoking, while the reverse also held true. The less informed, the less they believed in their ability to help people stop smoking.

Attitude and self-efficacy. The study investigated attitudes and how they related to participant belief in the ability to counsel patients to stop smoking. This required looking at attitudes toward people who smoke, effect and importance of communication training, and smoking cessation counseling itself.

Participant attitude towards patients who smoke related to perceived self-efficacy in counseling patients to stop smoking $(r=.361, p<.05)$. Medical students were asked to 
rate their impression of the role of medical providers in helping patients quit smoking, which involved the skills required to help patients find smoking cessation successes, identifying patients who wanted to quit smoking and who were open to discuss the issue of smoking and smoking cessation. The more positive the attitude about patients who smoke, the higher the belief that the medical student could be effective in helping patients quit smoking. The less positive, or more negative, the attitude, the less the medical student may feel they can help patients stop smoking.

Attitudes toward learning communication skills were defined by medical student impressions of learning and using communication skills. Communication skills are crucial in developing a relationship between doctors and patients and set the foundation for being able to discuss potentially difficult topics (AAMC, 1999), such as smoking and smoking cessation counseling. Acquiring and then using communication skills with patients provides medical professionals with tools to talk with patients, manage frustration, and deal with patient resistance (Brody et al., 1989; Chapman et al., 1993; Williams et al., 2003).

Regarding the variable of attitude about learning communication skills, medical students who had more positive attitudes also had a stronger belief that they could be helpful in aiding patient to stop smoking $(r=.601, p<.001)$. Medical students were asked to rate their attitude about learning communication skills, such as the potential applicability of skills, ease of skill learning, and evaluation of the instructor skill in the subject matter, as well as use of these skills with patients. The more positive the attitude, the stronger the belief that they could make a difference in helping patients stop smoking. 
The opposite is also true; the less positive the attitude, the weaker the belief that they could help patients with smoking cessation.

The variable of attitude toward smoking cessation counseling also had a relationship with perceived self-efficacy. This variable was measured by rating attitudes about overcoming barriers related to patient smoking cessation and about patient interest in smoking cessation. Medical students who had positive attitudes about the effectiveness of smoking cessation counseling also had a stronger belief that they could actually help patients quit smoking while students who had negative attitudes about smoking cessation actually felt less able to help patients quit smoking ( $\mathrm{r}=.695, p<.001)$.

Skill and self-efficacy. Skills were defined by use of Motivational Interviewing principles, which addressed participant ability to help patients identify problem areas and create solutions to effectively manage problems (Miller \& Rollnick, 2002). Self-efficacy is a component of motivational interviewing and was measured to examine the relationship between the two variables. Participants viewed three different clinical vignettes about people who practice addictive behaviors, including smoking. They were then asked to respond using elements of motivational interviewing, such as open-ended questions, listening indicators and questions related to describing the importance of change. It does not appear that an ability to use motivational interviewing techniques is related to medical student belief in the ability to counsel toward smoking cessation.

Developmental point of clinical training. Finally, no significant differences were found between any of the variables and year in training. Clinical experience did not factor into how much knowledge students had, how positive or negative their attitudes were, or how well they used motivational interviewing skills. 


\section{Recommendations and Implications for Clinical Applications and Future Research}

This study provides psychological and medical professionals with valuable information about the relationship between self-efficacy and knowledge about smoking, attitudes about smoking, smoking cessation, and communication skills training. Based on the significant and non-significant findings of the current study, several recommendations for clinical training and interventions, as well as research can be made. The following provides an overview of the specific findings and the implications and recommendations related to the study results and based on related literature.

Knowledge about smoking and smoking cessation counseling. It appears, from the findings, that students who had more knowledge about smoking and smoking cessation counseling also felt more able to counsel patients to stop smoking when compared to medical students with less knowledge on the subject. Perhaps students who obtained more information about the interaction between the pharmacological mechanism of smoking use, smoking cessation, and physician role in counseling (which are areas reflected in the Tobacco Use in American Medical Schools Questionnaire) felt better prepared to know how to manage the potential difficulties associated with smoking cessation. Ultimately, it appears that there is a positive relationship between knowledge and self-efficacy. The findings of the study may suggest that smoking and smoking cessation counseling information are important components of medical education and medical students at this university would benefit from didactic and experiential training in these areas.

This finding is also consistent with the literature (Spangler et al., 2002). Students must be informed about smoking, its effects, and strategies to help patients smoke in 
order to be effective in helping change the national epidemic. Training prior to and during clerkship years will likely benefit the student during different stages of training and education. There were no group differences found in this study, however, measuring any changes between groups may contribute information to the field as inconsistencies in the literature have been previously noted. Also, training by physicians and psychologists may help to maximize training because practitioners can address both the varied issues related to smoking and smoking cessation.

In addition, this research study and other studies found that students who have less knowledge about smoking are likely to have negative attitudes (Tormala \& Petty, 2006). Knowledge has a role in how medical students feel about their ability to help patients quit smoking; therefore students must have adequate training to feel confident in their ability to help patients quit smoking. Training is imperative and additional research to determine the most effective time of this training must continue to inform faculty about curriculum development.

A review of the literature on this subject supports the finding that a relationship exists between knowledge about patients who smoke and a medical student's sense of self efficacy in counseling for smoking cessation (Nieman et al., 2005). When preclerkship year students were taught about smoking use and smoking cessation counseling, they used interventions with patients and their self-efficacy increased in applying these interventions (Nieman et al., 2005). If students increased knowledge about smoking and smoking cessation counseling, and methods to facilitate change, it is likely that they would feel better prepared to screen and counsel patients who smoke. Furthermore, with current knowledge and interventions, success in working with patients who smoke may 
increase self-efficacy in medical providers because they feel they have the necessary skills to help facilitate such a change.

Outcomes in the current literature support the finding in the current study that there is a relationship between increased knowledge about patients who smoke and increased self-efficacy in counseling patients to stop smoking. In a published study, when pre-clerkship year students were taught and gained knowledge about smoking and smoking cessation counseling, they used learned interventions more frequently with patients and self-efficacy increased in applying these interventions (Nieman et al., 2005). There is published data that suggests that clerkship year students have more knowledge about patients who smoke than pre-clerkship year students (Schkrohowsky et al., 2007). This finding was not supported in this study. Despite the inconsistent findings in published research, differences were found, which is not consistent with the findings of this study.

There was no difference between students in pre-clerkship and clerkship years on measures of knowledge in this study. The literature suggests that student knowledge about smoking and smoking cessation increases after a specific training (Nieman, et al., 2005). This study did not include an intervention and the average total score of knowledge for all participants was 58\%. The median score for pre-clerkship year students was $58 \%$ while the median score for clerkship year students was $61 \%$. This is consistent with research that indicates that knowledge among medical students about smoking, its effects, and the role of counseling interventions is not adequate (Spangler et al., 2002). These scores are low and may have important clinical implications for the patients that these students treat. 
The findings of the study may warrant a change in curriculum development for medical students. Providing medical students with didactic training related to smoking and smoking cessation counseling may likely affect assessment and intervention. This training might include the psychological components to developing an addiction and maintaining it, as well as effective treatments to reduce or eliminate smoking. Measuring knowledge and self-efficacy before and after such an intervention may provide researchers with information needed to allow faculty to develop curriculum that facilitates knowledge acquisition, development of self-efficacy, and execution of required skills. This information will only further improve assessment and counseling and ultimately address the severity of this national epidemic.

Additionally, future research needs to examine the effect of training or didactic work on knowledge and the timing of training to be most effective. Since knowledge does have a relationship with self-efficacy, understanding how medical students use this information in practice will ultimately impact patient care (Nieman et al., 2005; Schkrohowsky, et al., 2007). Understanding how to best teach this important information will also impact the how effectively the information is acquired by each medical student. In turn, this acquired information will likely be demonstrated in the interaction between medical provider and patient.

While there was no difference in year in training found in this study, there is a relationship between knowledge and self-efficacy. As students increase knowledge about smoking, smoking cessation counseling, and methods to facilitate change, it is likely that they will feel better prepared to screen and counsel patients who smoke. What is more, with current knowledge and interventions, success in working with patients who smoke 
may increase self-efficacy in medical providers because they believe they have developed the necessary skills to help facilitate such a change.

The findings of this study may warrant a change in curriculum development in this medical school because the average total score for all participants in this study was 58\%. The median score for pre-clerkship year students was 58\% while the median score for clerkship year students was $61 \%$. These scores are low and may have important clinical implications for patients that these students treat. There is published data that suggests that clerkship year students have more knowledge about patients who smoke than pre-clerkship year students (Schkrohowsky et al., 2007). This finding was not supported in this study. The findings in this study may have important clinical implications and future research needs to examine possible differences in year in training on knowledge acquisition as it will allow faculty to better train students.

Attitudes about patients who smoke. Medical students who endorsed a more positive attitude toward patients who smoke also experienced higher levels of selfefficacy about counseling patients to stop smoking than students with more negative attitudes. It appears that students with more positive attitudes toward patients who smoke, are more likely to feel that medical providers have an important role in helping with smoking cessation and that skills are required to help patients find success, acknowledge patients want to quit smoking and are more open to discussing the issue of smoking. These positive attitudes may help medical students believe they have an important role in helping patients stop smoking. This attitude and development of self-efficacy may have far reaching implications for clinical practice and patient care. 
Based on the findings, medical students would likely benefit from training about the obstacles patients face when attempting to quit smoking, as it may provide education about just how difficult it is to quit smoking (Baerheim et al., 2007; Yedidia et al., 2003). This could also have far reaching effects, such as easing frustration about resistance to smoking cessation or increasing empathy about the challenges related to quitting smoking (Karam-Hage, et al., 2001). Medical faculty may also want to assess medical student attitudes because it may in turn affect perceived ability to help patients stop smoking. When attitudes are negative, belief in ability to facilitate change is low. This has the dangerous potential to reduce the likelihood that students will assess for smoking or provide counseling. Ongoing assessment of attitudes may also help educate students about their own biases and the potential effects on providing care. It may even help students develop a sense of personal and professional strengths that match well with a particular specialty.

While researchers have called for increased access to smoking cessation counseling exposure and training during medical school (Baerheim et al., 2007; Yedidia et al., 2003), this study could not provide a clear indication of when this intervention should occur because there was no difference in the relationship between self-efficacy and attitudes about patients who smoke between pre-clerkship and clerkship year students. Since a directional hypothesis was not stated for this question, the lack of relationship between the factors is surprising, given the findings in the aforementioned research studies. The possibility exists that there is no relationship among these variables and year in training, however, training needs to be conducted to assess for skill development. 
Research outcomes of related content areas suggested that when medical providers felt frustrated about patients who smoked, they did not provide appropriate interventions related to smoking cessation counseling (Saper, 2006; Sharpe et al., 1994). In turn, the medical provider did not feel able to help facilitate change in a patient, which decreased self-efficacy (Williams et al., 2003). The findings of the current study suggested that there is a relationship between attitudes about patients who smoke and self-efficacy to counsel patients on smoking cessation. This may also suggest that the more positive that medical students feel about patients who smoke and believe patients can quit smoking, they might also feel a higher sense of self-efficacy in their role to help facilitate this change. Additional research needs to address these issues more fully to enhance medical student learning and promote best practices in patient care.

Research also needs to examine the role of medical student attitudes about patients who smoke in the development of self-efficacy to counsel patients to quit smoking. This information will better prepare students to cope with frustration about these often difficult patients and use the interventions that will be most effective. Valid and reliable measures of attitudes (of variables related to this study) are scarce and perhaps if this measure is better developed, researchers and faculty will have a better understanding of how to best train and assess medical students deal with patients who smoke. If attitude development and evolution could be tracked and monitored via longitudinal research, the clinical implications would be plentiful: (1) faculty could identify students who need remediation or extra support to address attitudes, (2) medical students may find successes with patients who smoke and in turn self-efficacy may be 
affected, and (3) timing and type of training intervention may be applicable to other types of issues related to training and self-efficacy.

Attitudes about communication skills. In this study, medical students who had more positive attitudes about learning communication skills and using these skills with patients believed that they could help patients quit smoking more than students who had more negative attitudes. It appears that as scores on self-efficacy increased, attitudes became more positive about learning and using communication skills.

First, medical students must be provided with education on the use of basic communication skills, as it is a requirement of their education (AAMC, 1999). Sixtypercent of participants in this study had completed some training in communication skills. An evaluation of their attitudes about such training should be assessed in order to understand how they feel about learning these skills. When students have negative attitudes, they also do not feel as able to counsel patients to quit smoking. A lack of intervention only serves to perpetuate a health crisis in this country. Conducting training alone may not be sufficient; an assessment of attitudes about completing this training will help faculty better understand the perspective students have about such training, which will inevitably benefit interactions with patients.

Previous studies supported the finding that attitudes about learning and using communication skills had a relationship with self-efficacy (Jenkins \& Fallowfield, 2002). Researchers found statistically significant differences in the use of appropriate communication skills and in attitudes toward patients prior to and after a communication skills training intervention. While a direct relationship was not determined between communication skills, attitudes, and self-efficacy in this study, the variable of self- 
efficacy needs to be further studied to determine the important role in attitude development.

The current exploratory research study found a relationship between learning communication skills and self-efficacy. This study did not include the use of an intervention to train medical students in communication skills, but $60 \%$ of participants were exposed to communication skills training. A significant result was found. If more students were exposed to communication skills training, it would be interesting to determine if there were differences between pre-clerkship and clerkship year students, particularly because there was no difference between participant attitudes in the preclerkship or clerkship year. It is important to understand the modality of teaching communication skills as it relates to the development of self-efficacy.

Medical student attitudes toward communication skills learning also did not yield significant results between groups of students. As discussed previously, communication skills training are a critical component to creating successful relationships between medical providers and patients (Brody et al., 1989; Wolliscroft et al., 1989). What is not as concrete is the timing of the teaching of these interventions to maximize benefits during medical school (Aspergren, 1999) and this study could not contribute any information in this research area. Since no differences were found between year in training, this variable needs to be explored further due to potential future clinical and research implications.

Attitudes about smoking cessation counseling. As previously discussed, in this study medical students who endorsed higher scores of self-efficacy also endorsed more positive attitudes about smoking cessation counseling than students who had lower scores 
self-efficacy. It appears that when students had a strong understanding of the negative impact of smoking use and acknowledged the importance of smoking cessation counseling, they also felt they had the ability to provide this counseling.

Based on the findings of this study, this medical school may want to implement an assessment process to address the development of medical student attitudes. An assessment of student attitude about smoking cessation counseling could be a helpful tool to help students obtain more information and perhaps increase empathy or understanding about this difficult issue for patients and for medical providers. Assessment of attitude could also help students monitor their ability to be effective with patients and identify areas that may require remediation. No matter the medical specialty selected, students would benefit from a discussion about their attitudes related to many potentially difficult topic areas.

Researchers found that physicians who had a more positive attitude about smoking cessation counseling and its benefits were more likely to make a referral for such services (Meredith et al., 2005). It appears that when medical providers have skills to effectively screen for smoking use in patients and know how to talk with them about smoking and making referrals for smoking cessation, attitudes about these potentially difficult patients are more positive, yielding potentially more favorable outcomes. The role of self-efficacy is linked to attitudes and the findings in this study support that.

There were no differences found in this study between pre-clerkship and clerkship year students on attitudes about smoking cessation counseling. Because of the inconsistencies in published research (Cape et al., 2006; Woloschuk et al., 2002), this study investigated differences in pre-clerkship year students or clerkship year students in 
attitude and self-efficacy. These aforementioned studies found different results related to differences in attitude, perhaps due to the methodology chosen, but change in attitude was found.

The findings of this study are inconsistent with the literature because no difference was found. This was an unanticipated finding given the differences found in previous studies. Participants had no formal training in smoking cessation counseling and attitude development is solely based on personal opinion, rather than based on an educated opinion of the issue. The timing of training and experiential opportunities may effect attitude development and self-efficacy and obtaining an understanding of student attitude related to smoking cessation counseling will likely help researchers and faculty aid students in skill development and lead to improvement in attitudes toward patients.

Motivational interviewing skills. A relationship between self-efficacy and motivational interviewing could not be determined in this study due to the lack of variability within the sample. Only one participant scored in the proficient range for MI and therefore no determinations about the relationship of MI on self-efficacy or between years in training could be made. This is unfortunate for several reasons; (a) MI has been documented as an efficacious tool to help facilitate change and more specifically smoking cessation (Emmons et al., 2001; Prochaska et al., 1994). No further analysis in this study could support or refute these findings, (b) there could be no analysis of the potential relationship between MI and self-efficacy, and (c) no recommendations about training and intervention can be made based on current findings.

It appeared that participants in this study either had no exposure to MI or were unable to accurately demonstrate skills and, therefore, were not proficient in its practice. 
That was evident in the outcome of this study, because only one student scored in the proficient range. Based on previous research, motivational interviewing is an effective tool to help patients quit smoking (Britt et al., 2003). It can also be an effective tool to help students increase their belief that they can impact change in patients (Poirier et al., 2002). Because the majority of students were not proficient in the use of MI, clearly they would benefit from training in this area. Training students could have far reaching clinical implications because skills learned can be applied to numerous treatment situations. This would only allow students to be better prepared to manage patients who have problems with creating change. Since MI has components of self-efficacy, skills learned may serve to reinforce the belief that students can be effective in helping patients change. Ultimately, helping patients change addresses the national health crisis of smoking use.

Motivational interviewing espouses use of general communication skills (Miller \& Rollnick, 2008) and 60\% of students in this study received training in general communication skill use. Additional training is necessary to help students better communicate with patients. This result was not surprising because students received no formal training in MI and therefore it is reasonable to find that clinical experience has no relationship to the use of MI skills. It supports the conclusion that specific training in MI does have an impact on learning MI skills (Brown et al., 2004). This has important implications for curriculum development and research.

Future research needs to address the relationship between self-efficacy and motivational interviewing skills in students who have had formal training in MI. This study included a measure to actually assess skill level, rather than only assess participant 
perspective of skill level. This allows for an opportunity to truly measure the relationships between these variables. Research needs to be conducted to examine the role of students who are proficient in MI and self-efficacy by continuing to assess for actual skill level. This will likely make a significant contribution to the growing body of literature related to the uses of MI. Also, self-efficacy contributes a significant amount to the model of MI and it would be interesting to discover how this component is studied as a variable in relation to MI, as opposed to a component of MI. It is unclear if these skills are unidimensional, such as an aspect of personality, or multidimensional, as in a set of skills that culminate to create MI (Rosengren et al, 2008).

Research that is indirectly related to this study, but important in the design for studies similar to this one, needs to address the structure of teaching MI (online, in class role plays, etc), when it is taught to students, optimal teaching methods (Britt et al., 2003), and how to best teach medical students. This information will add to the strength of the study and will allow researchers and practitioners to use MI at the most optimal level. Physicians are the primary participants in studies that measure MI in the use of medical interventions (Britt et al., 2003). Focusing interventions and research on medical students can help ameliorate potential problems related to lack of proficiency in the practice of MI and potentially increase the practice of skills that help facilitate patient change.

Medical School Year in Training. If research outcomes could predict the best time in training to create didactic courses and interventions, medical students might be better equipped to manage smoking cessation counseling with their patients. Having a solid understanding of the relationship between attitudes and training could further help to circumvent biases and stereotypes, which would aid in the treatment of these patients. 
There are gaps in the literature related to the timing and methods of teaching these skills, which may have far reaching clinical implications not only for medical students, but also for the patients they treat. Understanding why these gaps exist and how to best measure these variables will likely produce reliable and valid research which can serve as the foundation for more future studies.

Previous research supports self-efficacy as a determinant of later behavior (Bandura, 1997); therefore, when medical students have higher levels of self-efficacy it is likely that the intended efficacious behavior will follow. Future research needs to address the level of self-efficacy and the actual behavior of providing smoking cessation counseling, which can be assessed by patient survey and self-reports. Further research then needs to examine how self-efficacy and counseling for smoking cessation actually impact patient quit rates. The results may help inform practitioners and medical school faculty to create meaningful interventions with lasting effects.

A longitudinal study may best study the evolution of self-efficacy and attitudes, which could have important clinical and research implications. If data from several studies can suggest that attitudes become more positive, more negative, or remain neutral, powerful interventions can be developed for medical students in order to help facilitate the growth of self-efficacy and ultimately improve patient care.

One trend that has emerged from the findings in this study relates to self-efficacy and attitudes. When attitudes were more positive, so were scores on a self-efficacy measure. Assessing for a possible predictive relationship between these variables would only further enhance the understanding of clinicians and researchers in this vital area and likely improve patient care. 
Study Design. Researchers who plan to conduct similar research may benefit from recruiting participants from classes or offering incentives which are amenable to participants. Low sample size limits the ability for researchers to ask questions that may yield salient information that could then be used to help with curriculum reform and development. A reasonable incentive was offered for participation in this study. However, since this study was not associated with a faculty member or class, this may have affected the recruitment strategy.

Only one student in this study was deemed proficient in the use of Motivational Interviewing skills. Due to this fact, comparisons about students between groups could not be made. Other researchers would benefit from monitoring and assessing medical students skill level prior to comparing this skill to other variables. As previously explored, MI skills may have an important relationship with knowledge and attitudes and must be explored further.

Finally, future research may need to include how knowledge, skills, and attitudes are demonstrated and modeled by faculty physicians and if knowledge, skills, and attitudes are conveyed to medical students in constructive and appropriate ways. If students learn the information, but do not have the opportunity to appropriately use it, then a gap between student and teacher exists, which is another area of research that may indirectly affect research on these variables.

\section{Conclusion}

This exploratory study examined several factors that may correlate with selfefficacy in medical students to provide smoking cessation counseling. The outcomes of this study suggest that knowledge and attitudes do have a relationship with medical 
student self-efficacy, while skills and year in training do not appear to have a relationship with medical student self-efficacy. There are several limitations of this study, which have been discussed at length. Future research, however, can build on this exploratory study to provide psychological and medical providers with important information about interventions with medical students. Additionally curriculum development changes that may provide the appropriate level of training for medical students also need to be examined. The outcomes of this research can directly affect the medical school from which participants were recruited and that can have local and eventually national effects. While this is an exploratory study, it does provide future researchers with possible ways to address limitations, but also addresses some strengths that can be used in larger studies.

There are several recommendations made based on the outcomes of the study and published literature, including the recruitment process, research design and analyses chosen, changes made to medical school curriculum, interventions to affect attitude development, and skill development. While this study could not provide more robust findings, it does provide ways to improve upon the design and how future findings may change medical student skills, knowledge, and attitudes, which in turn may have positive effects on relationships with patients. 


\section{References}

American Psychiatric Association (2002). Diagnostic and statistical manual of mental disorders ( $4^{\text {th }}$ ed.). Washington, DC: Author.

American Psychological Association (2002). Psychology matters: Glossary. Retrieved September 6, 2008 from APA website: http://www.psychologymatters.org/glossary.html\#c

American Psychological Association, The (2009). http://www.div17.org/. Retrieved June 22, 2009.

Ashworth, C.D., Williamson, P., \& Montana, D. (1984). A scale to measure physician beliefs about psychosocial aspects of patient care. Social Science Medicine, 19, 1235-1238.

Aspergren, K. (1999). BEME Guide 2: Teaching and learning communication skills in medicine- A review with quality grading of articles. Medical Teacher, 21(6), 563-571.

Association of American Medical Colleges (2008). Matriculants to U.S. medical school. Retrieved August 12, 2008 from AAMC website: http://www.aamc.org/data/facts/charts1982to2007.pdf.

Association of American Medical Colleges (2009). Curriculum Directory. Retrieved March 5, 2009 from AAMC website: http://services.aamc.org/currdir/about.cfm. Association of American Medical Colleges. (1999). Report III contemporary issues in medicine: Communication in Medicine. Medical School Objectives Project. October, 1999. 
Association of American Medical Colleges (2008). Facts: Applicants, matriculants, graduates, and residency applicants. Retrieved September 1, 2008 from AAMC website: http://www.aamc.org/data/facts/start.htm.

Association of Professors of Gynecology and Obstetrics (2009). The effective preceptor series. Retrieved March 5, 2009 from APOG website: http://www.apgo.org/binary/Preceptor\%20Brochure\%201-FINAL3.pdf.

Baerheim, A., Hjortdahl, P., Holen, A., Anvik, T., Fasmer, O.B., \& Grimstad, H., et al. (2007). Curriculum factors influencing knowledge of communication skills among medical students. BMC Medical Education, 7(35). Retrieved April 9, 2008, from the PsychARTICLES database.

Bandura, A. (1977). Self-efficacy: Toward a unifying theory of behavioral change. Psychological Review, 84(2), 191-215.

Bandura, A., Adams, N.E., \& Beyer, J. (1977). Cognitive processes mediating behavioral change. Journal of Personality and Social Psychology, 35(3), 125-140.

Bandura, A. (1997). Self efficacy: The exercises of control. New York: Freeman.

Bandura, A. (2002). Social foundations of thought and action. In D.F. Marks (Ed). Health psychology reader (pp.94-106). New York: Sage Publications.

Bandura, A. \& Locke, E.A. (2003). Negative self-efficacy and goal effects revisited. Journal of Applied Psychology, 88(1), 87-99.

Bandura, A., Ross, D., \& Ross, S.A. (1961). Transmission of aggression through imitation of aggressive models. Journal of Abnormal and Social Psychology, 63, 575-582. 
Bell, K. \& Cole, B.A. (2008). Improving medical students’ success in promoting health behavior change: A curriculum evaluation. Journal of General Internal Medicine, 23(9), 1503-1506.

Benowitz, N. (1999). Nicotine addiction. Primary Care: Clinics in Office Practice, 26,(3), 611-631.

Betz, N.E. (2004). Contributions of self-efficacy therapy to career counseling: A personal perspective. The Career Development Quarterly, 52, 340-355.

Bolen, C. (n.d.) The five-star doctor: An asset to health care reform. Retrieved April, 2, 2008, from http://www.who.int/hrh/en/HRDJ_1_1_02.pdf.

Borrell-Carrio, F., Suchman, A.L., \& Epstein, R.M. (2004). The biopsychosocial model 25 years later: principles, practice, and scientific inquiry. Annals of Family Medicine, 2(6), 576-582.

Britt, E., Blampied, N.M., \& Hudson, S.M. (2003). Motivational interviewing: A review. Australian Psychologist, 38(3), 193-201.

Brodie, D.A. \& Inoue, A. (2005). Motivational interviewing to promote physical activity for people with chronic heart failure. Journal of Advanced Nursing, 50, 518-527.

Brody, D.S., Miller, S.M., Lerman, C.E., Smith, D.G., \& Caputo, C.G. Patient perception of involvement in medical care: Relationship to illness, attitudes, and outcomes. Medical Care, 27, S110-127.

Broers, S., Smets, E., Bindels, P., Evertz, F.B., Calff, M., \& deHaes, H. (2005). Training general practitioners in behavioral change counseling to improve asthma medication adherence. Patient Education and Counseling, 58(3), 279-289. 
Brown, R.L., Pfeifer, J.M., Gjerde, C.L., Seibert, C.S., \& Haq, C.L. (2004). Teaching patient centered tobacco intervention to first year medical students. Journal of General Internal Medicine, 19, 534-539.

Burke, B.L., Arkowitz, H., \& Menchola, M. (2003). The efficacy of motivational interviewing: A meta-analysis of controlled clinical trials. Journal of Consulting Clinical Psychology, 71, 843-861.

Cabana, M.D., Rand, C.S., Powe, N.R., Wu, A.W., Wilson, M.H., Abboud, P.A.C., \& Rubin, H.R. (1999). Why don’t physicians follow clinical practice guidelines? A framework for improvement. Journal of American Medical Association, 282(15), 1458-1465.

Cantor, J.C., Baker, L.C., \& Hughes, R.G. (1993). Preparedness for practice: Young physicians’ views of their professional education. Journal of American Medical Association, 270, 1035-1040.

Cape, G., Hannah, A., \& Sellman, D. (2006). A longitudinal evaluation of medical students knowledge, skills, and attitudes towards alcohol and drugs. Addiction, 101, 841-849.

Castaldo, J. et al., (2005). Physician attitudes regarding cardiovascular risk reduction: The gaps between clinical importance, knowledge, and effectiveness. Disease Management, 8(2), 93-105.

Centers for Disease Control. (2002). Cigarette smoking among adults: United States 2000. Morbidity and Mortality Weekly Report, 51(29), 642-645. 
Centers for Disease Control (2000). Use of FDA-approved pharmacologic treatments for tobacco dependence: United States, 1984-1998. Morbidity and Mortality Weekly Report, 49, 665-668.

Chapman, S. (1993). The role of doctors in promoting smoking cessation. British Medical Journal, 307, 518-519.

Cummings, S.R., Stein, M.J., Hansen, B., Richard, R.J., Gerbert, B. \& Coates, T.J. (1989). Smoking counseling and preventive medicine: A survey of internists in private practice and a health maintenance organization. Archives of Internal Medicine, 149, 345-349.

Dani, J. \& Harris, R.A. (2005). Nicotine addiction and comorbidity with alcohol abuse and mental illness. Neurobiology of addiction, 8(11), 1464-1470.

deBlok, B.M., deGreef, M.H., tenHacken, N.H., Sprenger, S.R., Postema, K., \& Wempe, J. (2006). The effects of a lifestyle physical activity counseling program with feedback of a pedometer during pulmonary rehabilitation in patients with COPD: A pilot study. Patient Education and Counseling, 61(1), 48-55.

Deveugle, M., Derese, A., van den Brink-Muinen, A., Bensing, J., \& DeMaesender, J. (2005). Consultation length in general practice: Cross-sectional study. British Medical Journal, 325, 472-474.

DiClemente, C.C. (1981). Self-efficacy and smoking cessation maintenance: A preliminary report. Cognitive Therapy and Research, 5, 175-187. 
DiClemente, C.C. and Velasquez, M.M. (2002). Motivational interviewing and the stages of change. In R. Miller and W. R. Rollnick (Eds) Motivational interviewing: Preparing people for change ( $2^{\text {nd }}$ ed.). (pp. 201-216). New York: The Guilford Press.

Dijkstra, A. \& DeVries, H. (2000). Self-efficacy expectations with regard to different tasks in smoking cessation. Psychology and Health, 15, 501-511.

Dunn, C., DeRoo, L., Rivara, F.P. (2001). The use of brief interventions adapted from motivational interviewing across behavioral domains: A systemic review Addictions, 96, 1725-1742.

Engel, G. (1977). The need for a new medical model: A challenge for biomedicine. Science, 196, 129-136.

Emmons, K.M., Hammond, S.K., Fava, J.L., Velicer, W.F., Evans, J.L., \& Monroe, A.D. (2001). A randomized trial to reduce passive smoke exposure in low-income households with young children. Pediatrics, 108(1), 18-24.

Fadlon, M., Pessach, J.,\& Toker, A. (2004). Teaching medical students what they think they already know. Education for Health, 17(1), 35-41.

Field, A. (2005). Discovering statistics using SPSS. $2^{\text {nd }}$ Ed. Thousand Oaks, CA: Sage.

Foster, K.Y., Diehl, N.S., Shaw, D., Rogers, R.L., Egan, B., Carek, P., et al. (2002). Medical students’ readiness to provide lifestyle counseling for overweight patients. Eating Behaviors, 3, 1-13. 
Goldstein, G., Niaura, R., Willey-Lessne,C., DePue, J., Eaton, C., Rakowski, W.\& Dube, C. (1997). Physicians counseling smokers: A population-based survey of patients' perceptions of health care provider-delivered smoking cessation interventions. Archives of Internal Medicine, 157(12), 1313-1319.

Griffith, C.H. \& Wilson, J.F. (2001). The loss of student idealism in the $3^{\text {rd }}$ year clinical clerkship. Evaluation of the Health Professions, 24(1), 61-71.

Gulliver, S.B., Hughes, J.R., Soloman, L.J., \& Dey, A.N. (1995). Self-efficacy and relapse to smoking in self-quitters. Addiction, 90, 767-772.

Heppner, P.P. \& Heppner, M.J. (2004). Writing and publishing your thesis, dissertation, \& research: A guide for students in the helping professions. United States: Thompson, Brooks/Cole.

Hettema, J., Steele, J., \& Miller, W.R. (2005). Motivational interviewing. Annual Review of Clinical Psychology, 1, 91-111.

Hoffman, M.A. \& Driscoll, J.M. (2000). Health promotion and disease prevention: A concentric biopsychosocial model of health status. S.D. Brown and R.W. Lent (Eds.), Handbook of Counseling Psychology ( ${ }^{\text {rd }}$ Ed.). (pp. 532-570). New York: John Wiley \& Sons, Inc.

Jenkins, V. \& Followfield, L. (2002). Can communication skills training alter physicians’ beliefs and behavior in clinics? Journal of Clinical Oncology, 20(3), 765-769.

Karam-Hage, M., Nerenberg, L., \& Brower, K.J. (2001). Modifying residents’ professional attitudes about substance abuse treatment and training. The American Journal on Addictions, 10, 40-47. 
Kattapong, V.J., Locher, T.L., Secker-Walker, R.H., \& Bell, T.A. (1998). Tobaccocessation patient counseling: American college of preventive medicine practice policy statement. American Journal of Preventative Medicine, 15(2), 160-162.

Kerse, N., Buetous, S., Mainous, A.G., Young, G., Coster, G., \& Arroll, B. (2004). Physician-patient relationship and medication compliance: A primary care investigation. Annals of Family Medicine, 2, 455-461.

Lasser, K., Boyd, J.W., Woolhandler, S., Himmelstein, D., McCormick, D. \& Bor, D.H. (2000). Smoking and mental illness: A population-based prevalence study. The Journal of the American Medical Association, 284, 2606-2610.

Liaison Committee on Medical Education (2008). Accreditation standards. Electronically retrieved on March 20, 2008 from http://www.lcme.org/standard.htm.

Maddux, J.E. (2005). The power of believing you can. In C.R. Snyder \& S.J. Lopez (Eds.). Handbook of positive psychology (pp. 277-287). New York: Oxford University Press.

Martino, S., Haeseler, F., Belitsky, R., Pantalon, M., \& Fortin IV, A.H. (2007). Teaching brief motivational interviewing to year three medical students. Medical Education, 41, $160-167$.

McNeill, A. (2001). Smoking and mental health: A review of the literature. London: SmokeFree London Programme, London Region National Health Service. Meredith, L.S., Yano, E.M., Hickey, S.C., \& Sherman, S.E. (2005). Primary care provider attitudes are associated with smoking cessation counseling and referral. Medical Care, 43(9), 929-934. 
Michie, S. \& Abraham, C. (2004). Interventions to change health behaviours: Evidencebased or evidence-inspired? Psychology and Health, 19(1), 29-49.

Miller, W.R., Hedrick, K.E., \& Orlofsky, D.R. (1991). The helpful responses questionnaire: A procedure for measuring therapeutic empathy. Journal of Clinical Psychology, 47, 444-448.

Miller, W.R. \& Rollnick, S. (1991). Motivational interviewing: Preparing people to change addictive behavior. New York: The Guilford Press.

Miller, W.R. \& Rollnick, S. (2002). Motivational interviewing: Preparing people for change. ( $2^{\text {nd }}$ ed.). New York: The Guilford Press.

Miller, W.R., Rollnick, S., \& Butler, C. (2007). Motivational interviewing in health care: Helping patients change behavior. New York: The Guilford Press.

Miller, W.R., Sovereignm R.G., \& Krege, B. (1988). Motivational interviewing with problem drinkers. The drinker's check-up as a preventive intervention. Behavioural Psychotherapy, 16, 251-268.

Miller, W. R., Zweben, A., DiClemente, C. C., \& Rychartik, R. G. (1992). Motivational enhancement therapy manual: A clinical research guide for therapists treating individuals with alcohol abuse and dependence. Rockville, MD: National Institute on Alcohol Abuse and Alcoholism.

Moyers, T.B., Martin, T., Manuel, J.K., \& Miller, W.R. (2004). Motivational Interviewing Treatment Integrity (MITI) coding system. The university of new mexico center on alcoholism, substance abuse, \& addictions. Retrieved on September 4, 2008 from website: http://casaa0031.unm/edu. 
Moyers, T.B., Miller, W.R., Hendrickson, S.M.L. (2005). How does motivational interviewing work? Therapist interpersonal skill predicts client involvement within motivational interviewing sessions. Journal of Consulting and Clinical Psychology, 73(4), 590-598.

Moyers, T.B. \& Rollnick, S. (2002). A motivational interviewing perspective on resistance in psychotherapy. In Session: Psychotherapy in Practice, 58(2), 185193.

Multon, K.D., Brown, S.D., \& Lent, R.W. (1991). Relation of self-efficacy beliefs to academic outcomes: A meta-analytic investigation. Journal of Counseling Psychology, 18, 30-38.

Nieman, L.Z., Velasquez, M.M, Groff, J.Y, Cheng, L., \& Foxhall, L.E. (2005). Implementation of a smoking cessation counseling module in a preceptorship program. Family Medicine, 37(2), 105-111.

Noonan, W. C., \& Moyers, T. B. (1997). Motivational interviewing: A review. Journal of Substance Misuse, 2, 8-16.

Ogedegbe, G. \& Chaplin, W. (2005). Motivational interviewing improves systolic blood pressure in hypertensive African Americans [Abstract]. American Journal of Hypertension, 18, A212.

Okuyemi, K.S., Nollen, N.L., \& Ahluwalia, J.S. (2006). Interventions to facilitate smoking cessation. South African Family Practice Vol. 49 (1), 28-39. 
Olson, D.H. (1999). Empirical approaches to family assessment. The Journal of Family Therapy. Published as a special edition.

Ormond, J.E. (1999). Human learning. ( $3^{\text {rd }}$ Ed.). Upper Saddle River, NJ: Prentice Hall.

Ozer, E.M., Adams, S.H., Rieder Gardner, L., Mailloux, D.E., Wibbelsman, C.J., \& Irwin, C.E. (2004). Provider self efficacy and the screening of adolescents for risky behaviors. Journal of Adolescent Health, 35, 101-107.

Pederson, L., Blumenthal, D.S., Dever, A., \& McGrady, G. (2006). A web-based smoking cessation and prevention curriculum for medical students: why, how, what, and what next? Drug and Alcohol Review, 25, 399-47.

Poirier, M.K., Clark, M.M., Cerhan, J.H., Pruthi, S., Geda, Y.E., \& Dale, L. (2002). Teaching motivational interviewing to first year medical students to improve counseling skills in health behavior change. Mayo Clinic Process, 79, 327-331.

Pololi, L. \& Price, J. (2000). Validation of an instrument to measure the learning environment as perceived by medical students. Teaching and Learning in Medicine, 12(4), 201-207.

Prochaska, J. O., DiClemente, C. C., \& Norcross, J. (1992). In search of how people change. American Psychologist, 47, 1102-1114.

Prochaska, J.J., Teherani, A., \& Hauer, K.E. (2006). Medial students' use of the stages of change model in tobacco cessation counseling. Society of General Internal Medicine, 22, 223-227.

Prochaska, J. O., Velicer, W. F., Rossi, J. S., Goldstein, M. G., Marcus, B. H., Rakowski, W., Fiore, et al.(1994). Stages of change and decisional balance for 12 problem behaviors. Health Psychology, 13, 39-46. 
Project MATCH Research Group. (1993). Project MATCH: Rationale and methods for a multisite clinical trial matching patients to alcoholism treatment. Alcoholism: Clinical and Experimental Research, 17, 1130-1145.

Quattrocki, E., Baird, A., \& Yurgelun-Todd, D. (2000). Biological aspects of the link between smoking abd depression. Harvard Review of Psychiatry, 8, 99-110.

Ranney, L., Melvin, C., Lux, L. McClain, E., \& Lohr, K. (2006). Systemiatic review: Smoking cessation integration strategies for adults and adults in special populatons. Annals of Internal Medicine, 145 (11)

Rees, C., Shard, C., \& Davies, S. (2002). The development of a scale to measure medical students’ attitudes towards communication skills learning: The communication skills attitude scale (CSAS). Medical Education, 36, 141-147.

Resnicow, K., Dilorio, C., Soet, J.E., Borrelli, B., Hecht, J., \& Ernst, D. (2002). Motivational interviewing in health promotion: It sounds like something is changing. Health Psychology, 21(5), 444-451.

Richmond, R. (1999). Teaching medical students about tobacco. Thorax, 54, 70-78.

Rider, E.A., Hinrichs, M.M., \& Lown, B.A. (2006). A model for communication skills assessment across the undergraduate curriculum. Medical Teacher, 28(5), e127e134.

Robinson, J.D. \& Baker, J. (2006). Psychological consultation and services in a general medical hospital. Professional Psychology: Research and Practice, 37(3), 264267.

Rogers, C. R. \& Kramer, P.D. (1995). On becoming a person. New York: Houghton. 
Rosengren, D.B., Baer, J.S., Hartzler, B., Dunn, C.W., \& Wells, E.A. (2005). The video assessment of simulated encounters (VASE): Development and validation of a group-administered method for evaluating clinician skills in motivational interviewing. Drug and Alcohol Dependence, 79, 321-330.

Rosengren, D.B., Hartzler, B., Baer, J.S., Wells, E.A., \& Dunn, C.W. (2008). The video assessment of simulated encounters-revised (VASE-R): reliability and validity of a revised measure of motivational interviewing skills. Drug and Alcohol Dependence, 97, 130-138.

Rosenstock, I.M., Stretcher, V.J., \& Becker, M.H. (1988). Social learning theory and health belief model. Health Education and Behavior, 15(2), 175-183.

Rollnick, S. \& Miller, W.R. (1995). What is motivational interviewing? Behavioural and Cognitive Psychotherapy, 23, 325-334,

Rollnick, S., Miller, W.R., \& Butler, C.C. (2008). Motivational interviewing health care: helping patients change behavior. New York: The Guilford Press.

Saper, J.R. (2006). “Are you talking to me?” Confronting behavioral disturbances in patients with headaches. The Journal of Head and Face Pain, 46, S3, S151-S156.

Scales, R. \& Miller, J.H. (2003). Motivational techniques for improving compliance with an exercise program: Skills for primary care physicians. Current Sports Medicine Reports, 2(3), 166-172.

Schkrohowsky, J.G., Kalesman, B., \& Alberg, A.J. (2007). Tobacco awareness in three U.S. medical schools. Journal of Addictive Diseases, 26(3), 101-106.

Schunk, D.H. (2003). Self-efficacy for reading and writing: Influence of modeling, goal setting, and self-evaluation. Reading and Writing Quarterly, 19, 159-172. 
Scott, C.S. \& Neighbor, W.E. (1985). Preventative care attitudes of medical students. Social Science Medicine, 21(3) ,299-305.

Sloane, P.D., Slatt, L.M., Ebell, M.H., Jacques, L.B., \& Smith, M.A. (2007). Essentials of family medicine. ( $5^{\text {th }}$ ed.). New York: Lippincott, Williams, \& Wilkins.

Sharp, L.K. \& Lipsky, M.S. (2002). Screening for depression across the lifespan: A review of measures for use in primary care settings. American Family Physician, 66, 1001-1008.

Sharpe, M., Mayou, R., Seacroatt, V., Sarawy, C., Starwick, H., Bulstrode, C., Dawber, R., et al. (1994). Why do doctors find some patients difficult to help? The Quarterly Journal of Medicine, 87(3), 187-193.

Smith, I.K., Lancaster, C.J., Delhenem V.E., \& Fleming, G.A. (2002). The relationship between medical students' locus of control and promotion of breast selfexamination. Medical Education, 24, 164-170.

Spangler, J.G., George, G., Foley, K.L., \& Crandall, S.J. (2002). Tobacco intervention training: Current efforts and gaps in U.S. medical schools. Journal of the American Medical Association, 288, 1102-1109.

Stuart, K., Borland, R., \& McMurray, N. (1994). Self-efficacy, health locus of control, and smoking cessation. Addictive Behavior, 19, 1-12.

Swan, G.E., McAfee, T., Curry, S.J., Jack, L.M., Javitz, H., Dacey, S., Bergman, K. (2003). Effectiveness of bupropion sustained release for smoking cessation in a health care setting: A randomized trial. Archives of Internal Medicine, 163, 23372344. 
Tabachnick, B.G. \& Fidell, L.S. (2001). Using multivariate statistics (4 ${ }^{\text {th }}$ Ed.). Boston, MA: Allyn and Bacon.

Thorndike, A.N., Rigotti, N.A., Stafford, R.A., \& Singer, D.E. (1998). National patterns in the treatment of smokers by physicians. Journal of American Medical Association, 279, 604-608.

Tormala, Z.L. \& Petty, R.E. (2005). Contextual contrast and perceived knowledge: Exploring the implications for persuasion. Journal of Experimental Social Psychology, 43 (1), 17-30.

Tovian, S.M. (2006). Interdisciplinary collaboration in outpatient practice. Professional Psychology, Research and Practice, 37, 268-272.

U.S. Department of Health and Human Services (2000). Healthy people 2010: Understanding and improving health. Washington, D.C.: U.S. Department of Health and Human Services, Government Printing Office.

Velicer, W.F., Fava, J.L., Prochaska, J.O., Abrams, D.B., Emmons, K.M., \&Pierce, J.P. (1995). Distribution of smokers by stage in three representative samples. Preventative Medicine, 24, 401-411.

Velicer, W.F., Prochaska, J.O., Fava, J.L., Rossi, J.S., Redding, C.A., Laforge, R.G., et al. (2000). Using the transtheoretical model for population-based approaches to health promotion and disease prevention. Homeostasis, 40(5), 174-195.

Verma, K.J. \& Mallick, K. (1999). Researching education: Perspectives and techniques. Philadelphia, PA: Falmer Press. 
Vogt, F., Hall, S., \& Marteau, T.M. (2005). General practitioners’ and family practitioners’ negative beliefs and attitudes toward discussing smoking cessation with patients: A systemic review. Addiction, 100, 1423-1431.

Vogt, T.M., Hollis, J.F., Lichenstein, E., Stevens, VJ, Glasgow, R., \& Whitlock, E. (1998). The medical care system and prevention: the need for a new paradigm. HMO Practice, 12(1), 5.

Webster’s Dictionary. (2009). Retrieved on March 5, 2009 from website: http://www.merriam-webster.com/dictionary/knowledge.

West, D.S., DiLillo, V., BUrsac, Z., Gore, S.A., \& Greene, P.G., (2007). Motivational interviewing improves weight loss with type 2 diabetes. Diabetes Care, 30, 10811087.

White, L.L., Gazewood, J.D., \& Mounsey, A.L. (2007). Teaching students behavior change skills: Description and assessment of a new motivational interviewing curriculum. Medical Teacher, 29, e67-e71.

Williams, G.C., Levesque, C., Zeldman, A., Wright, S., \& Deci, E.L. (2003). Health care practitioners’ motivation for tobacco-dependence counseling. Health Education Research, 18(5), 538-553.

Wolliscroft, J.O., Clahoun, J.G., Billiu, G.A., Stross, J.K., MacDonald, M., Templeton, B. (1989). House officer interviewing techniques: Impact on data elicitation and patient perceptions. Journal of General Internal Medicine, 4, 108-114.

Woloschuk,W. , Harasym, P.H., \& Temple, W. (2002). Attitude change during medical school: A cohort study. Medical Education, 38, 522-534. 
Yedidia, M.J., Gillespie, C.C., Kachur, E., Schwartz, M.D., Ockene, J., Chepaitis, A.E., et al. (2003). Effect of communications training on medical student performance. Journal of the American Medical Association, 290(9), 1157-1164.

Zimmerman, B.J. (2000). Self-efficacy: An essential motive to learn. Contemporary Educational Psychology, 25, 82-91. 
Preparing Medical Students 129

Appendices 
Preparing Medical Students 130

Appendix A

Questionnaires 


\section{Demographic Questionnaire}

Please check (x) one answer for each question.

1. Gender:

Male

Female

2. Year in Training:

MSI

MSII

MSIII

MSIV

3. Have you smoked cigarettes in the past?

Yes

No

4. Do you currently smoke cigarettes?

Yes

No

5. As a child, did your parent (s)/caregiver(s) smoke cigarettes?

Yes

No

6. Have you ever been exposed to Motivational Interviewing?

Yes

No

If you answered Yes, please answer the following:

How did you learn about MI?

$\begin{array}{ll}\text { Seminar___ } & \text { Brochure_- } \\ \text { Class ___ (Please indicate) } & \\ \text { Other___ }\end{array}$

7. Have you been exposed to smoking cessation interventions?

Yes

No

8. Have you been exposed to communication skills training?

Yes

No

9. If you know which medical specialty in which you intend to practice, please indicate it here: 
10. How frequently do you or do you intend to screen patients for tobacco use?

Always

Sometimes

Never

11. How often do you or do you intend to offer smoking cessation counseling or referral for patients who use tobacco?

Always

Sometimes

Never 
Preparing Medical Students 133

Provider Attitudes Scale 


\section{Provider Attitudes Scales}

Please check the number that best describes your response to each of the following questions regarding the delivery of preventive services.

a.

b. of questions asks you how confident you are that you can do the following.

The next set

How confident are you that you can:

$$
\begin{array}{ll}
\text { Not at all } & \text { Extremely } \\
\text { Confident } & \text { Confident }
\end{array}
$$

12. Ask patients about tobacco use?

$$
\begin{array}{lllllllllll}
0 & 1 & 2 & 3 & 4 & 5 & 6 & 7 & 8 & 9 & 10
\end{array}
$$

13. Deliver brief messages to patients who use tobacco?

$$
\begin{array}{lllllllllll}
0 & 1 & 2 & 3 & 4 & 5 & 6 & 7 & 8 & 9 & 10
\end{array}
$$

14. Determine the most appropriate referrals for patients who use tobacco?

$$
\begin{array}{lllllllllll}
0 & 1 & 2 & 3 & 4 & 5 & 6 & 7 & 8 & 9 & 10
\end{array}
$$

15. Follow-up on referrals related to patients' tobacco use?

$$
\begin{array}{lllllllllll}
0 & 1 & 2 & 3 & 4 & 5 & 6 & 7 & 8 & 9 & 10
\end{array}
$$


Preparing Medical Students 135

Tobacco Use in American Medical Schools Questionnaire 
Tobacco Use in American Medical Schools Questionnaire

Indicate whether the following statements are True or False by circling your response.

16. Evidence suggests that providing written

True False

information, i.e. pamphlets, during the

consultation significantly improves the

efficiency of smoking cessation advice

$\mathrm{T}$

F

17. Cigarette smoking is the single most preventable source of premature morbidity and mortality

$\mathrm{T}$

F

18. $80-90 \%$ of chronic obstructive

pulmonary disease morbidity and mortality

is associated with smoking.

$\mathrm{T}$

$\mathrm{F}$

19. 10 years after giving up smoking the risk of death from coronary heart disease for former smokers is approximately the same as for people who have never smoked

21. Smoking among pregnant women is associated with an increased risk of spontaneous abortion and fetal death

$\mathrm{T}$

F

22. Nicotine's pharmacological effects include:

a) Increased vasopressin release

$\mathrm{T}$

F

b) Dose-related increases in euphoria

T F

c) Development of tolerance with repeated use

$\mathrm{T}$

$\mathrm{F}$

d) Decreased norepinephrine release

$\mathrm{T}$

F 
23. Physician advice to stop smoking:

a) Is twice as effective when combined with a follow-up visit

$\mathrm{T}$

$\mathrm{T}$

b) Results in a one-year quit rate of about $40 \%$

c) Is more effective in patients who have a smoking-related illness

d) Is provided to more than $75 \%$ of smokers in primary care practice

24. Nicotine gum is contraindicated in all patients with heart disease

25. Nicotine gum is most effective for patients who demonstrate evidence of high nicotine dependency

26. Nicotine gum can be used to help patients cut down the number of cigarettes they smoke

\section{$\mathrm{F}$}

F

$\mathrm{T} \quad \mathrm{F}$

T $\quad \mathrm{F}$

T $\quad \mathrm{F}$

$\mathrm{T} \quad \mathrm{F}$

T $\quad \mathrm{F}$

27. Patients who are likely to be most successful at quitting smoking include:

a) Light smoker (smoke less than 10 cigarettes a day)

$\mathrm{T}$

F

T $\quad \mathrm{F}$

b) Women

c) Patients with a history of a recent myocardial infarction

$\mathrm{T}$

F

d) Patients who consume alcohol at hazardous levels

$\mathrm{T}$

$\mathrm{F}$

28. Getting a patient to set a specific day to stop smoking improves their chances of stopping

$\mathrm{T}$

F

29. Doctors detect more than $80 \%$ of their patients who smoke

30. Most smokers give up smoking without 
obtaining specialized assistance

31. Doctors can have a significant impact

on the reduction in numbers of smokers

32. Patients' first preference for assistance to stop smoking is their doctor
$\mathrm{T}$

$\mathrm{F}$

$\mathrm{T}$

F

$\mathrm{T} \quad \mathrm{F}$

33. What is the mean number of attempts to quit smoking before success is achieved?

$$
\begin{array}{llllll}
(\quad) 2 & (\quad) 3.5 & (\quad) 5.5 & (\quad) & (\quad) 8
\end{array}
$$

34. Nicotine is primarily a :

\section{( ) Depressant ( ) Stimulant ( ) Hallucinogen}

35. Smoking is most prevalent among which one of the following demographic groups:

( ) Male white collar workers ( ) Male blue collar workers

( ) Female blue collar workers ( ) Female white collar workers

36. The percentage of cigarette smokers who state they would like to quit is approximately:

$$
\text { ( ) } 10 \% \quad \text { ( ) } 25 \% \quad(\quad) 50 \% \quad \text { ( ) } 75 \%
$$

37. The percentage of lung cancer deaths attributed to smoking is approximately:

$$
\text { ( ) } 20 \% \quad(\quad) 40 \% \quad(\quad) 60 \% \quad(\quad) 80 \%
$$

38. Smoking increases the risk of developing cancer in the following organs (check all that are TRUE) :

$$
\begin{aligned}
& \text { ( ) Lung ( ) Larynx ( ) Esophagus ( ) Oral cavity } \\
& \text { ( ) Kidney ( ) Bladder ( ) Pancreas }
\end{aligned}
$$

39. I feel that in everyday clinical practice I would detect the following percentage of patients who smoked: (Please circle your response)

$\begin{array}{lllllllllll}0 & 10 & 20 & 30 & 40 & 50 & 60 & 70 & 80 & 90 & 100 \%\end{array}$

40. In what percentage of patients do you think you would routinely ask about smoking? (Please circle your response)

$\begin{array}{lllllllllll}0 & 10 & 20 & 30 & 40 & 50 & 60 & 70 & 80 & 90 & 100 \%\end{array}$ 
41. The main barriers to patients' participation in health promotion activities include:

STRONGLY

DISAGREE
STRONGLY

AGREE

$\begin{array}{lllllll}-3 & -2 & -1 & 0 & 1 & 2 & 3\end{array}$

a. Patient unwillingness

b. Lack of individual's responsibility for their own health

c. Their social and economic environment (i.e. poverty, poor housing, etc.)

42. How difficult is it to help patients stop smoking?

\begin{tabular}{lllllll}
\multicolumn{1}{ll}{-3} & -2 & -1 & 0 & 1 & 2 VERY \\
VERY & & & & & EASY
\end{tabular}

43. I feel that I require further skills in counseling patients about how to stop smoking:

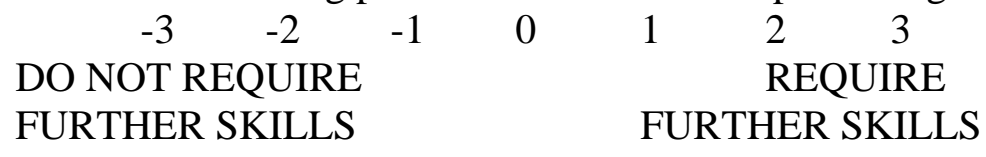

44. Smoking, due to its sensitive nature, is difficult to raise in medical practice:

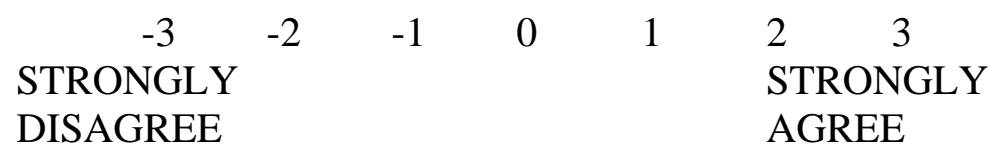

45. I believe my efforts overall, as a medical practitioner, would be worthwhile in changing patients' smoking habits:

$$
\begin{array}{lllllll}
-3 & -2 & -1 & 0 & 1 & 2 & 3
\end{array}
$$

46. Other referral agencies or health professional are generally better equipped than medical practitioners to deal with getting patients to stop smoking:

$$
\begin{array}{lllllll}
-3 & -2 & -1 & 0 & 1 & 2 & 3
\end{array}
$$


Preparing Medical Students 140

47. I fear that I would lose patients if I raised the issue of their smoking:

$\begin{array}{lllllll}-3 & -2 & -1 & 0 & 1 & 2 & 3\end{array}$


Preparing Medical Students 141

Communication Skills Assessment Scale 


\section{Communication Skills Assessment Scale}

Please read the following statements about communication skills learning. Indicate whether you agree or disagree with all of the statements by circling the most appropriate response. Remember,

$1=$ strongly disagree

$2=$ disagree

$3=$ neutral

4= agree

$5=$ strongly agree

48. In order to be a good doctor I must have good communication skills. 12345

49. I can't see the point in learning communication skills.

50. Nobody is going to fail their medical degree for having poor communication skills

51. Developing my communication skills is just as important as developing my knowledge of medicine

12345

52. Learning communication skills has helped or will help me respect patients

53. I haven’t got time to learn communication skills

54. Learning communication skills is interesting

55. I can’t be bothered to attend sessions on communicating skills

12345

56. Learning communication skills has helped or will help facilitate my team-working skills

57. Learning communication skills has improved my ability to communicate with patients

58. Communication skills teaching states the obvious and then complicates it

59. Learning communication skills is fun

60. Learning communication skills is too easy 
61. Learning communication skills has helped or will help me respect my colleagues

62. I find it difficult to trust information about communication skills given to me by nonclinical lecturers

12345

63. Learning communication skills has helped or will help me recognize patients' rights regarding confidentiality and informed consent

12345

64. Communication skills teaching would have a better image if it sounded more like a science subject

65. When applying for medicine, I thought it was a really good idea to learn communication skills

66. I don't need good communication skills to be a doctor

12345

67. I find it hard to admit to having some problems with my communication skills

68. I think it's really useful learning communication skills on the medical degree

69. My ability to pass exams will get me through medical school rather than my ability to communicate

70. Learning communication skills is applicable to learning medicine

12345

71. I find it difficult to take communication skills learning seriously

12345

72. Learning communication skills is important because my ability to communicate is a lifelong skill.

12345

73. Communication skills learning should be left to psychology students, not medical students 
Preparing Medical Students 144

Quality Improvement Trial for Smoking Cessation Questionnaire 
Quality Improvement Trial for Smoking Cessation Questionnaire

74. Do you feel that you need to change or improve the way you counsel or will counsel and treat or will treat patients who smoke?

Mark one

Definitely

Probably

Maybe

No

75. How skilled do you think you are or will be in providing the following services for patients who smoke?

\begin{tabular}{c|c|c|c}
$\begin{array}{c}\text { Not at } \\
\text { all } \\
\text { skilled }\end{array}$ & $\begin{array}{c}\text { Slightly } \\
\text { skilled }\end{array}$ & $\begin{array}{c}\text { Somewh } \\
\text { at } \\
\text { skilled }\end{array}$ & $\begin{array}{c}\text { Very } \\
\text { skilled }\end{array}$ \\
\hline
\end{tabular}

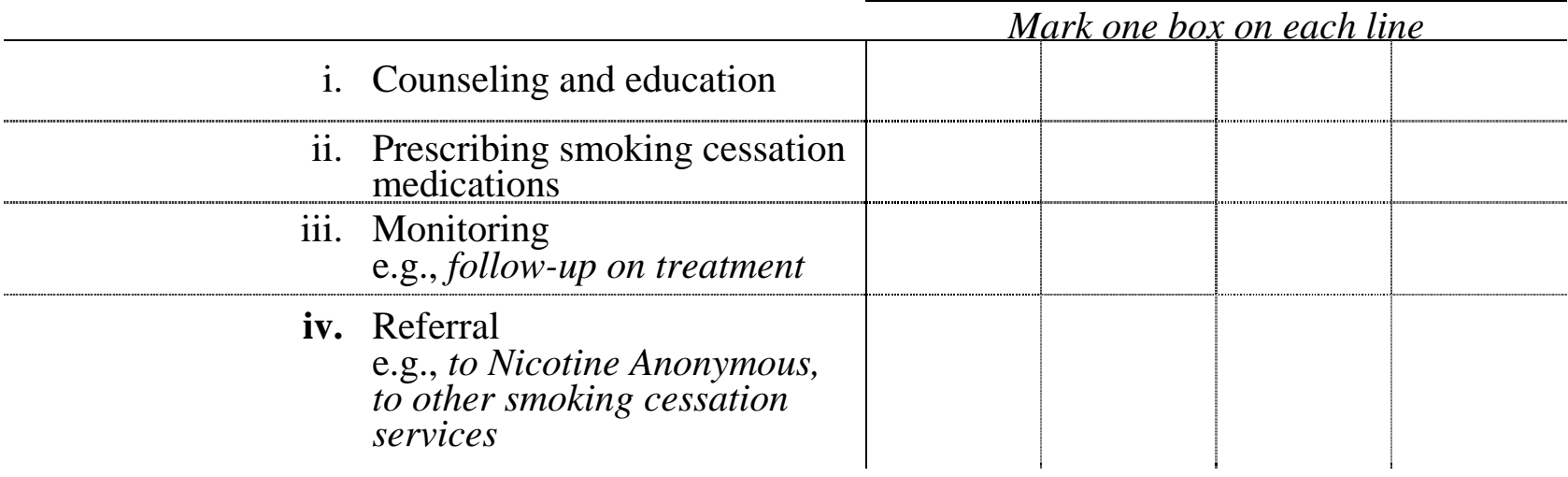

76. Of the smokers you see, or will see at this facility, about what percentage of the time in a typical month do you or would you:

\begin{tabular}{c|c|c|c|c} 
None & $\leq$ & $26-$ & $51-$ & $76-$ \\
$(0 \%)$ & $25 \%$ & $50 \%$ & $75 \%$ & $100 \%$ \\
\hline
\end{tabular}

\begin{tabular}{c|c|c|c|c|c}
\hline $\begin{array}{l}\text { Personally counsel to quit } \\
\text { smoking }\end{array}$ & & & & & \\
\hline ii. $\begin{array}{l}\text { Prescribe medicine for } \\
\text { smoking cessation (either } \\
\text { nicotine replacement therapy } \\
\text { or buproprion) Please assess } \\
\text { WHAT YOU WOULD DO } \\
\text { Refer smoker to a Smoking } \\
\text { Cessation Program }\end{array}$ & & & & & \\
\hline iii. & & & & \\
\hline
\end{tabular}




\section{iv. Refer smoker to an outside Smoking Cessation Program}

77. The following items are factors that clinicians report limit their ability to recognize or provide optimal smoking cessation care. How much does each factor limit/would limit your ability to provide "optimal" smoking cessation care for your patients?

\begin{tabular}{c|c|c}
$\begin{array}{c}\text { Does not } \\
\text { limit }\end{array}$ & $\begin{array}{c}\text { Limits } \\
\text { somewhat }\end{array}$ & $\begin{array}{c}\text { Limits } \\
\text { a great deal }\end{array}$ \\
\hline
\end{tabular}

POTENTIAL LIMITING FACTORS Mark one box on each line

\begin{tabular}{l|l|l|l}
\hline Patient not interested in quitting & & & \\
\hline Medical problems were more pressing & & & \\
\hline Preferred medication difficult to obtain & & & \\
\hline Counselors or educators not available & & & \\
\hline Referral not convenient & & & \\
\hline Limited visit time for counseling/education & & &
\end{tabular}

78. To what extent do you agree or disagree with the following statements? If you have not seen patients, anticipate the response.

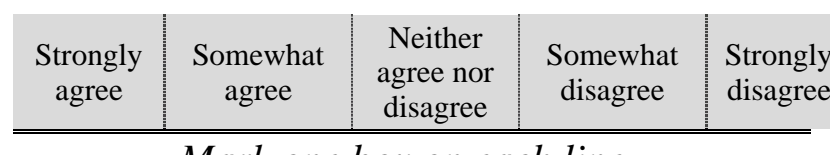

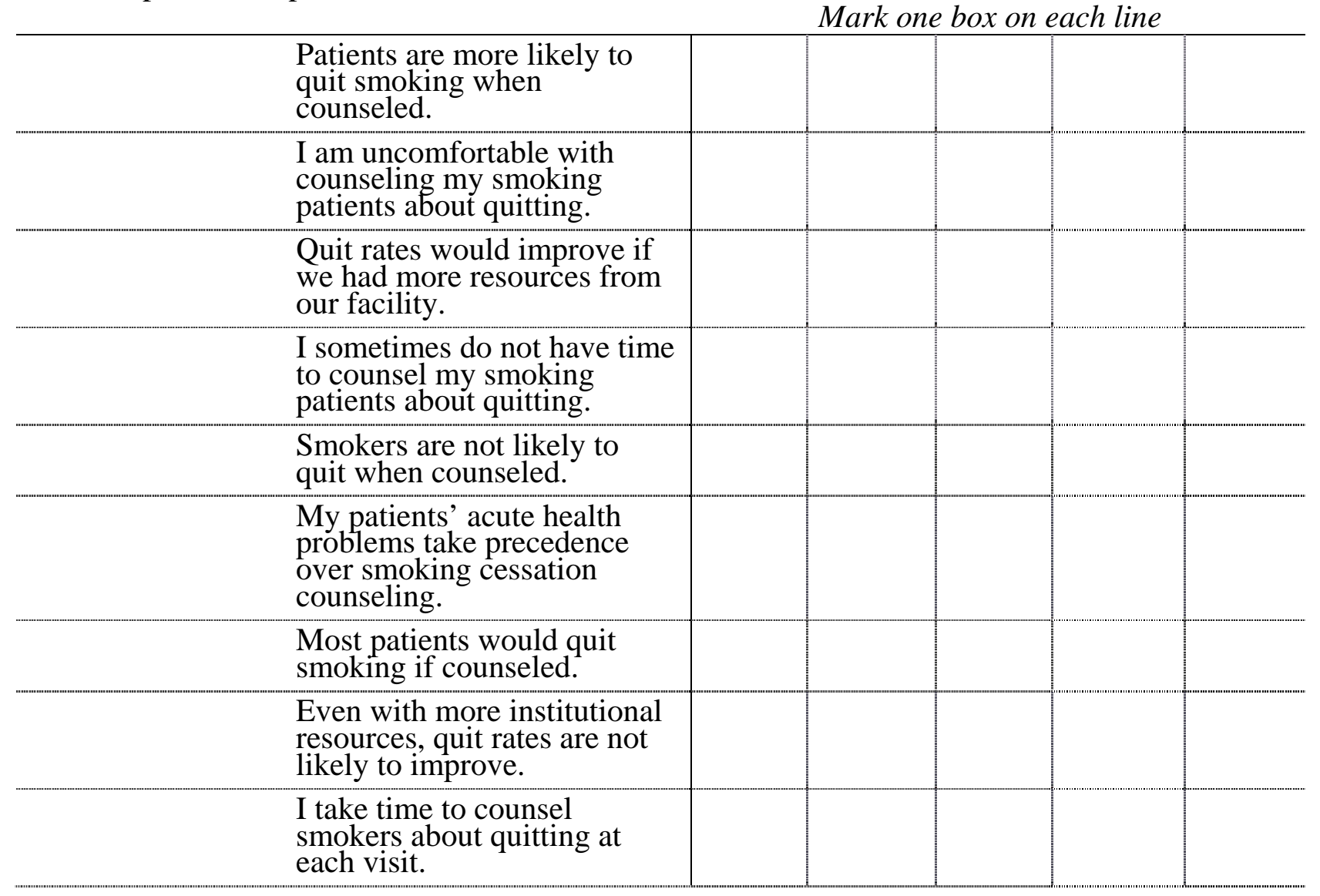


Preparing Medical Students 147

Quit rates are so low that smoking cessation counseling is no longer a priority. 
Preparing Medical Students 148

Video Assessment of Video Encounters-Revised Questionnaire 
Video Assessment of Video Encounters-Revised Questionnaire

79. Write a response that indicates you are listening.

80. Write a response that indicates you are listening.

81. Write a response that you think would be most helpful in this situation.

82. Write a summary that you might say to Lisa and which touches on the things that you think are most important.

83. Write what you would say to Lisa that might elicit from her statements that support making healthy changes (e.g., concerns and/or recognition of problems, intention and/or optimism about prospective changes.)

84. There are many different directions to explore with Lisa. Select the question or statement that you think would be the most helpful to explore with Lisa now, if you wanted to increase her motivation to change; then indicate why you chose that one in the space below.

(1) What was your drinking like on the evening of the DUI?

(2) You indicated that being here is not a high priority to you. What would you rather be doing?

(3) You said, “ something ain’t right” about your situation. Tell me more about that.

(4) Tell me about your drinking patterns. How often and how much do you drink?

(5) So what does an alcoholic look like to you?

What reason(s) led you to choose this item?

85. Write a response that indicates you are listening.

86. Write a response that you think would be most helpful in this situation

87. Write a response that indicates you are listening.

88. Write a summary that you might say to Ulysses and which touches on the things that you think are most important.

89. Write what you would say to Ulysses that might elicit from her statements that support making healthy changes (e.g., concerns and/or recognition of problems, intention and/or optimism about prospective changes.) 
90. Choose the statement or question that you think might be most helpful to explore with Ulysses, if you wanted to increase his motivation to changes; then indicate why you chose that one in the space below.

(1) You mentioned that being homeless is bad for your health and puts you atrisk for legal difficulties. If so, why not give treatment a chance?

(2) Don't you think your housing situation might improve if you stopped your drug use?

(3) So, even though all these though things happened because of your drug use, you're still not sure you need treatment?

(4) What were things like when you were clean?

(5) What sorts of experiences have you had with treatment?

What reason(s) led you to choose this item?

91. Write a response that you think would be most helpful in this situation.

92. Write a response that you think would be most helpful in this situation.

93. Write a response that you think would be most helpful in this situation.

94. Write a summary that you might say to Bailey and which touches on the things that you think are most important.

95. Write a response that you think would be helpful in eliciting from Bailey statement that support her making healthy changes in her pattern of substance use (e.g., concerns and/or recognition of substance-related problems, intention and/or optimism about prospective substance-related changes.) 
96. Choose the question or statement that you think might be most helpful to explore with Bailey, if you wanted to increase her motivation to change; then indicate why you chose that one in the space below.

(1) What relationship do you see between your drug use and dropping grades?

(2) Your parents don't believe you and that bothers you. What upsets you about that?

(3) So, how often and what sorts of drugs are you using?

(4) Your situation does sound hard and would probably be easier if you were off the weed for awhile. What do you think?

(5) You said your parents would worry if they know what was really going on. Bailey, can't you see that they're already worried and that's why they brought you here? 
Preparing Medical Students 152

Appendix B

Letters 
Preparing Medical Students 153

Letter of Informed Consent 


\section{WestVirginiaUniversity。}

College of Human Resources \& Education

\section{Dear Participant,}

This letter is a request for you to take part in a research project to examine factors that predict self-efficacy in providing smoking cessation counseling in medical students. This dissertation project is being conducted by Aubree M. Guiffre, MS MFT in the Counseling Psychology doctorate program in the Department of Counseling, Rehabilitation Counseling, and Counseling Psychology at WVU with supervision of Dr. Margaret Glenn, Ed.D., CRC, an associate professor and chair of the Department of Counseling,

Rehabilitation Counseling, and Counseling Psychology. Your participation in this project is greatly appreciated and will take up to 60 minutes to fill out the attached questionnaire.

Your involvement in this project will be kept as confidential as legally possible. All data will be reported in the aggregate. You must be 18 years of age or older to participate. I will not ask any information that should lead back to your identity as a participant. Your participation is completely voluntary. You may skip any question that you do not wish to answer and you may discontinue at any time. Your class standing will not be affected if you decide either not to participate or to withdraw. West Virginia's University's Institutional Review Board acknowledgement of this project is on file.

At the completion of data collection, two participants will be randomly selected to receive one \$50 gift card to the WVU Medical School Bookstore and one \$50 gift card to Starbucks.

If you decide to participate in the study, please do not share the study questions or your responses with other medical students.

I hope that you will participate in this research project, as it could be beneficial in understanding the impact of self-efficacy in providing smoking cessation counseling. Thank you very much for your time. Should you have any questions about this letter or the research project, please feel free to contact Aubree Guiffre at (724) 747-8263 or by email at aubree.guiffre@gmail.com

Thank you for your time and help with this project.

Sincerely,

Aubree M. Guiffre, MS MFT

West Virginia University

Counseling Psychology

Doctoral Candidate

(724) 747-8263

E-mail: aubree.guiffre@gmail.com
Margaret K. Glenn Ed.D.

Associate Professor

West Virginia University

PO Box 6122

Morgantown, WV, 26506

304.293.2276

E-mail: Margaret.glenn@mail.wvu.edu

John $\mathrm{H}$. 